



\section{(8) Ontario}

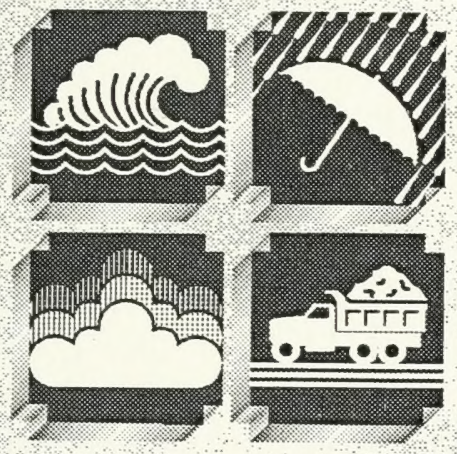

1992 STATUS REPORT ON

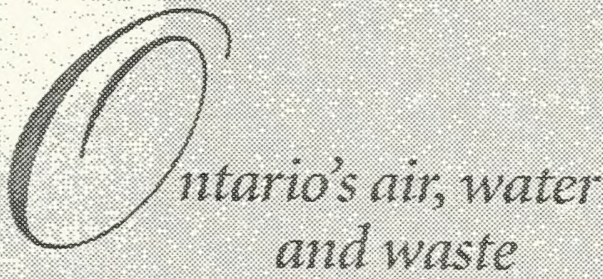



The development and production of this report required the expertise and assistance of numerous staff of the Ministry of Environment and Energy. In particular, the following people were instrumental in bringing this project to fruition:

Project Coordinators:

Beverley Hanna-Thorpe

Nicola Crawhall

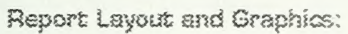

Kim Massicotte

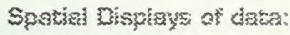

Bernie Neary

Extarma d Assivance:

Technical Writer: David Francis

- Lanark Communications, Toronto

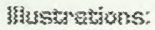

Compendium Design International

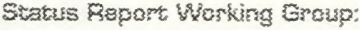

Beverley Hanna-Thorpe (Chair)

Bill Bardswick

Ed deGrosbois

Andrezej Dominski

Jack Donnan

Les Fitz

Cathy Grant

Phil Kiely

Judy Keith

Mary Kirby

Garth Lesfresne

P.K. Misra

Bernie Neary

Dave Neufeld

Dan Ionescu

Gerry Rees

George Rocoski

Ilan Salamon

Christine Staddon

John Stager

Wing Tse

Serge Villard

Graham Whitelaw

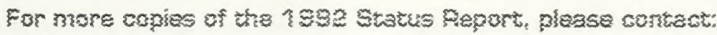

Ontario Ministry of Environment and Energy

Public Information Centre

323-4321

or toll free at: $1-800-565-4923$

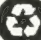

Printed on recycled paper

ISBN

PIBS 



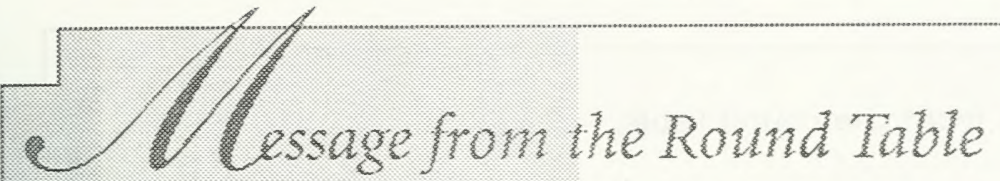

In September 1992 the Ontario Round Table on Environment and Economy submitted a report to the Premier and the people of Ontario titled, "Restructuring for Sustainability".

The report recommended the integration of economic and environmental reporting; in essence, linking human and ecosystem health to economic and environmental indicators.

The Round Table called this "sustainability reporting".

By publishing the 1992 Status Report on Ontario's Enxironment, the Ministry of Environment and Energy (MOEE) has taken an important first step in support of sustainability reporting. The Status Report contains ratuable information on the levels of pollution in $\mathrm{On}_{\text {- }}$ tario's air, water and land, and the trends for key pollutants within these media Additional information is presented on an ecosystem basis for acid rain, one of Ontario's major environmental concerns. The public has a right to the routine publication of environmental information so that progress on resolving environmental problems can be tracked and emerging issues can be identified and explained.

The Round Table urges the Government of Ontario to build on the MOEE report by including in future reports information gathered by other ministries on fisheries, wildife, forests, agriculture, and other resource sectors. No single ministry is responsible for the state of the environment. Environmental reporting is dearly a multi-ministerial responsibility for which information must be assembled from a variety of sources.
In future reports, efforts should also be made to present information on an ecosystem basis, showing the complex linkages that exist between human activity and environmental quality. The acid rain chapter in this report is an example of ecosystem reporting which could be developed and applied to other environmental issues and resource sectors. Ecosystem reporting is advocated since it has the potential to inform more comprehensive and integrated economic and environmental decision making than separate reports on the pollution of air, water or land, or on single resource sectors in isolation of other resource and environmental concerns. The Round Table therefore encourages all ministries to adopt the ecosystem approach to information gathering and presentation.

As the 20th century draws to a close, there is an urgent need to develop new tools and techniques to support better decision-making, including state of the environment and sustainability reporting. Economic reports and indicators are widely available and profoundly influence the decisions of individuals as well as public 
and private sector decision makers. But economic information, in and of itself, is not complete since it does not capture the impacts of economic activity on the environment. Sustainability reports are required which integrate environmental and economic reporting and allow impacts on human and ecosystem health to be understood and acted upon. The Round Table believes that sustainability reporting must be a major decision support tool in the 21st Century and is committed to working with governments and other stakeholders to develop and refine this tool.
In the final analysis, reporting must serve the purpose of promoting better decisions - that is, more comprehensive and balanced decisions consistent with increased transparency and accountability of the decision-making process. The public has a right to information that will facilitate their involvement in environmental and sustainability decision making, as affirmed in the recently enacted Environmental Bill of Rights. The Ministry of Environment and Energy has taken a significant first step along this path, and the Round Table looks forward to continued progress. 


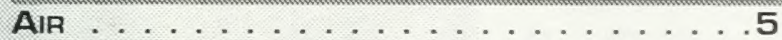

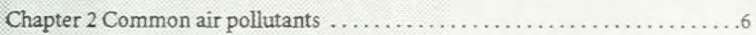

Chapter 3 Toxic Air pollutants . . . . . . . . . . . . . . . . . . . 17

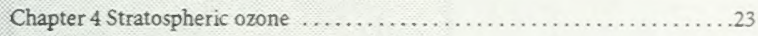

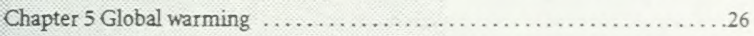

ACID RAIN $\ldots \ldots \ldots \ldots \ldots \ldots$

Chapter 6 How acid rain affects the environment $\ldots \ldots \ldots \ldots \ldots \ldots \ldots \ldots \ldots \ldots \ldots$

Chapter 7 Acid rain: are We making progress? . . . . . . . . . . . . . . 37

WATER ......................

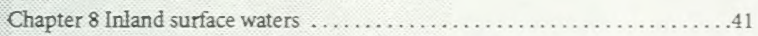

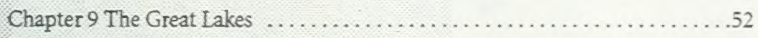

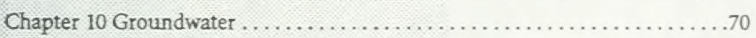

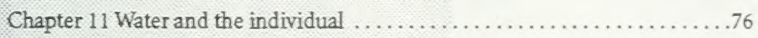

WASTER MANAGEMENT $\ldots \ldots \ldots \ldots .79$

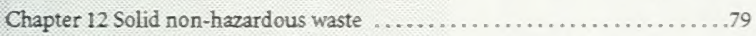

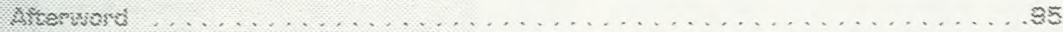

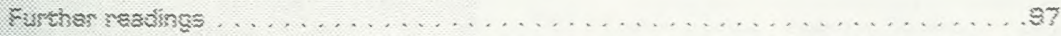




\section{Pathways of Pollution}

Figure 1.1

Air, water, land and fung things interact to form a complex wab of fife called the acosystem. Due to the intardependent natura of this system, the introduction of pollutants into one part of the eccusystern will often haw corrasponding and sometimes unexpected consequonces in other parts.

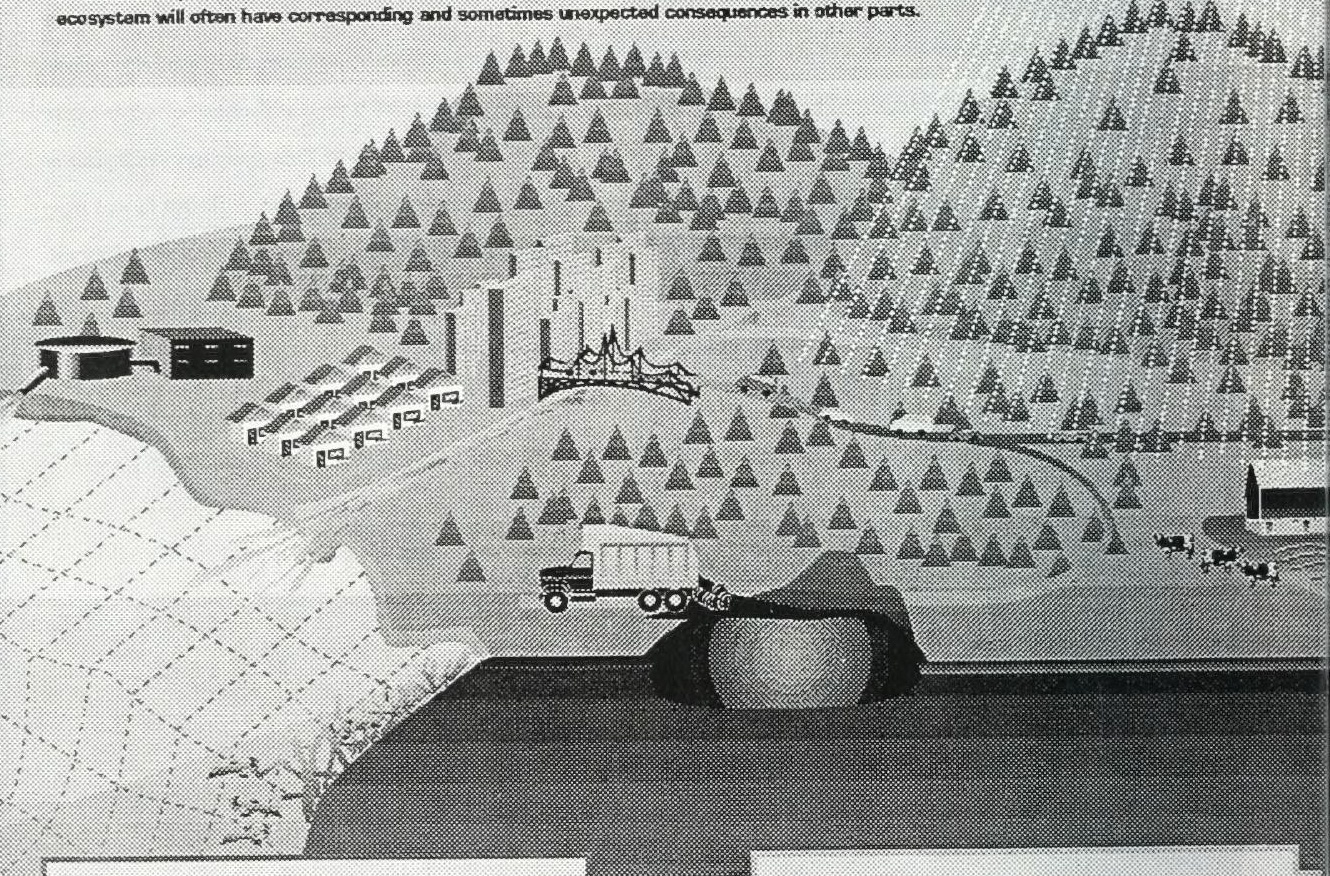

\section{Air Pathways}

Polutants are released into the air from a vanaty of sources such as vehicles, industrial plants, electricty generating planks landfil sites, pesticide applicstion, and the use of clearing agents and solvernts.

These politutants can be transported great distances by air currents, can be picked up in precipitation and deposited in water bodias and soit, and can be absorbed by humans, other animais, plants, fish, and other organisms.

\section{Soil Pathways}

Seepage from landfils, the application of pesticidas and fartaizers, spils of lquid industnal waste, and poor mant tenance of septic tils frelds can al introduce contaminants into the soil Air pollution that settles on land also contributes to sol contamination.

Plants and anitnals can ingest these contamnants in the soil. Water moving thraugh the soil can cany these contaminants into groundwater. 


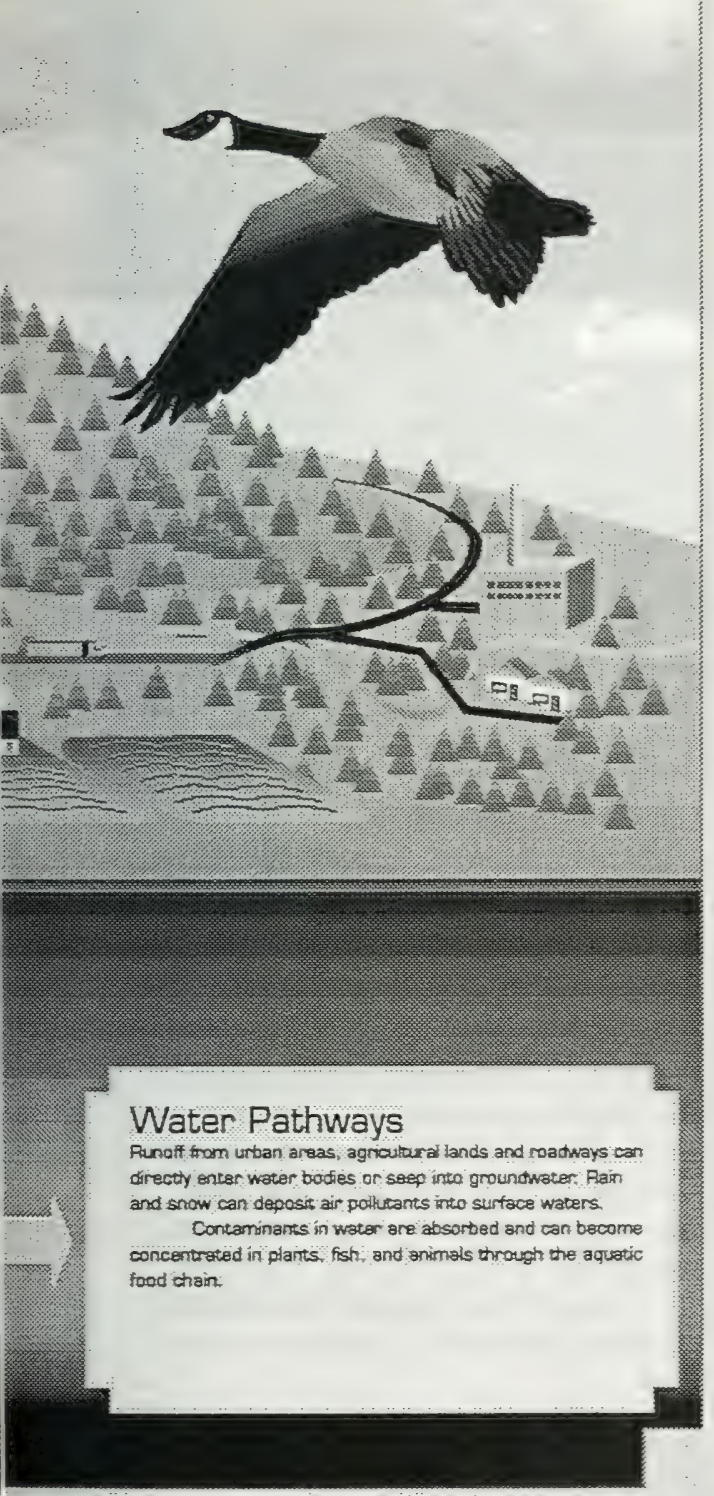
arroduction

How cleart is the ait in our cities? Are there cancetcaising chemicals in our drinking water? Is the ozone layer thinning? Is acid rain still a problem? Are we nunning out of space for our garbage? Is our environment getting better or worse?

People want answers to these and other questions about the envixonment. That is why this report has been pubfished tis object is to give Ontarians a convenient overview of the current status of provincial air and water quality and waste management, to document and explain the forces affecting these areas, and to meastre the effectiveness of actions to protect and improve the quality of Ontaria's eavironment:

This is Ontario's first status report on the environment, and as such, sould be considered a pitot project The report prepared by the Ontario Ministry of Enritonment and Energy (MOEE\}, is limited to matters of environmental quakity that fall within the miristrys area of responsibility - specifically, air quality water quality, acid rain and waste. managentent it does not contain information on issues such as the state of wildife, wetlands, forests or agriculturalland in On tarto. For the most part, the information presented in the report is based of dise gathered up to 1992 


\section{introduction continued}

Ontario intends to issue further reports on the status of the environment on a regular basis. Collaboration between MOEE and other ministries and agencies with environmental responsibilities will make these reports more comprehensive.

Making environmental monitoring and reporting information and analysis publicly available on a regular basis is an important contribution to social, economic, and environmental decision making. It draws attention to problems and give us benchmarks for evaluating the impact of our activities. It shows us what we have accomplished so far and reminds us of what remains to be done. As we work towards achieving a more sustainable relationship with the environment, environmental reporting will play an increasingly important role. This report is a first step in that direction.

\section{CHAPTER 1 \\ ONTARIO'S ENVIRONMENT AND ITS ECONOMY}

Ontario's environment is characterized by its great size and diversity. With an area of 1,068,580 square kilometres, Ontario is Canada's second largest province. Situated in the middle of North America between the salt waters of Hudson Bay and the freshwaters of the Great Lakes, Ontario spans some 15 degrees of latitude, onesixth of the distance between the North Pole and the equator. Its climate ranges from sub-Arctic in the north to temperate in the south, with occasional summer overtones of sub-tropical heat and humidity when air masses from the Gulf of Mexico move through the southern part of the province. Its landscapes are equally diverse, embracing the farmlands, mixed forests, and urban agglomerations of the south, the lakes, rivers, evergreen forests and ancient rocks of the Canadian Shield and the scrub and muskeg of the Hudson Bay lowland.
This vast territory is also generously endowed with natural resources. Ontario has more than 800,000 square kilometres of forest, of which slightly less than half are available for commercial use. The province is a leading producer of copper, nickel, uranium, gold and silver, and has about half of Canada's most fertile agricultural land. Lakes and rivers cover nearly a fith of the province's surface, providing energy for hydroelectric power as well as water for domestic, industrial and recreational use. Ontario's inland waters and the Great Lakes also support an abundance of wildlife and provide the basis for major sport and commercial fisheries.

The environment is made up of air, land, water and living things. These interact to form a variety of distinct natural communities or ecosystems. Ecosystems exist on many scales, from local to global, but all perform the important function of cycling life-sustaining energy and materials between the living and non-living parts of the environment. As Figure 1.1 shows, the processes that accomplish this create a complex web of relationships among the different parts of the system. Because of this network of interdependence, a disturbance affecting one part of an ecosystem will often have corresponding and sometimes unexpected consequences in other parts of the system.

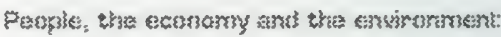

Part of our impact on ecosystems stems from the sheer size of our population, especially when large numbers of us are concentrated in cities. Part of it also comes from our technology, which gives us the power to consume resources and alter the environment rapidly and on a large scale.

In Ontario, the human impact on the environment is considerable. More than 10 million people - well over 


\section{introduction continued}

\section{FGUURE 2.2. PORULATTON DENSTTY BY WATERSHED}

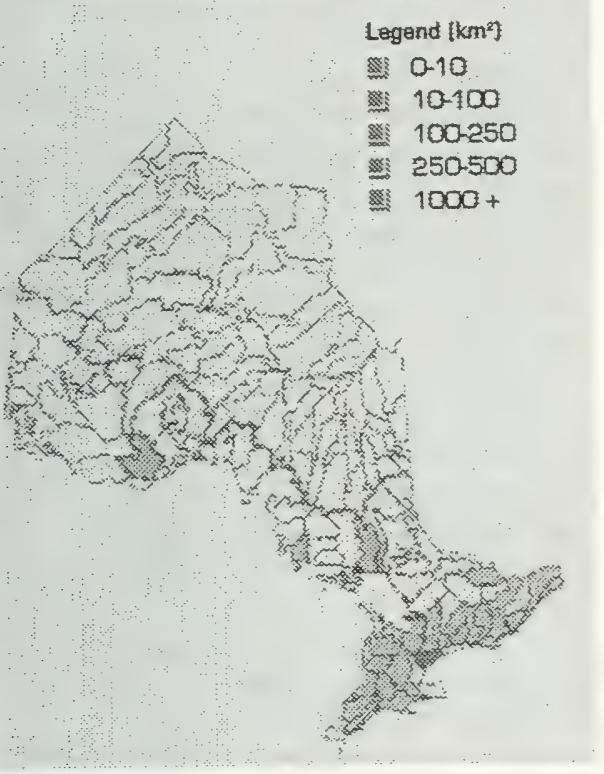

a third of Canada's population - call Ontario home.

Most of them - more than 80 per cent - are urban dwellers, and nearly half of them live in the Golden Horseshoe, the megalopolis stretching around the western end of Lake Ontario from Oshawa to St Catharines. Altogether, close to 90 per cent of the population lives in southem Ontario, a region that comprises about 10 per cent of the province's area (Figure 1.2).

In addition, Ontario is Canada's most highly industrialized province, accounting for more than 40 per cent of its industrial output. There are more than 22,000 mills, smelters, factories and other industrial facilities in the province, involved in such activities as pulp and

\section{FIGURE 1.3: FARMLAND BI WHTESSHED}

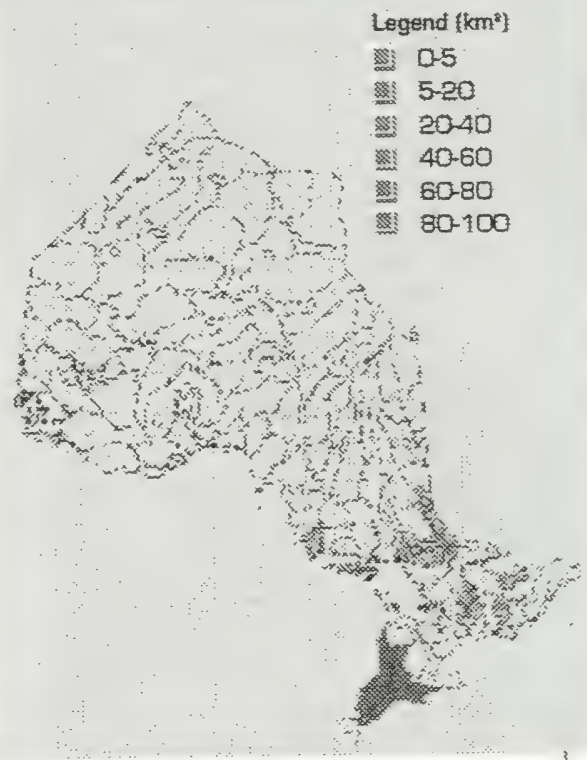

paper production, metal processing, petroleum refining, chemical production, food processing and many other types of manufacturing. Maintaining and expanding this industrial output requires the consumption of large quantities of energy and resources and results in the release of air pollutants, water pollutants and hazardous wastes.

The impact of industrialization is greatest in southern Ontario, where the vast majority of these plants are located. Half of them are in Metropolitan Toronto. Most of the rest are in other localities within the Golden Horseshoe or in the Sarnia-Windsor region. In the north, industrial activity is much more dispersed and 


\section{introduction continued}

is focused primarily on resource processing operations such as pulp and paper mills and metal smelters.

Industrial pollution, however, is not the only source of environmental stress. Agricultural pesticides and herbicides are a significant source of toxic chemicals in both air and water, and chemical fertilizers, and livestock wastes contribute to water pollution. The impact of agricultural pollution is most evident in the southwestern and southeastern counties, where about 50 per cent of the land is under cultivation (Figure 1.3).

In the north, mining and forestry impose additional stresses on the environment. Both can significantly alter or disrupt wildlife habitat. Poor forestry practices may also cause soil erosion, pollution from pesticide and herbicide use, and depletion of the forests themselves if care is not taken to regenerate areas that have been cut. Mining also may produce acidic and toxic wastes that can contaminate ground and surface water. Abandoned mines are a further source of these contaminants.

The conveniences of modern day living are also sources of pollution. Car and truck emissions contribute to urban smog. Fridges and air conditioners contain chemicals that deplete the ozone layer. Towns and cities continually generate sewage and garbage which require proper treatment and disposal. Even ordinary household items such as paints, cleaners and cosmetics can be sources of harmful pollutants.
Moreover, a society such as ours has a large appetite for energy - to power industries, heat homes and run cars. Much of this energy comes from fossil fuels, such as gasoline, oil and natural gas. In fact, 77 per cent of the energy used by Ontario consumers is derived from fossil fuels. Ontario's motor vehicles alone use more than 15 billion litres of gasoline and diesel fuel a year. Electricity also supplies many needs, but about a quarter of what Ontario generates comes from the burning of coal and other fossil fuels. The rest is produced by nuclear power ( 48 per cent) and water power ( 29 per cent).

The production of this energy imposes both costs and risks on the environment. The burning of fossil fuels contributes to urban air pollution, global warming and acid rain. Nuclear energy creates radioactive wastes that are difficult to dispose of safely and hydro power can have major impacts on watersheds and wildlife habitat.

For the most part, environmental problems that are created in Ontario have their greatest effect in Ontario. But because ecosystems know no borders, Ontario's environmental quality affects and is affected by the environmental quality of surrounding regions and other parts of the world. A clean environment is something we owe both to ourselves and to the rest of the global community. 


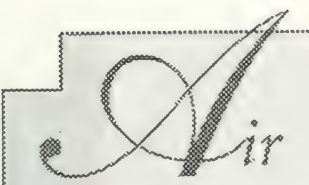

Air is a mixture of many different kinds of gases and suspended particles. Most of these come from natural sources. Others are created and released into the air as a restult of human activities. When concentrations of some of these gases and particles become too high, they can harm human health and damage the environment.

Air pollution linked to human activity comes from point sources such as large factories or thermal-electric power plants and from area sources such as motor traffic or household furnaces. Some of the gases and particles released from these sources affect only the area near the source, but others may be carried by air currents, affecting areas hundreds of kilometres away.

Air pollutants affect the environment in at least three ways. They can directly damage the health of plants and animals that breathe the air. They can contaminate other parts of the environment such as soils and water. And they can change the makeup of the atmosphere and the way in which some of its mast important processes function.

The chapters in this section look at four aspects of air quality that face Ontario residents today: comman air pollutants, toxic air pollutants, stratospheric ozone depletion, and global warming.

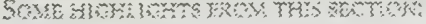

- Ontarians are polluting less. Emissions of some of the most common air polfutants, such as sulphur dioxide, nitrogen dioxide, airborne particles and carbon monoxide, have decfined over the fast two decades, in some cases substantialfy. Emissions of sulphur dioxide, for example, fell by 73 per cent between 1970 and 1992

- In Ontario, there has been less success in dealing with ground-level ozone more commonly known as smog. Average ground-level ozone concentrations were higher at the end of the 1980 s than at the beginning. Because of its exposure to ozone-laden winds from the United States, southwestern Ontario was affected most frequently by groundlevel ozone poliution. Elfty percent of ground-level ozone measured during high ozone periods was transported from the American mid-west.

Odours from recuced sulphur compounds such as trydrogen sulphide (roiten egg gas) are still a major problem in places suct as Fort Frances and Cornwall, which have kraft puifp mills.

- Since the introduction of unleaded gasoline, the concentration of lead in outdoor air has declined drantatically. However, cancentrations of manganese, used as a substitute for tead in gasoline, are increasing.

- In ouldoor air in Ontario, concentrations af toxic com. pounds such as benzene, formaldehyde and dioxins and furans are generally very low.

- The high altitude ozone layer over Toronto bas thinned by about four per cent since the late 1970 s. Between 1986 and 1991, Ontario cut its tuse of azone depleting substances by $50 \%$.

- Since 1890 avernge annual temperatures bave risen by $0.5^{\circ} \mathrm{C}$ in northern Ontario ard by $0.6^{\circ} \mathrm{C}$ in the south.

- Ontario is Canada's largest producer of carbon dioxide in terms of totaf emissions but ranks only seventh among the provinces in emissions per head of population. 


\section{CHAPTER 2 COMMON AIR POLLUTANTS}

The most common air pollutants in Ontario are sulphur dioxide $\left(\mathrm{SO}_{2}\right)$, nitrogen dioxide $\left(\mathrm{NO}_{2}\right)$, carbon monoxide (CO), total reduced sulphur compounds (TRS), particulate matter $(\mathrm{PM})$, and ozone $\left(\mathrm{O}_{3}\right)$.

While all of these contaminants occur naturally, human activity increases these natural levels substantially. At higher concentrations most of these pollutants are a health hazard, affecting the respiratory and cardiovascular systems and making breathing more difficult, especially for people with chronic respiratory diseases. A number of them also damage plants and crops and speed up the aging of plastic, rubber, dyed fabrics and other materials. Some have foul odours or form a dirty haze that decreases visibility (Table 2.1).

High air pollution levels usually occur in urban or industrial centres due to emissions from traffic, factories and buildings. But rural areas are sometimes affected as

\section{TABEE 2.1 COMMON AIR POLZUTANTS AND THETR EFFECTS}

\begin{tabular}{|c|c|c|c|}
\hline Pollutant & Sources & Health effects & Dther effects \\
\hline Sulphut dinxide & $\begin{array}{l}\text { Smeltets trilities, primary metal } \\
\text { industries, refineries, mining and } \\
\text { other sources }\end{array}$ & $\begin{array}{l}\text { Respiratory itritants, Increase yut } \\
\text { nerability fo respiratory diseases } \\
\text { and agravate existing respiratory } \\
\text { ailments. People with asthma, }\end{array}$ & $\begin{array}{l}\text { Damage to plants Acid tain. Dam } \\
\text { age fo materials Metal corrosion }\end{array}$ \\
\hline Nitrogen dioxide & $\begin{array}{l}\text { Transportation (vehicte, air, rail), } \\
\text { uritities, industrial processes, } \\
\text { primary metals, other sources }\end{array}$ & $\begin{array}{l}\text { bronchin's, other chronielung } \\
\text { äseases and beart disease are } \\
\text { particularly sensitive }\end{array}$ & $\begin{array}{l}\text { Damage to ptants Acid rain. } \\
\text { Odouc Flaze Dantage to marertals } \\
\text { (melat corrosion, fading of dyes } \\
\text { cracking of plastic and rubber). }\end{array}$ \\
\hline Orone $\quad \therefore \quad \vdots$ & $\begin{array}{l}\text { no direct source. Formed by. } \\
\text { combrimation of mitrogen oxide } \\
\text { and trydrocarbons }\end{array}$ & & $\begin{array}{l}\text { Damage ro ptants. Damage to } \\
\text { marerials f fading of dyes, cracking } \\
\text { of rubber and plastics\}. }\end{array}$ \\
\hline 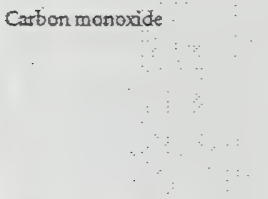 & $\begin{array}{l}\text { primarihy vehuele, other trans- } \\
\text { portation, ehemical industries, } \\
\text { primary metals } \\
\therefore \quad \therefore \quad\end{array}$ & 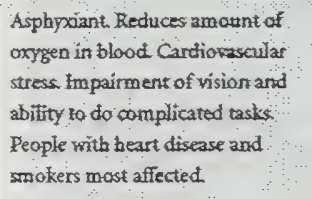 & \\
\hline Particulate matter & $\begin{array}{l}\text { transportation, primary metals, } \\
\text { pulp and paper mills, utritities fuel } \\
\text { combustion }\end{array}$ & $\begin{array}{l}\text { Respiratory irritant Partides atso } \\
\text { may have toxic substances bonded } \\
\text { to theml. }\end{array}$ & $\begin{array}{l}\text { Damage to plants soiling. } \\
\text { Corrasion Reduced visibility. }\end{array}$ \\
\hline Reduced sulphur campounds & $\begin{array}{l}\text { reduced sulphur compounds: steel } \\
\text { industries, refineries, pulp and } \\
\text { paper milts, chemical plants }\end{array}$ & & Odour \\
\hline
\end{tabular}




\section{dir contrinused}

well, when pollution is carried by air currents. The time of day and the weather can also have an important effect on pollution levels.

The quantity of a particular pollutant in outdoor air at a certain time and place is known as the ambient concentration. Ambient concentrations of the six common pollutants have been monitored regularly across Ontario since the early 1970 s. This monitoring program not only helps to identify pollution risks but also provides information that can be used to indicate long-term pollution trends and measure the effectiveness of pollution control measures.

Ontario has set air quality criteria (AQCs) for each of these six pollutants which indicate when pollution levels become too high. The criterion is given as an average ambient concentration for a certain length of exposure such as a day, an hour, or a year, and it marks the point at which the pollutant becomes potentially harmful.

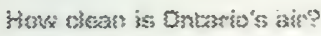

Ontario's air quality has improved substantially over the past twenty years. Ambient levels of sulphur dioxide, carbon monoxide, suspended particles and nitrogen dioxide have all declined - in some area substantially. The sharp reduction in levels of sulphur dioxide alone represents a major advance in public health. Studies conducted by the Urban Air Group at McMaster University suggest that every one part per hundred million increase in average annual sulphur dioxide levels results in one extra doctor's visit per year for every person in the province.

Still, some serious air quality problems remain. Ground-level ozone levels have shown a resurgence in the last few years. In places where industry and vehicle traffic are densely concentrated, pollution levels rise rapidly when weather conditions favour their buildup. As a result, many centres in the province continue to experience periodic episodes of moderate to poor air quality.

A useful indicator of overall air quality around the province is the Air Quality Index (AQI). Published since 1988 , the index is based on individual readings for each of the common pollutants and is presented as a single number. As Table 2.2 shows, the index is divided into five categories, depending on the possible health, vegetation, property, and aesthetic effects of different levels of pollutants.

A special component of the Air Quality Index - the Air Pollution Index (API) - measures 24-hour running averages of sulphur dioxide and particulate matter. If the API reaches unacceptable levels and weather conditions favour a buildup of these pollutants, the government can order major emitters to reduce or cease operations.

Some vegetation begins to show adverse effects from air pollution when the Air Quality Index enters the moderate range (index values 32-49). Aesthetic effects such as odours, haze, and soiling of materials are also evident in this range. Effects on human health are generally not noticeable until the index passes 50 and depend on the pollutant involved. Ozone, carbon monoxide and nitrogen dioxide are considered health threats when concentrations are in the poor range (index values 50 99). People with respiratory problems are the first to be affected, but as the index rises the number affected increases.

Figure 2.1 shows the number of days at various monitoring sites for which the Air Quality Index was above 31 for one hour or more during 1992. Almost all these instances of readings higher than 31 , however, 


\section{Bir combincied}

were in the moderate range and are unlikely to have been a threat to human health. The very high number of readings above 31 at Fort Frances and most of those at Cornwall were due to reduced sulphur compounds, which are not a health hazard. For most other Ontario communities, ozone and suspended particles were the main pollutants. Altogether, only five locations reported $A Q I$ values greater than 50 in 1992, and in only one of these (Windsor College Street) was there actually a risk to health. That occurred at the College Street site in
Windsor, where ozone concentrations were in the poor range for a period of four hours. The same site also recorded the highest AQI level for 1992 (a value of 71 , due to suspended particles).

Although poor air quality days do occur, in general the health risk from outdoor air in Ontario commurities is low. To measure effectiveness in controlling air pollution, the rest of this chapter looks at how emissions of each of these pollutants has changed over the past 10 to 20 years.

TABIE 2.2 ONTARIO'S AIR QUATITY INDEX

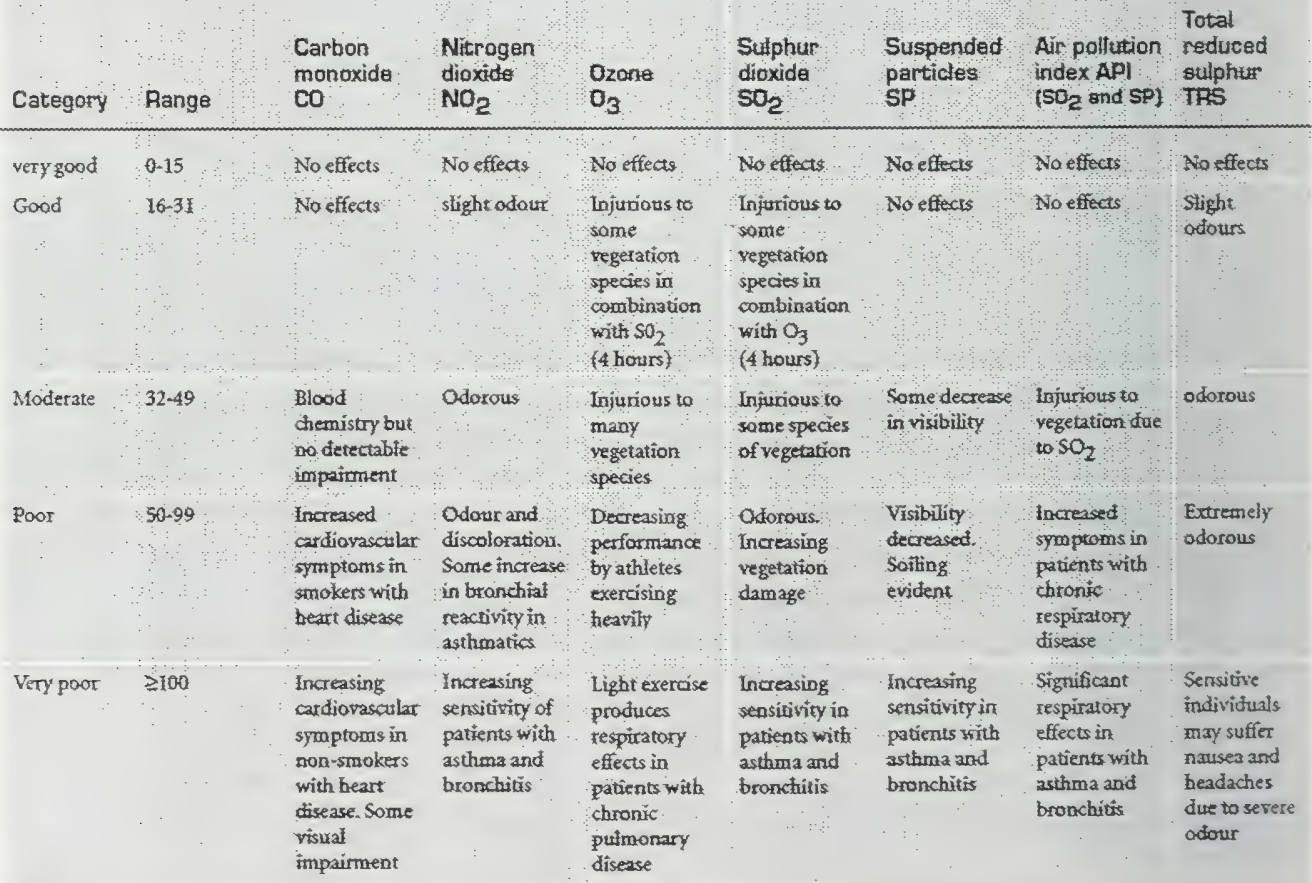




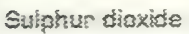

Sulphur dioxide is a colourless gas produced by the combustion of sulphur-containing fuels like oil and coal and by certain industrial processes. In 1992, Ontario industries, businesses, and households released about 900,000 tonnes of it to the atmosphere. Approximately 75 per cent of this amount came from electric power stations burning coal and oil and non-ferrous metal smelters and sintering plants using high-sulphur ores. (Sintering is a roasting process for concentrating ores.) Most of the remaining emissions came from iron ore smelters, petroleum refineries, pulp and paper mills, and home, office and factory heating.

Because it is the principle component of acid rain, sulphur dioxide has been the focus of some very strenuous and successful efforts to reduce emissions. Between 1970 and 1992, province-wide emissions of $\mathrm{SO}_{2}$ declined by 73 per cent, thanks to tighter emission controls, improved process technology, and conversion to low-sulphur fuel Emissions from smelters alone decreased by 80 per cent over the same period (Figure 2.2). By the end of 1994, Ontario's overall $\mathrm{SO}_{2}$ emissions are targeted to reach 885,000 tonnes, with most of the reductions coming from Ontario Hydro, the smelting operations of Inco and Falconbridge, and the sintering operations of Algoma Steel.

As emissions have declined, ambient concentrations of sulphur dioxide have also declined. Between 197I and 1992 , the yearly average of ambient sulphur dioxide concentrations for all monitoring sites in the province decreased by about 83 per cent (Figure 23). In 1992, the highest concentrations were recorded in industrial cities such as Sarnia, Hamilton, and Sudbury, where there were thermal power stations, smelters, or petrochemical

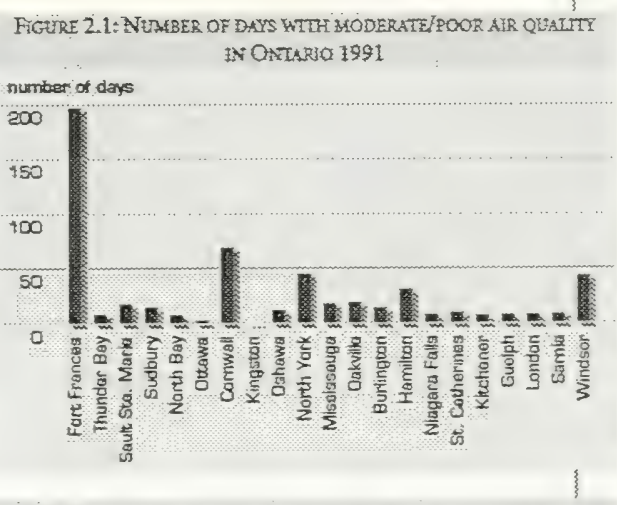

FHGLRE 2.2: SULPHLT DIOXIDE EMISTONS 1:A ORTARTO, 1970-1992

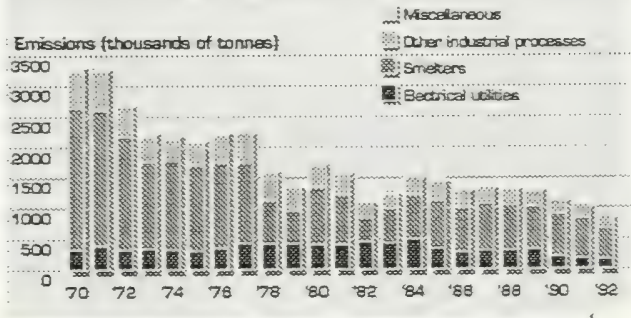

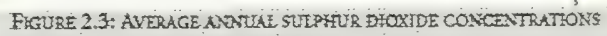
iN ONTARio, 1971-1992

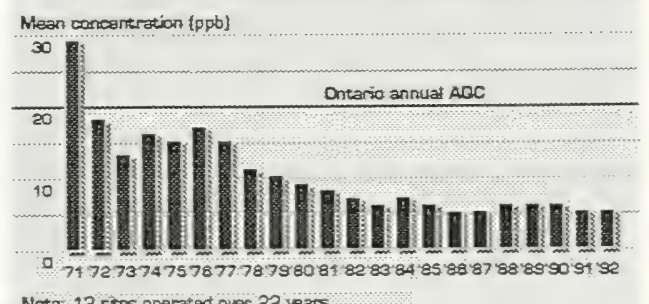

Nota 12 stes operated over 22 years 


\section{ais contringed}

FIGURE 2.4: LOCAL SUIPHUR DTOXIDE CONCENTRATIONS. ANIEEAL AVERAGE, 1992

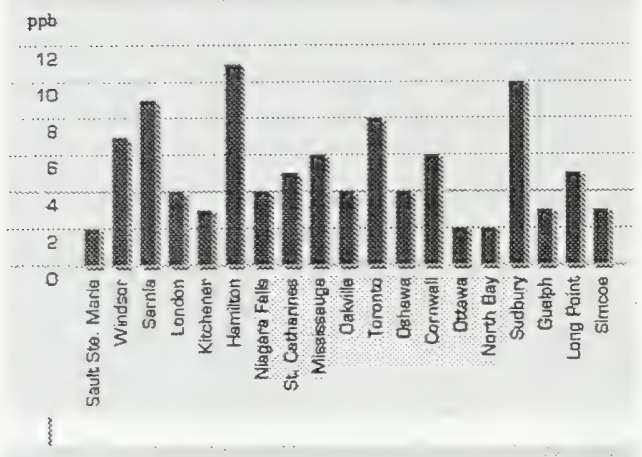

FICURE 2.5: EMMSSTONS OF NITROGEN OXIDES IN ONTARF 1983-1992

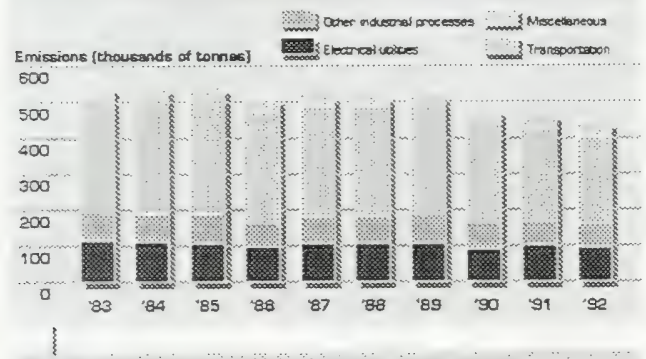

FIGURE 2.6: VeHECLES - KIOMETRES TRAVELLED IN ONTARIO

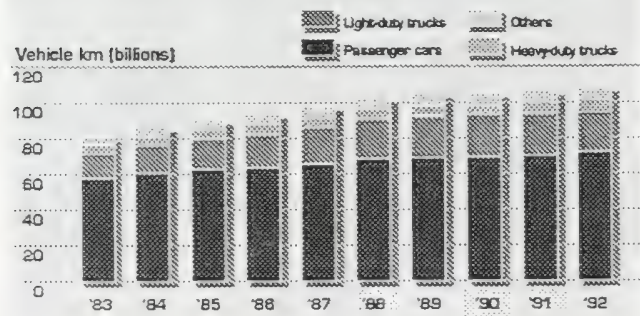

refineries (Figure 2.4). However, none of these places exceeded the annual air quality criterion, although a total of 15 locations ( 13 of them in the Sudbury area) exceeded the one-hour criterion at least once.

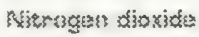

The air around us is mostly a mixture of nitrogen and oxygen - about 78 per cent of the former and about 21 per cent of the latter. Whenever anything is burned in air at a high temperature, as in a furnace or a car engine, these gases combine readily to form various oxides of nitrogen. The most common of these is nitrogen dioxide, a reddish-brown gas with a pungent and irritating odour that is commonly seen hanging over cities during the summer.

About 60 per cent of Ontario's nitrogen oxide emissions come from various means of transportation, mostly from motor vehicles. Other sources include thermalelectric generating plants, incinerators and chemical processes. Altogether, Ontario produced nearly 450,000 tonnes of nitrogen oxides in 1992.

Nitrogen oxide emissions had remained fairly constant during the 1980 s, but fell by more than 20 per cent between 1989 and 1992 (Figure 2.5), thanks largely to the introduction of new vehicle emission standards. These resulted in a significant decrease in transportation emissions, even though Ontario vehicles recorded an increase in total kilometres travelled (Figure 2.6).

Because motor vehicles are the major source of emissions, getting nitrogen oxide emissions down and keeping them there - is a difficult long-term proposition. Better technology and regular inspection and maintenance can reduce the emissions per vehicle. But every additional car or truck on the road is a new source 


\section{air cartinued}

of emissions and the number of vehicles in Ontario continues to increase from year to year.

The yearly average of nitrogen dioxide concentrations at monitoring sites in Ontario improved by about 13 per cent between 1975 and 1983 and this has remained faidy constant since then (Figure 2.7 ). The highest levels are normally found in larger cities, especially during rush hours when traftic density is greatest. However, there were no instances of exceeding the hourly air quality criterion in 1992 (Figure 28).

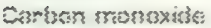

Carbon monoxide is a colourless, odourless gas that forms when carbon fuels are bumed without sufficient oxygen. The use of various forms of transportation is responsible for about 75 per cent of emissions, with the burning of fossil fuels for home heating and commercial and industrial operations accounting for most of the rest: In spite of an increase in the number of vehicles on the roads, carbon monoxide emissions have declined by about 30 per cent over the last decade. In 1992, they totalled nearly 1,900,000 tonnes (Figure 2.9 )

Lower emissions have generally led to improvements in ambient concentrations of carbon monoxide. By 1983, average annual concentrations had fallen by approximately 75 per cent from their levels a decade before, and they have remained relatively steady since then (Figure 2.10). Neither the one-hour nor the eight-hour air quality criteria were exceeded in 1992 (Figure 2.11).
FICLRE 2.7: AVERAGE ATWUA NTKOGET DHOXTDE CONCEMTRATONS 1R: ONTARO, 1975-1992

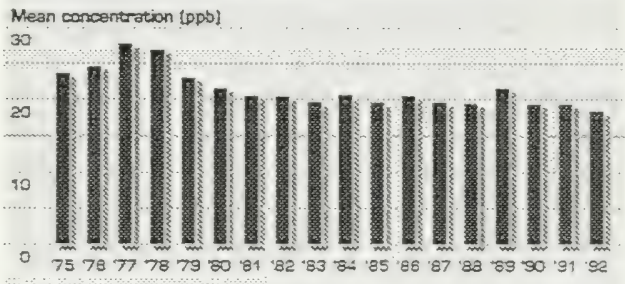

Note: 15 stes operatad over. 18 years

\section{FHGURE 2 8- LOCAL NTTROGEN DHOXIDE CONECETTHATH} I-HOt? ALAOALM 1992

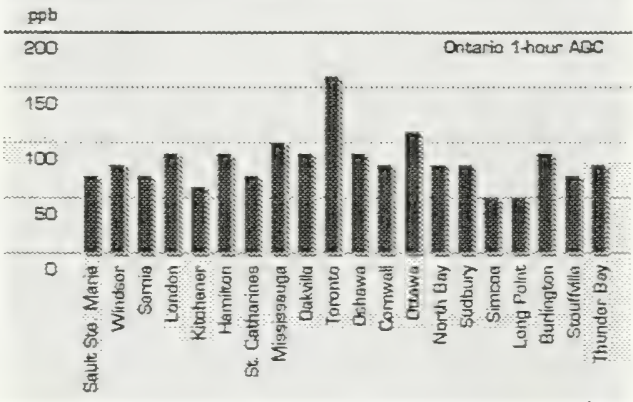

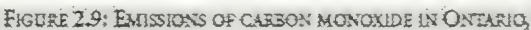
1983-1992

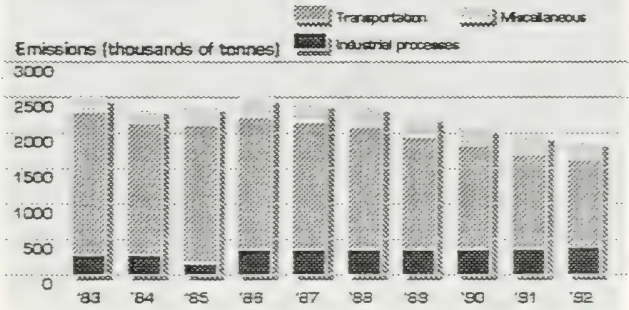




\section{air continued}

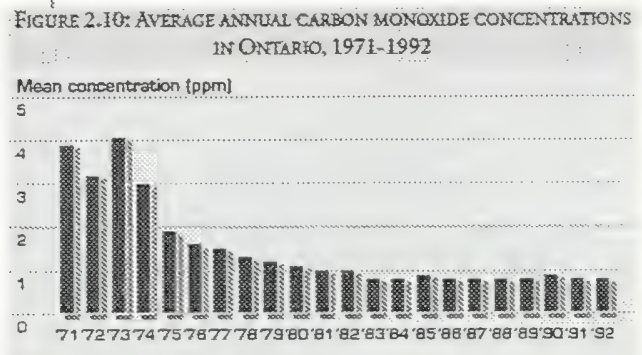

Note: 9 sies operaced over 22 years

\section{FIGUTE 2. 1- LOCAL CARBON MONOXADE CONCENTRATIONS.} 1-HOUB AND 8-ZOOUR MAXMMUAS,

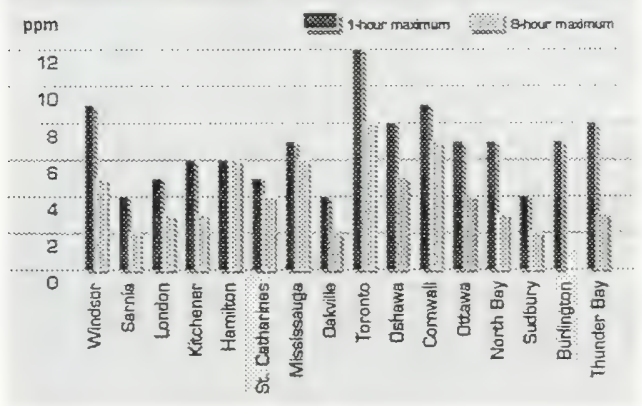

$\xi$

FIGURE 2,12: AVERAGE ANNUAL TRS CONCENTRATONS IN ONTARTO, 1983-1992

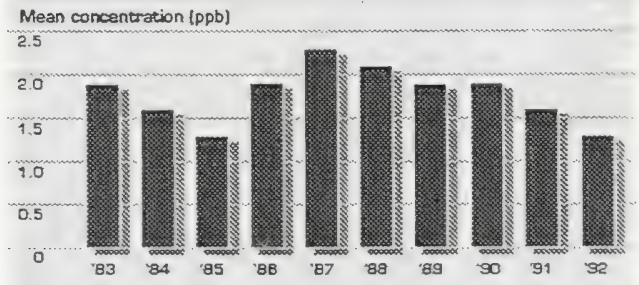

Note: 6 stres operated over 10 years

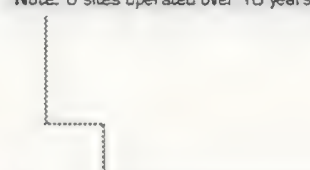

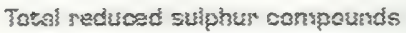

Total reduced sulphur compounds are a group of sulphur-containing gases with a highly disagreeable odour that can be detected even at very low concentrations. Hydrogen sulphide, with its rotten egg odour, is probably the best known of these. Although they are not normally considered a health hazard, reduced sulphur compounds are the primary cause of odours in towns where kraft pulp mills are located. Other sources include steel mills and petroleum refineries.

Province-wide averages of total reduced sulphur compounds (TRS) declined in the early 1980s, then increased towards the middle of the decade. Since 1988, they have shown a generally declining trend (Figure 2.12). The 1985 average is unusually low because of production shutdowns and decreases in emissions at the kraft pulp mill in Cornwall and monitoring problems at Fort Frances.

As Figure 2.13 shows, the one-hour air quality criterion for TRS is most commonly exceeded in towns such as Fort Frances, Cornwall, Terrace Bay, and Red Rock, as a result of kraft pulp mill operations. Iron and steel or petroleum refinery operations also contribute to occasional instances of readings in excess of the criterion in Hamilton and a few other locations. The Ministry of Environment and Energy is now working with major industrial emitters to reduce emissions to more levels. 


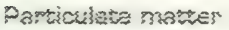

Major emitters of particulates include incinerators, construction sites, quarries, metal smelters, motor vehicles and pulp and paper mills. In cities, vehicle exhaust and road dust are the principal sources. In Ontario, these and other sources related to human activities account for about 200,000 tonnes of emissions a year, but natural sources such as forest fires may contribute up to five times as much.

Fugitive sources, such as road and construction dust and surface erosion are virtually impossible to measure. As a result, estimated emissions, as shown in Figure 214, are not necessarily a good predictor of ambient levels. Until the mid-1980s, particulate emissions showed a slight upward trend but have declined since then, probably because of cleaner emissions from motor vehicles, industries and other combustion sources. The highest emission rates are in urban areas.

During the past 22 years, average province-wide concentrations of particulate matter have fallen by 61 per cent, with a 17 per cent decrease over the last 10 years (Figure 2.15). Typical levels of total suspended particulate (TSP) are shown in Figure 2.16 for selected monitoring sites across Ontario. There were no instances of exceeding the annual TSP criterion at these sites in 1992.
FICLRE 2.13: NLMGER OF INSIANCES WHERE 1-HOZR KRAFI PUTP MEEI TRS CRTERION W"AS EXCEEDED, 1992

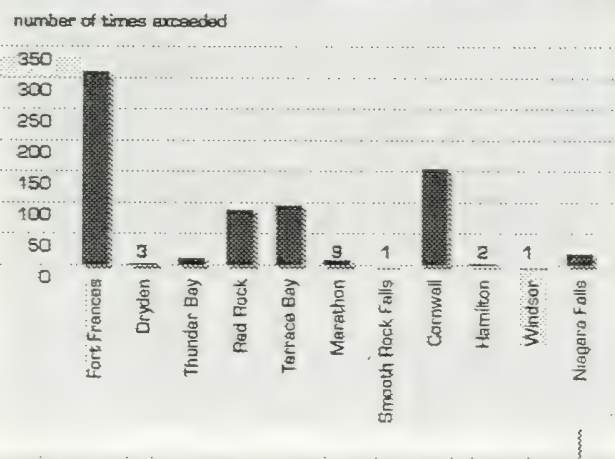

FEGURE 214: PARTCULATE EMISTONS FN ONTARIO 1983-1992

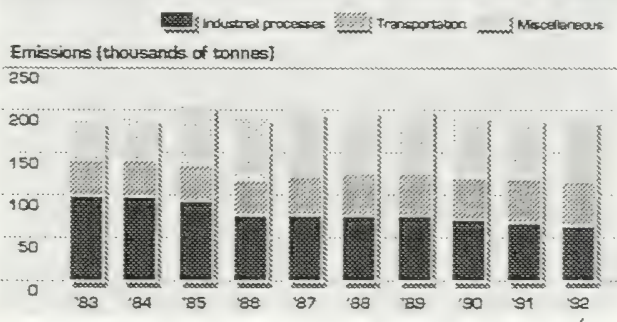

EIGUTE 2.15: AVERAGE ANRUAL TSP COACENTEATHON LN ONTALO, $1971-1992$

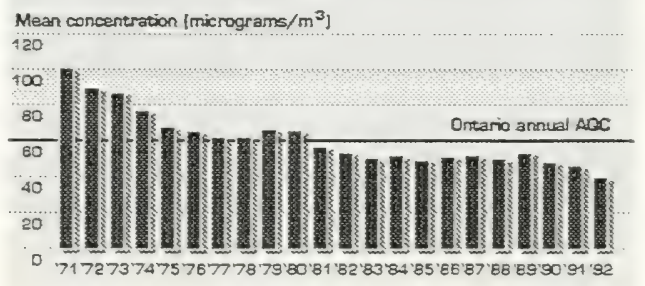




\section{eir' contringed}

FICURE 2.16: AVERAGE ANRTALI TSP CONCENTRATHONS IN SELACT LOCAEITIES, 1992

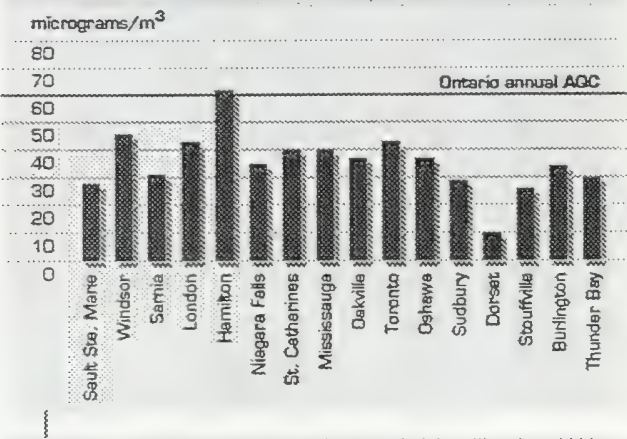

EIGURE 2.17: ONIARHO VOC EMISTONS BY SHCTOR

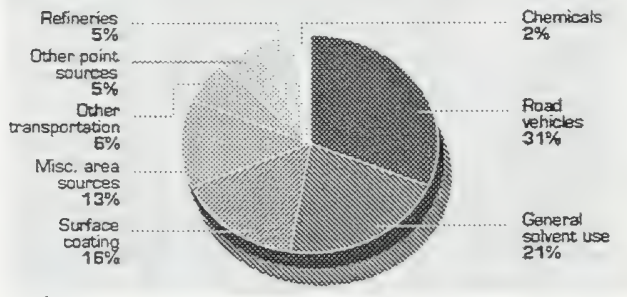

\section{Grounthevel azone}

Ozone is a form of oxygen, made up of three oxygen atoms instead of the usual two. At high altitudes it filters harmful ultraviolet radiation from incoming sunlight, but at the earth's surface it is an unwelcome pollutant.

Small amounts of ozone form and break up naturally in clean air at the earth's surface as a result of the action of sunlight on nitrogen oxides (NOx). In polluted air, however, ozone formation is increased by the higher levels of nitrogen oxides reacting with other chemicals - notably volatile organic compounds (VOCs), that evaporate from sources such as gasoline and solvents.

Weather conditions have a considerable influence on surface ozone levels. Air masses can carry ozone or its nitrogen oxide and VOC precursors over several hundreds of kilometres. Levels can soar during summer hot spells, when dry, sunny weather favours ozone formation and stagnant air masses prevent its dispersal. Indeed, ground-level ozone is primarily a summer pollutant.

Ozone is a major component of photochemical smog and forms near or downwind of sources of NOx and VOCs. Motor vehicles are a major source of both groups of substances. Other major sources of VOCs include a variety of solvent-based materials, from printing inks to nail polish remover, and surface coatings such as paints and varnishes (Figure 2.17). 
In spite of increased vehicle usage, VOC emissions have remained fairly close to the 1987 level of 630,000 tonnes per year throughout the past decade. Like nitrogen oxides they have also shown a moderate decline since 1990. In the case of VOCs, this can be attributed to new vehicle emission standards, changes in the composition of gasoline used in the summer and the effects of economic recession.

Natural sources such as forests and forest fires also release significant quantities of VOCs to the atmosphere. In fact, emissions from natural sources may be as much as three times greater than those from sources related to human activities.

Although towns and cities are major sources of both NOx and VOCs, ozone pollution is not exclusively an urban problem. Approximately 50 to 60 per cent of ground-level ozone concentrations in Ontario blow into the province from sources south of the lower Great Lakes (Figure 218). In rural areas in the path of these air streams, ozone levels often exceed the provincial onehour air quality criterion. Indeed, instances of exceeding the criterion have been more frequent at rural sites in southwestern Ontario than in large cities such as Toronto and Hamilton - and certainly far more significant than at rural sites such as Hawkeye Lake, north of Thunder Bay, which are not exposed to the same air tlow (Figure 2.19).
FEGURE 2.18: ARENS FROM WAHCH AR ARRNES DURA: HIGA OZONE PERTODS EN SOUTHERY ONEARIO 1983-1992

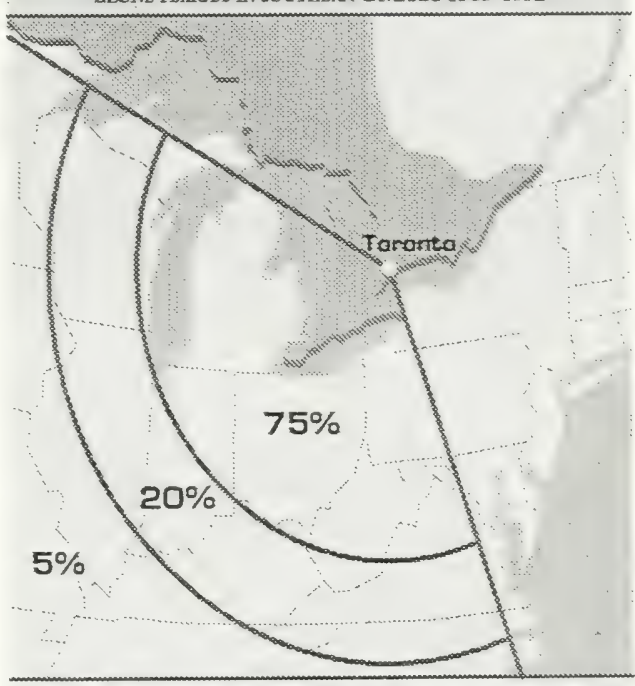

Noter the movement of these air masses from south of the Great Lakes wo Southem Ontario transport $50-50 \%$ of the czone and precursors measured during high worie periods.

FTGURE 2.19: NUTBBER OE INYLANCES A HEXE 1-HOUZ OZONE CRTEEFON WIS EXCEEDED KT SEEECTED LOCAITHES, $1985-1992$

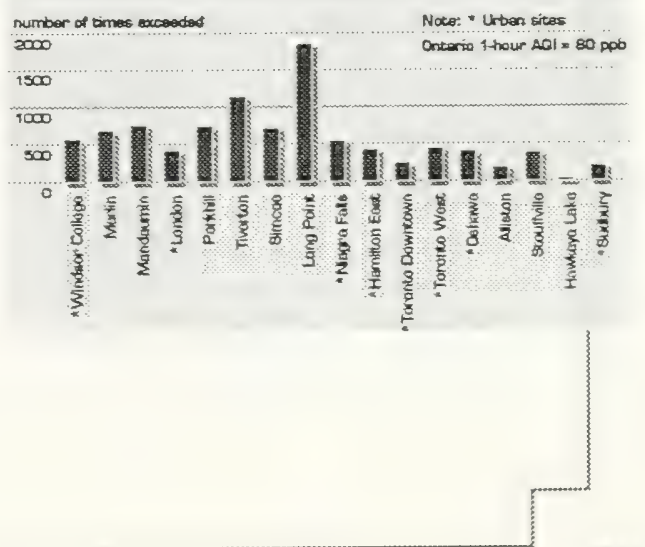




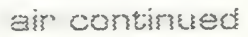

FIGUTRE 2.20: AVERAGE OZONE CONCENTRATHON AND ENSTANCES WHERE CRITERTON WAS EXCEEDED IN ONTARTO 1983-1992

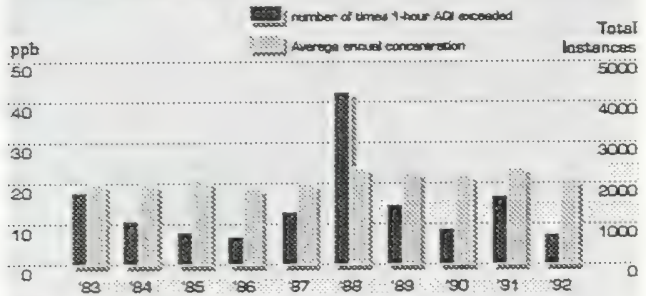

Note' 23 sites operated over 10 years
Figure 2.20 shows province-wide trends from 1983 to 1992 for average annual ozone concentrations and instances of exceeding the one-hour air quality criterion. These instances were highest in 1983, 1988, and 1991, and annual averages were higher in all four years from 1988 to 1991 than in any of the preceding years. Weather factors explain part of this pattern, but the complex interaction of weather conditions and precursor emissions makes it difficult to analyze ozone trends with certainty.

\section{Ferdiscing zair poltution}

Toronto passed Canada's first anti-pollution bylaw in 1907 to regulate smoke, but society did not begin to get really serious about air pollution until the late 1960 s. Average province-wide reductions of common pollutants within the last two decades can be attributed to the MOEE's abatement activities and enforcement of air pollution regulations, such as the Ambient Air Quality Criteria, and the General Air Pollution Regulation, which fall under the Ontario Environmental Protection Act. These activities have required industries, motorists and others to reduce their emissions of various pollutants.

Changing economic conditions have also forced a move towards more efficient and cleaner technologies in many areas. The oil crisis of the early 1970 s, for example, encouraged the development of smaller and lighter cars that used less fuel. Economic downturns, as well, usually bring a temporary decline in pollution Ievels, simply because less is being produced and less is being consumed. 


\section{ONTARHO REFERENCE MAAP}

\begin{tabular}{|c|c|c|c|}
\hline Reference & Site Name & Reference & Site Name \\
\hline 9 & Windsor & 14 & Waipole Island \\
\hline 2 & London & 15 & Ottawa \\
\hline 3 & Kamiton & 16 & Niagara Falls \\
\hline 4 & Oaknila & 17 & St Catharines \\
\hline 5 & NAEsisEAUgs & 18 & North Bay \\
\hline 6 & Toponto & 19 & sudbury \\
\hline 7 & Stotffitas & 20 & Guelph \\
\hline 8 & Osthestre & 21 & Long Point \\
\hline 9 & Dombrall & 22 & Simcoe \\
\hline 10 & Forset & 23 & Burington \\
\hline 17 & Sat Sta Morio & 24 & Kitchener. \\
\hline 12 & Thunder sey & & \\
\hline 13 & Servie & & \\
\hline
\end{tabular}

\section{CHAPTER 3}

\section{TOXIC AIR POLLUTANTS}

Air is one of the most common routes by which people can be exposed to toxic pollutants. These pollutants can be divided into two categories, persistent and non-persistent substances. Once released, non-persistent toxic compounds, such as benzene, quickly break down into harmless byproducts. They are therefore a health concern when they are emitted continuously.

Persistent substances, such as PCBs, present a particulariy difficult problem, because they may remain in the environment long after the source of emission is capped. Many persistent toxic substances accumulate in living tissues and can be transmitted through food chains in increasing concentrations from one organism to another. Thus, even very small amounts of these substances in the air can eventually build up to harmful levels in the bodies of people and of birds, animals and fish that are regularly exposed to them.

Most toxic air pollutants are either heavy metals like lead or organic chemical compounds. All metals are persistent substances and so are many of the organic compounds.

With very few exceptions, an organic compound is essentially one that contains carbon. There are millions of different chemicals in this family and most of them, like sugar, are harmless. But some organic groups contain a number of toxic compounds. The most commonly toxic organic chemicals are:

- chlorinated organic compounds, such as dioxins and furans, PCBs (polychlorinated biphenyls), and organochlorine pesticides like chlordane and DDT; 


\section{air continued}

- volatile organic compounds (VOCs) such as benzene;

- a group of benzene derivatives known as PAHs (polynuclear aromatic hydrocarbons).

There are potentially hundreds of toxic air pollutants. A number of these substances are released into the air from industrial sources. Others, like pesticides and herbicides, are used on farms and in gardens. And many others are found in everyday products like gasoline, paint and cosmetics. Some are synthetic chemicals, others are of natural origin and some, like dioxins, furans and heavy metals, come from both natural sources and sources related to human activities.

\section{T3xic ais polizstartis in Contario}

At elevated levels, some toxic air pollutants have been linked to a wide variety of health problems, including acute poisoning, cancer, genetic mutations, organ damage and changes to the nervous system. With very few exceptions, concentrations of the most important air toxics are low throughout Ontario and well within the safe range indicated by provincial guidelines.

Where comparisons can be made, levels of toxic air pollutants in Ontario communities compare favourably

FIGURE 3.1: PERSONAL EXPOSURE TO VOLATILE ORCANIC COMPOUNDS

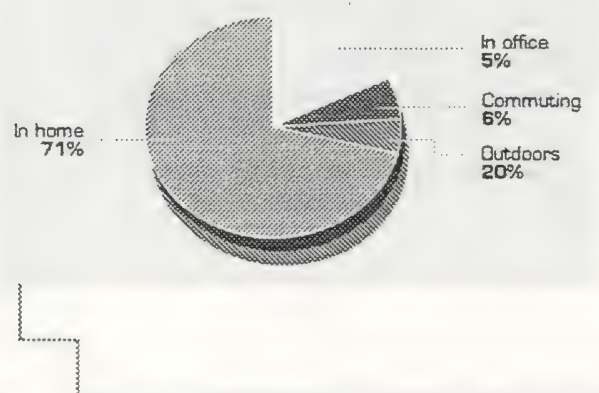

with levels measured in similar locations in the United States and western Europe. In the case of benzene, average median concentrations at urban and suburban sites in the U.S. were 50 to 100 per cent higher than those in most Ontario cities. For other toxic chemicals - B(a)P, formaldehyde, perchloroethylene, methylene chloride and dioxins and furans - Ontario values were similar to or less than those reported for comparable areas in the United States, Germany, France and Finland.

In fact, most Ontarians likely face much greater exposure to toxic chemicals indoors than outdoors. The average home or office, for example, may contain elevated levels of formaldehyde, VOCs and PAHs from sources such as synthetic carpets, plywood, paints, glues, solvents, wood-burning fireplaces, and cigarettes. Not only are concentrations of these chemicals often higher in indoor air, but people in Ontario also spend a much greater part of their time indoors. A recent study of a group of office workers in Windsor showed that they encountered the highest concentration of toxic substances while commuting, but 71 per cent of their total exposure to air toxics occurred at home (Figure 3.1).

This section focuses on eight pollutants that currently appear to present the greatest health risk because

\section{FIGURE 32: AVERAGE ANNUALL CONECNTAATION OF LEAD IN TSP IN ONTARTO, 1971-1992}

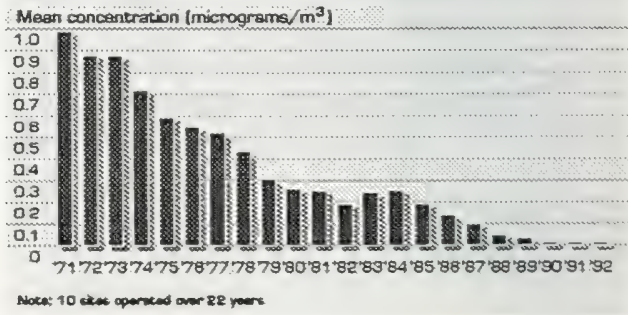


of their high toxicity and their prevalence in the atmosphere. These substances include two heavy metals, five organic compounds commonly found in urban air, and dioxins and furans.

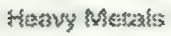

Small quantities of some metals, such as iron, are essential to the human body. Others, such as lead, mercury and cadmium are highly toxic, especially to the kidneys and the nervous system. This section focuses on two metals, lead and manganese.

Lead particles are the most common heavy metals in the air. Lead is especially toxic to children, who absorb it much more readily than adults. Until recently, the largest single source of lead in the atmosphere was leaded gasoline. However, with the introduction of unleaded gasoline in Ontario in 1974 and the subsequent phasing out of leaded fuels over the next decade and a half, the presence of lead-contaminated particles in the air has dropped dramatically (Figure 3.2).

Some 840 tonnes of lead are still emitted to the atmosphere annually, most of it (about four-fifths) from mining and metal processing operations (Figure 3.3). The highest atmospheric lead levels in the province are now found near lead processing plants in Toronto and Mississauga. Because high concentrations of lead may still occur in the vicinity of such point sources, their emissions are closely monitored to ensure they do not exceed the provincial standard of 5 micrograms per cubic metre of air for 24 hours.

As ambient concentrations of lead have declined, however, those of another metal, manganese, have in-

\section{FIGURE 3.3; ONTARFO LEAD EMISSTONS BY SECTOR}

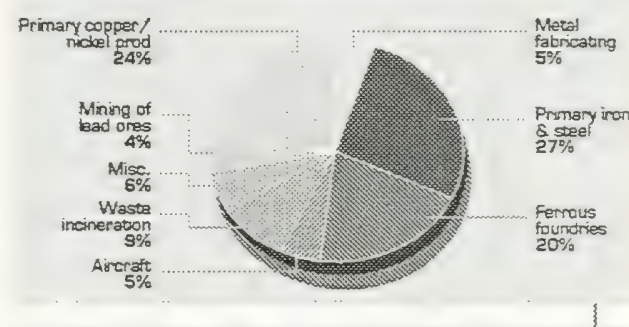

FIGURE 3.4: AVERAGE ANAUAZ CONCEMTRATION OF MRTGANESE NTSP RO ONEARIO $1983-1992$

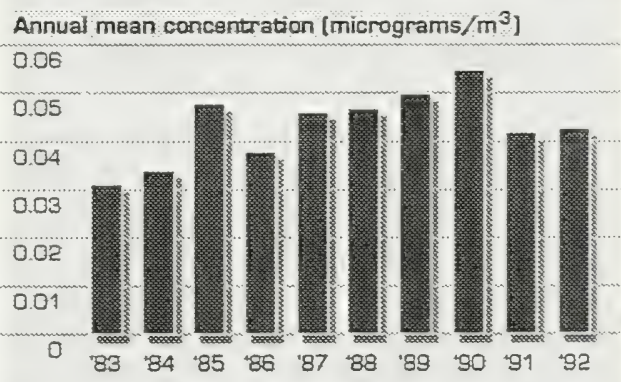

Note: 10 sites operated over 10 years

creased. Manganese was used as a substitute for lead in unleaded gasoline. Annual average concentrations of manganese increased steadily throughout the 1980 s and were almost twice as high at the end of the decade as they were at the beginning (Figure 3.4). Although manganese has industrial uses, its more recent use as a substitute for lead in gasoline likely accounts for the rise in manganese concentrations. 
FIGURE 3.5: MEDTAN AIR CONCENTRATONS AT SEEECTED IOCAITIES

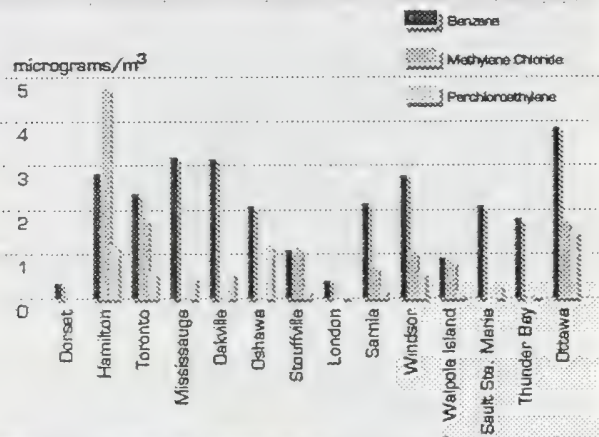

Note: MOE quiceline for methylene chloride is 1765 morograms $/ \mathrm{m}^{3} / 24 \mathrm{trs}$. MLEE quideñne fro PCE is 4000 micrograrns/ $\mathrm{m}^{3} / 24$ hours Interim guideline for bentene to be introduced in 1994

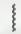

TABIE 3.1: AKBIENT CONCENTRATIONS OF B(A)P, DIOXNS, FURANS AND PORNALDDEHYDE AT SELZCTED IOCALITIES

\begin{tabular}{|c|c|c|c|}
\hline Site & $\underset{\left(\mathrm{ng} / \mathrm{m}^{1}\right)}{\mathrm{B}(\mathrm{a}) \mathrm{P}}$ & $\begin{array}{l}\text { Dioxinst } \\
\text { Furans } \\
\text { fpgtm }{ }^{2} \text { t }\end{array}$ & $\begin{array}{l}\text { Formaldehyde } \\
\left\{\mu g / \mathrm{m}^{2}\right\}\end{array}$ \\
\hline Dorset & 0.0 & $1.19 \% 0.40$ & \\
\hline Toronta Iskand & & 10610.92 & 216 \\
\hline $\begin{array}{l}\text { Windsor } \\
\text { (downtown) }\end{array}$ & 0.2 & $3.34 / 4.90$ & 2.05 \\
\hline $\begin{array}{l}\text { Windsor } \\
\text { (Collegel } \\
\text { Prince) }\end{array}$ & 0.0 & & \\
\hline $\begin{array}{l}\text { Windsor } \\
\text { (Wright) } \\
\text { Water) }\end{array}$ & 0.1 & & \\
\hline Otzawa & $\because$ & & 3.03 \\
\hline $\begin{array}{l}\text { Sault Ste. } \\
\text { Marie }\end{array}$ & 0.9 & & \\
\hline Thunder Bay & a.t & & \\
\hline Guideline & $0.3\left(\mathrm{ng} / \mathrm{m}^{2}\right)$. & $30 \mathrm{pg} / \mathrm{m}^{3}$ & $65 \mu \mathrm{g} / \mathrm{m}^{3}$ \\
\hline
\end{tabular}

Manganese is an essential element in people's diets and, in fact, most of the manganese in people's bodies comes from food. Health effects do not occur from low level exposure to manganese in air and food. However, exposure in more concentrated doses can lead to harmful effects. Miners and metal workers exposed to high levels of manganese dust sometimes experience a synd rome known as manganism, which is marked by mental and emotional disturbances and slowness and clumsiness of movement. So far, manganese concentrations around the province have been well within the MOEE's guidelines.

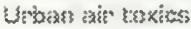

Of all the toxic chemicals that come from typical city sources such as industries and motor vehicles, those of greatest concern are formaldehyde, benzo(a)pyrene [B(a)P], benzene, methylene chloride and perchloroethylene (PCE).

Formaldehyde is widely used as a fungicide and preservative and as a raw material in the manufacture of plastics, plywood and particle board. B(a)P, a byproduct of the incomplete combustion of carbon fuels, is found in wood smoke, cigarette smoke, diesel exhaust and coke oven emissions. Benzene is an easily vaporized component of gasoline and is also found in the exhaust gases of gasoline engines. Methylene chloride is used commonly as a paint remover and degreasing solvent, and is an industrial byproduct, while PCE is a degreasing solvent and a dry cleaning fluid as well. All of these compounds are either known or probable carcinogens. PCE and $\mathrm{B}(\mathrm{a}) \mathrm{P}$ are also highly persistent in the environment. 


\section{air gantirาused}

Concentrations of urban air toxics in almost all localities, though, have been well below current provincial guidelines. The highest normally occur in urban industrialized areas such as Toronto, Hamilton, and Windsor. As might be expected, the lowest levels of toxic contaminants are usually found at rural sites, such as Dorset near the southwest boundary of Algonquin Park. Between 1989 and 1992, one of the air toxics guidelines, for $B(a) P$, was exceeded on a number of occasions. These elevated levels were recorded at a site adjacent to the Al. goma Steel mill in Sault Ste. Marie, and at several monitoring sites in Hamilton.

MOEE and Environment Canada began to monitor ambient air concentrations of these chemicals in 1989. Figure 3.5 shows ambient air concentrations for benzene, methylene chloride and PCE at several locations in the province between 1989 and 1991 . Table 3.1 shows ambient concentrations of $\mathrm{B}(\mathrm{a}) \mathrm{P}$ and formaldehyde at selected locations for the same period. In both cases, these concentrations are median - or mid-range - values. These levels - like those of most other air pollutants can vary considerably over a short distance. While downtown Hamilton, for example, had the highest midrange value in the province for methylene chloride, another site in the city had no detectable level and a third recorded only a trace.

As yet, no provincial guidelines for benzene have been set, but mid-range values run from a low of 0.35 micrograms per cubic metre at Dorset to a high of 8.30 micrograms per cubic metre at a site in Hamilton exposed to emissions from major traffic routes and nearby steel mills. Readings at other sites have been closer to the lower end of this range.

\section{Wioxitus anc' Emrons}

There are more than 200 different varieties of polychlorinated dioxins and furans. These highly persistent compounds are commonly produced as byproducts of combustion or chemical processes involving chlorine. Prolonged exposure even to very low doses of some of these substances has produced cancer in laboratory animals.

Average concentrations of dioxins and furans in outdoor air have been measured at three sites in Ontario: Toronto, Windsor, and Dorset (Table 3.1). Surprisingly, levels at Toronto were very similar to those at Dorset. The similarity underscores the fact that dioxins and furans come from a wide variety of sources - mostly from industry and traffic in Toronto and wood burning in Dorset.

The highest levels were recorded at Windsor, where there is a large concentration of industrial soures. Although levels there were three to four times higher than in Toronto and Dorset, they were still well within the current provincial guidelines. Some industries in Sarnia and Hamilton, and pulp and paper factories that use chlorine in their processes are also sources of dioxins and furans.

Secting standards to prokect human heatt

Not enough is known yet about the effects of sustained exposure to very low levels of these pollutants over many years and decades. Most of what is known about their toxic effects is based on exposure to much larger doses in the workplace or on laboratory experiments on animals whose bodily processes may differ in important ways from those of humans. Where there is 


\section{ais continkled}

evidence of the long-term effects on humans, it is often complicated by other factors and therefore difficult to interpret.

Because of this lack of direct information, guideline levels for environmental exposure are set very cautiously. They are usually based on the dosage at which no adverse effects are observed in laboratory animals. A large safety factor is then added to produce the guideline value for humans.
However, the evidence on the effects of long-term exposure to low levels of these pollutants are monitored to determine that the safety factors are adequate in all cases. For this reason, MOEE will continue to review its guidelines and modify them as more information becomes available.

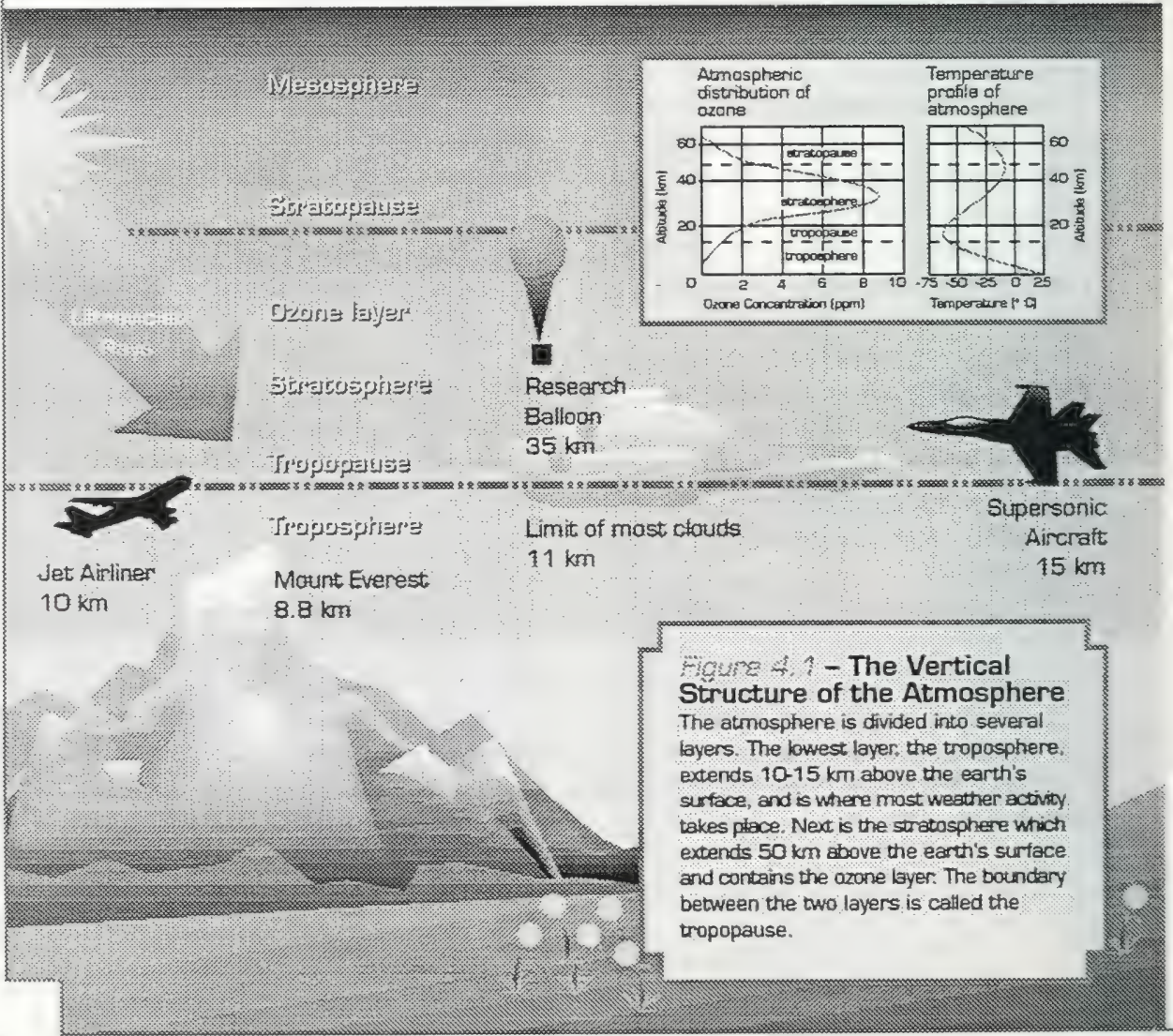




\section{CHAPTER 4: STATOSPHERIC OZONE}

The stratospheric ozone layer, located 25 to $35 \mathrm{~km}$ above the earth's surface, makes up no more than $5 / 10,000$ of one per cent of the atmosphere's total mass at a concentration of about 8 to 10 parts out of a million (Figure 4.1). Yet this thin, wispy veil of gas is a crucial component of the upper atmosphere.

The ozone layer acts as a protective shield for life below by absorbing the sun's harmful ultraviolet rays before they reach the earth's surface. As an absorber and emitter of warming infrared radiation, ozone also plays a critical role in shaping the structure of the atmosphere and determining the patterns of the world's climate.

Fears about the possibility of human damage to the ozone layer have been around since the 1960 s, but they were confirmed dramatically in 1985 with the discovery of the Antarctic ozone hole - a continent-sized area of severe but temporary ozone depletion that develops every September and October. In most of the rest of the world, ozone depletion has been much less severe but still noticeable. Over the middle latitudes of North America, it appears to have been occurring at the rate of four to five per cent per decade.

Research has shown a strong link between the destruction of stratospheric ozone and the chemical activity of several widely used chlorine and bromine compounds. The best known of these are the chlorofluorocarbons (CFCs), used as refrigerating and air conditioning fluids, solvents, and foaming agents (Figure 4.2). Others include halons (bromine compounds used in fire extinguishers), methyl chloroform (a metal-cleaning agent) and carbon tetrachloride (used mostly in the making of CFCs).
Figure 4. 2: CEC USE IN CANADA BI SECTORS, 1991

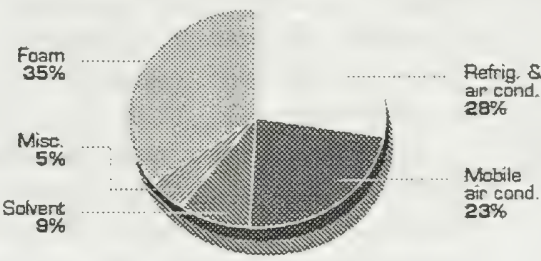

Total CFCs x 9000 metric tonnes

$\mathrm{CFCs}$ and halons are responsible for most ozone depletion. Environment Canada estimates that Canada accounts for 1.7 per cent of the world's supply of these chemicals, and Ontario is the biggest producer and user in the country.

One thing these chemicals have in common is a very long lifetime in the atmosphere, ranging from about six years for methyl chloroform to several hundred years for some of the CFCs. This is long enough to allow them to migrate into the stratosphere. Once there, they are broken down by intense ultraviolet radiation, releasing chlorine or bromine atoms. These react with

FIGURE 4 3. DESTRDCTION OF ORONB BX CHLORINE

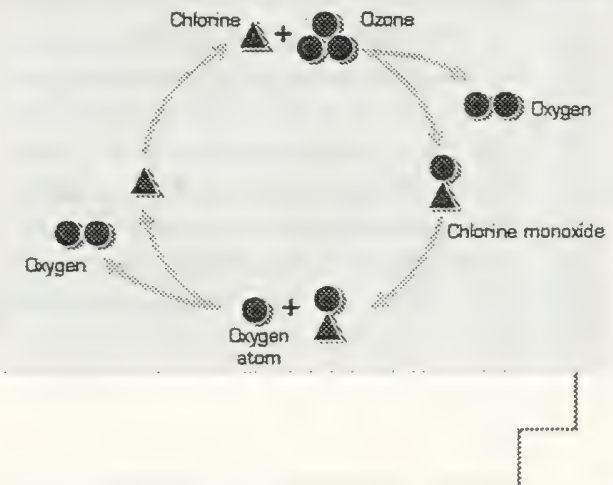




\section{air cortinued}

ozone, destroying it in the process and forming new, unstable chemicals that soon split apart, releasing the chlorine or bromine to begin the process again. In this way, each chlorine or bromine atom has the capacity to destroy one hundred thousand or more molecules of ozone (Figure 4.3)

As the amount of ozone in the stratosphere decreases, we can expect more ultraviolet radiation to reach the earth's surface. Some varieties of UV are more destructive than others. Fortunately, the most powerful, UV-C, is entirely screened out by the ozone layer. The least powerful, UV-A, is only partially absorbed, and most of it reaches the earth's surface. However, it is the middle variety, UV-B, that causes most concern, because it is still very potent and able to do a good deal of biological damage. Under normal conditions, some UV-B penetrates the ozone layer, but as ozone amounts decrease, a significantly greater amount can be expected to reach the earth's surface.

UV-B stimulates the formation of vitamin D in the body, but too much of it causes sunburn and speeds up the aging of the skin. Repeated overexposure can lead to skin cancer, as well as cataracts and other eye diseases, and may damage the immune system. Among lightskinned peoples, skin cancer rates tend to increase towards the equator, where the ozone layer is not as dense and UV-B intensity is greater. Changes in the normal in- tensity of UV-B could also damage some plants, including food crops and some plankton that are essential to ocean and lake food chains.

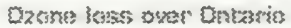

The amount of ozone in the stratosphere varies with the latitude and season. It also can vary considerably from day to day and year to year at any given location. This natural variability sometimes makes it difficult to analyze trends in ozone amounts. However, as Figure 4.4 shows, total ozone amounts began to show a noticeable decrease over Toronto in the late 1970 s and declined by about four per cent during the following decade. Data are not available for other locations in Ontario, but other sites in Canada show a similar pattern.

More recently, the rate of ozone decline has increased, at least in part because of the temporary effects of volcanic particles from the eruption of Mount Pinatubo in the summer of 1991. A study of ozone over Toronto between 1989 and 1993 showed that winter concentrations decreased by an average of 4.1 per cent a year. During the same period, average summer concentrations declined by 1.8 per cent a year. Over the four years of the study, the intensity of UV-B radiation at ground level in Toronto increased by an average of 35 per cent annually in winter and 6.7 per cent in summer. 
It should be noted, however, that these are relatively large percentage increases of small amounts, and that UV-B levels in southern Ontario are still low in comparison to those found farther south. As the effects of the Pinatubo eruption fade, it remains to be seen whether ozone and UV-B levels return to values closer to those of the late $1980 \mathrm{~s}$.

Nevertheless; as nature's first line of defence against ultraviolet radiation weakens, the sun's rays must be treated with more caution. To help Canadians avoid excessive ultraviolet exposure, Environment Canada issues a daily UV-B index with its weather forecasts. The index uses a scale of $0-10$ to indicate the relative amount of UV-B that can be expected, given the season, time of day and current weather. The higher the number is on the index, the greater the UV-B intensity and the faster your skin will burn when exposed. At a value of 10 - typical of a clear, summer day in the tropics - light, untanned skin will burn in less than 15 minutes.

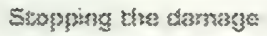

The international community has moved with unusual swiftness and unanimity to halt the destruction of the ozone layer. In 1987, 24 nations met in Montreal to formulate an action plan for controlling ozone-depleting substances. By September 1992, the Montreal Protocol, as the plan is known, had been signed by 86 countries responsible for considerably more than 90 per cent of the world's CFC and halon supply.

The protocol now requires all signatories to eliminate the consumption of halons by the end of 1993 and CFCs by the end of 1995. Carbon tetrachloride is to be completely phased out by the year 2000 and methyl chloroform by 2005. Hydrochlorofluorocarbons (HCFCs) have been authorized as a temporary substitute for CFCs. These are much less powerful ozone destroyers but still have some potential for damaging the ozone layer. They also contribute to global warming. Present agreements call for a phased reduction of HCFCs to begin in 2004 and to be completed by 2030 .

In response to the Montreal Protocol, Canada reduces its annual use of ozone depleting substances (ODS) from 20,000 tonnes in 1986 to 10,000 tonnes in 1991. Ontario accounts for approximately half of the total use of ODS's in Canada. This $50 \%$ cut in only 5 years is due to strong provincial regulatory controls and swift industrial innovation.

Even after production of these chemicals has ceased, thousands of tonnes of them - mostly CFCs in refrigerators and air conditioning systems - could still remain in use for several years. To reduce the risks from spillage or other accidental venting of these, Ontario recently introduced regulations banning the use of CFCs and HCFCs in new motor vehicle air conditioners, beginning with the 1996 model year. Pre-1996 models would still be allowed to use CFCs. The regulations would also prohibit the venting of CFCs, HCFCs, and hydrofluorocarbons to the atmosphere. In addition, anyone servicing refrigeration equipment containing tluorocarbons will have to complete a brief training course and be certified by the province.

How long will it take for the ozone layer to recover? The production of ozone-depleting substances is now declining sharply. But those released in the past continue to make their way into the stratosphere, and some of 


\section{air continesed}

those still in use will do so in the future. As a result, levels of these chemicals in the stratosphere are still increasing. Scientists estimate that the quantity of ozone-destroying chemicals in the stratosphere will peak around the turn of the century and decline thereafter. However, given the long lifetimes of these chemicals, it will be several decades yet before much of the current damage will be reversed and ozone levels in the stratosphere recover significantly.

\section{CHAPTER 5 \\ Global WARMing}

The atmosphere provides a blanket of insulating gases that keep the earth's surface from losing heat too rapidly, thus maintaining a favourable temperature to support life. The insulating action of these gases is commonly known as the greerhouse effect and the gases themselves are known as greenhouse gases. Without the greenhouse effect, the earth would lose the heat it absorbs from the sun much more rapidly, leaving it, on average, about $33^{\circ} \mathrm{C}$ cooler than it is now - too cold to support life as we know it

The most abundant greenhouse gases in the atmosphere are water vapour, carbon dioxide and methane. Others include ozone, CFCs and nitrous oxide. The most significant characteristic of all these gases is their ability to absorb and re-emit infrared radiation, which is given off by the earth as it cools. Surprisingly, these gases constitute only a very small part of the atmosphere. Water vapour, which represents up to four per cent of the atmosphere's mass, is by far the most common and the most variable from place to place. Carbon dioxide, how- ever, makes up only about 355 of every million parts of the atmosphere, while methane constitutes only about 17 parts out of every ten million.

All play a critical role in the earth's climate system. Studies of fossilized air in ancient ice from Greenland and Antarctica show a very close correspondence between the amount of greenhouse gases in the air and the earth's temperature. Greenhouse gas concentrations are lowest during ice ages and highest during warm periods.

Concentrations of greenhouse gases have been rising since the beginning of the industrial revolution more than 200 years ago. The most significant increase has been in the amount of carbon dioxide, which is now more than 20 per cent higher than at any time in the past 160,000 years and is increasing globally at a steady rate of about 0.5 per cent per year (Figure 5.1). Most of this increase has come from the burning of fossil fuels such as coal and oil. A smaller portion comes from the accelerated rate of clear cutting and burning the world's forests.

Methane levels are now more than twice what they were in pre-industrial times. Methane comes from many different sources, including natural wetlands, rice paddies, landfills, coal mines, the digestive systems of cattle and sheep, and gas and oil extraction and transmission. Levels of other greenhouse gases - ground-level ozone, nitrous oxide, and CFCs - are also increasing.

As greenhouse gas concentrations rise, the atmosphere is able to hold more heat. This should cause temperatures to increase significantly, but because the earth's climate system is so complex, how it will respond to these increases is not entirely clear. The climate system has several interacting parts, including not only the 
atmosphere but also the oceans, the continents, the polar ice masses, and all the earth's plants and animals. All these will respond in different ways to an increase in greenhouse gases and to any extra warming of the atmosphere. Some of these responses may moderate or offset any warming tendency. Others may intensify it. Other characteristics of the climate system - such as rainfall and snowfall, evaporation rates, or the movement of weather systems - may change as well.

Scientists have developed elaborate computer models to help them predict how the climate system will respond to increased levels of greenhouse gases. Their predictions suggest that with a doubling of $\mathrm{CO}_{2}$ emissions, the earth's average temperature will increase by anywhere from $1.5^{\circ} \mathrm{C}$ to $4.5^{\circ} \mathrm{C}$, with the amount of warming being least in the tropics and increasing towards the poles.

Since the difference in average global temperature between the last ice age and the present is only about 5 to $6^{\circ} \mathrm{C}$, even the lowest of these estimates could cause noticeable changes in Ontario's climate. Not only might it get warmer, but it might affect the amount and location of rainfall, or the frequency of droughts, the length of the growing season, or the water levels of the Great Lakes. These changes, in turn, could affect almost everything from the health of Ontario's forests to the kinds of crops we grow, to the efficiency of hydro dams.

These changes would require personal and economic adjustments that could be difficult and costly. That's why, from both a provincial and global perspective, global warming is a major concern.
FYGUTRE 5.1: ATNOSPHEREC CAREON DIOXJDE CONCENTRITIONS $1959-1992$

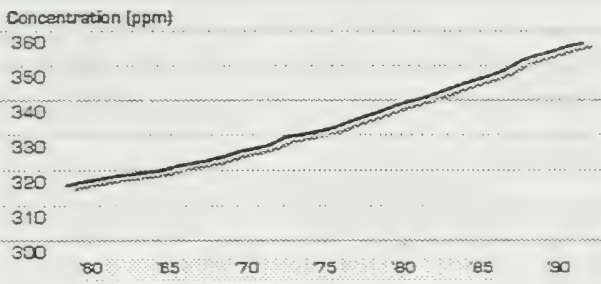

Source U.S. Nationat Doeanic and Amospheric Adrinistration, Envirament Canada

Emissions themselves are not an actual indicator of warming. There must be evidence of long-term changes in global and regional temperatures and changes in temperature-dependent natural processes, such as the advance or recession of glaciers and the freezing of lakes.

Greenhouse gases come from both natural sources and sources related to human activity. Globally, natural sources of some greenhouse gases, such as carbon dioxide and nitrous oxide, are much greater than the sources related to human activities. But in the relatively stable climate system that we have enjoyed since the end of the last ice age, nature has been able to remove greenhouse gases from the atmosphere at about the same rate as they were produced. The biological, chemical, and physical processes that remove these gases are known as sinks, and they have also been able to remove a portion but not all - of the greenhouse gases emitted by sources linked to human activities. It is this surplus of emissions from sources linked to human activities that is causing greenhouse gas concentrations to rise. 


\section{air continued}

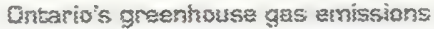

In 1990, an estimated 166 million tonnes of carbon dioxide were emitted by sources related to human activities in Ontario. By far the greatest part of these emissions, more than 90 per cent, came from the burning of fossil fuels for energy - for transportation, industrial energy, electric power generation and heating (Figure 5.2).

Methane is produced when organic matter decays in the absence of oxygen. In Ontario, about two thirds of the nearly 1.1 million tonnes emitted as a result of human activities in 1990 came from landfills and sewage treatment systems, while most of the remaining third came from cattle and sheep.

Nitrous oxide emissions from human activities in the province totalled nearly 31,000 tonnes in 1990. Nearly 55 per cent of this came from the production of adipic acid, which is used for making certain types of nylon. Close to 40 per cent came from the burning of fuels. CFC emissions were estimated at 6,577 tonnes. These came mostly from the leakage or discarding of refrigerator and air conditioning fluids and the use of CFCs as solvents.

Kilogram for kilogram, carbon dioxide is actually the least powerful of the major greenhouse gases, but because of the amount emitted it is the most important contributor to greenhouse warming. Per person, Canadians are among the top emitters in the world. In 1987, each Canadian produced an average of 18.4 tonnes of carbon dioxide from the burning of fossil fuels for energy. To some extent, this is the result of special circumstances - a widely dispersed population and great distances between major cities, a cold climate and resource-intensive industries. But it is also a product of heavy dependence on fossil fuels and an extensive use of energy resources.

Although Ontario is Canada's leading industrial producer, its carbon dioxide emissions, on a per capita basis, have been below the national average. In 1987, Ontario produced 16.6 tonnes of carbon dioxide per capita from energy-related emissions, ranking seventh among the provinces and 10 per cent below the national average. Globally, the comparison is less favourable. The world as a whole produces about 22 billion tonnes of carbon dioxide a year from energyrelated sources. Ontario's emissions amount to about 7 one-thousandths of that amount even though our population is less than 2 one-thousandths of the global total.

Between 1960 and 1979, Ontario's energy-related carbon dioxide emissions more than doubled, largely because of increases in population, industrial expansion and an improved standard of living that encouraged a greater use of cars and other energy-consuming devices. Since then, there has been a moderate decrease, with emissions for 1991 about 12 per cent lower than for 1979. 
To some extent, improvements in energy efficiency have put a brake on the growth of carbon dioxide emissions, but the most decisive influence on emissions has been economic conditions. Decreases in emissions have usually coincided with periods of economic recession, as in 1975, 1979-82 and 1990-91. The only exception is the 1984-86 emission decrease, which resulted from an expansion of nuclear generating capacity (Figure 5.3).

Still, efforts to improve energy efficiency have been significant. As Figure 5.4 shows, the amount of carbon dioxide emitted for every $\$ 1000$ of economic output has declined by an average of 2.5 per cent a year over the past two decades. Without these improvements in energy efficiency, Ontario's carbon dioxide emissions would now be much higher.

\section{3.}

Scientists estimate that the buildup of greenhouse gases during the past couple of centuries should already have caused the earth's average temperature to rise anywhere from $0.4^{\circ} \mathrm{C}$ to $1.3^{\circ} \mathrm{C}$ during the past 100 years. Analyses of global temperatures, in fact, show an increase of about $0.5^{\circ} \mathrm{C}$ since 1861 . The 1980 s were the warmest decade on record and 1990 and 1991 were the warmest years.

As Figure 5.5 shows, the warming has not occurred evenly, but has proceeded by steps. Temperatures began to rise in the 1890 s, levelled off in the 1940s, and then began to rise again in the late 1970s. Nor has warming occurred equally in all parts of the world or even in all parts of Canada. In northem Ontario, the temperature increase since 1890 has been the same as the global average, $0.5^{\circ} \mathrm{C}$. But in southern Ontario, it has been slightly

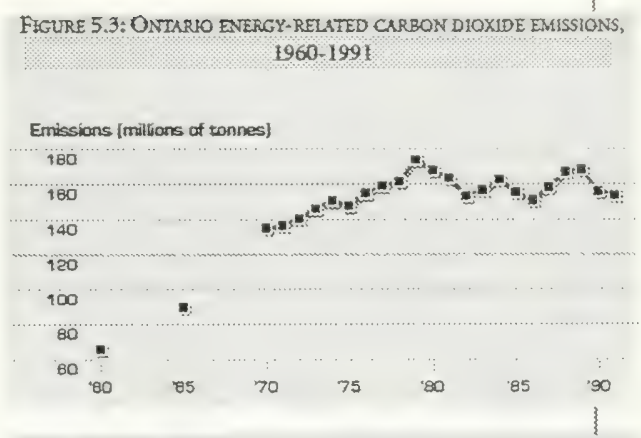

FIGURE 5.4: ONTARIO ENERGY RELATED CARBON DIOXIOE EMISSLNS PER UNIT ECONOMIC OUTPUT

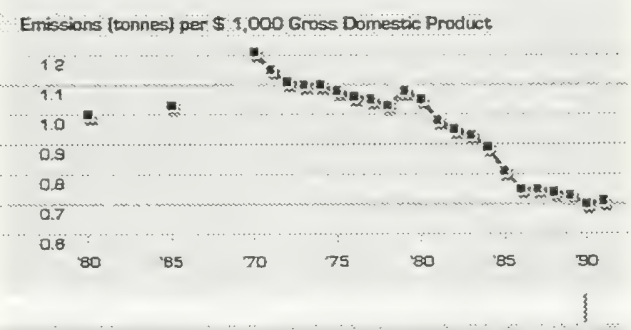

FIGURE 5.5: GLOBAL SURFACE TEMPERATURE TREND, 1861-1992

\section{Temperature charge $[\mathrm{C}]$}

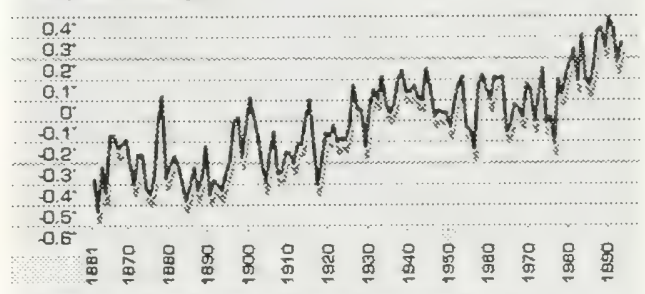

Note: graph shows variations of annual tomperature using a 30 yoer $(1950-79$ ) average temperature as a referenca point [represented by the $O^{\circ} C \mathrm{Cline}$ ]

Source: Dok Pidge National Laborabory 


\section{FIGSTRE 5.6A: TEMARRATURE TREND IN NORTHERN ONEARSO} $1895-1992$

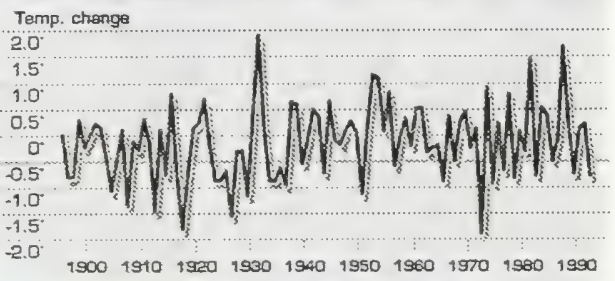

Note: graph shows vanatons of anwual temperatures using a 30-year $11950-79]$ everage comperadure as a reference pout frepresented by the O'C bne)

Source: Environment Cansda

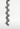

FIGURE 5.6B:TEAPERATTRE TREND NN THE GREAT LAKES ST. LAWRENCE LOWLANDS REGION, 1895-1992

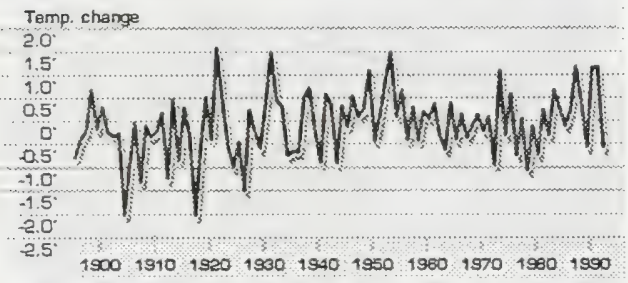

Note; graph shows variations of annul temperabures using a 30 -year $[1950-79]$ average temperatire as a reference point (represented by the $\mathrm{O}^{\prime} \mathrm{C}$ (ine)

Source: Envirosment Canada

more, $0.6^{\circ} \mathrm{C}$ (Figure 5.6a\&b). As a whole, Canada has warmed by $1.0^{\circ} \mathrm{C}$ in the past century. The greatest warming has been on the Prairies and in the central sub-Arctic. Parts of the eastern Arctic, however, have actually become slightly cooler.

Further evidence of warming comes from studies of lake ice that Environment Canada has carried out at eight Ontario sites over the past two to four decades. The studies have noted a weak trend towards earlier freeze-up dates and a much stronger trend towards earlier break-up dates, resulting in a general shortening of the ice seasons at these lakes. Although this evidence suggests a slight cooling of temperatures in the late fall, it is offset by a more substantial warming in the spring. These trends may indicate changes in precipitation and other climatic elements as well.

Clearly, some warming has occurred. But can this be attributed to a human-induced buildup of the greenhouse effect? So far, it cannot be so attributed with complete certainty. Climate is naturally variable, and there have been periods within the past 10,000 years when temperatures have been as warm as they are now or even slightly warmer. However, there is a reasonable probability that increasing levels of greenhouse gases are the cause. If this is so, then global temperatures within the next century can be expected to rise to higher levels than at any time in the history of human civilization.

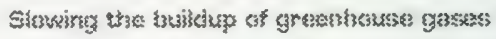

It will take at least another decade, if not longer, for scientists to establish a conclusive link between a greater greenhouse effect and global warming. In the meantime, the buildup of greenhouse gases can be slowed through measures such as reforestation, energy conservation, the use of less polluting fuels like natural gas and the development of alternative energy sources. These will not only improve the chances of dealing with the risk of global warming but will also pay dividends in many other ways - providing cleaner air and water, reducing acid rain, conserving resources, preserving the ozone layer and making ecosystems healthier. 


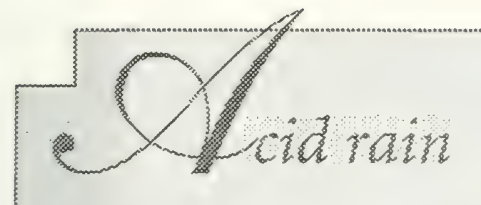

A study of the effects of acid rain offers many examples of the complex linkages among different parts of the enFironment. It also shows how humar activities in one place can have consequences in another, perhaps hundreds or thousands of kilometres away. In the case of acid rain, the chain of events begins with the release of acid gases from thermal power stations, smelters and cars and ends with the destruction of fish and other forms of lake life, often in environments far from obvious centres of pollution.

Acid rain was first described in the 1850 s by a Brittsh scientist in England's industrial Midlands, but it was not considered a serious problem until a century later when fish populations began to decline in lakes in Europe and eastern North America. In Ontario, lake acidification was first reported in the early 1960s, in the Sudbury area. A few years later, researchers from the University of Toronto noticed that lake water had acidified and fish populations had dectined in Killarney Park on the northeast corner of Georgian Bay. During the 1920 s, Lake acidification was reported in other parts of central and northern Ontario, notably in the MuskokaHaltburton cottage country. Subsequent research demonstrated that there were links between emissions of acid gases, rainwater chemistry, lake acidification and effects on lake life.

It was not until the mid-1980s, however, that Canadian Ontario and U.S. governments began to develop co-ordinated policies for controlling acid rain. The problem has been complicated by the fact that these gases can travel long distances, crossing provincial and international borders as they are carried along by atmospheric currents. Much of the acid rain affecting southern Ontario comes from the United States. Similarly, much of the acid rain affecting the eastern states and provinces originates in Ontario. Solving the problem has therefore required close co-operation between governments. In spite of these difficulties, however, important progress has been made.

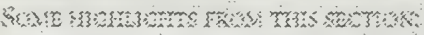

A. An estimated 19,000 of the total 250,000 lakes in Ontario are acidic enough to cause damage to species living in them.

- In Ontario, emissions of sulphur dioxide (the major cause of acid rain) have declined by more than 70 per cent since 1970. Areas of high sulphate deposition (mote than $20 \mathrm{~kg}$ per hectare a year) have also dectined.

- Some lakes are recorering from acidification. One study of 38 Sudbury-area lakes reported a substantial dectine in acifity in the 1980 s. Decreasing acidity and the recorery of fish populations have been reported in some other lakes. There is, as yet, there is no evidence of recovery for lakes in central Oratario. 


\section{acid pain contrimed}

FICURE 6. 1: CAPACTTY TO NEIJRRUIZE ACID DEPOSTHON

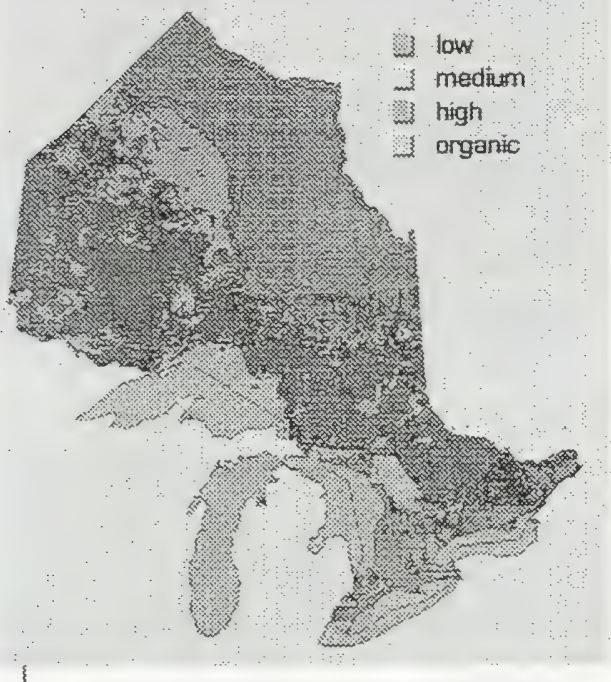

CHAPTER 6 HOW ACID RAIN AFFECTS THE ENVIRONMENT

\section{What ac aco rain?}

Pure rainwater, even in unpolluted areas of the world, is usually slightly acidic. Acid rain, formed from acidifying pollutants in the air, is substantially more so.

Acidity is measured on the $\mathrm{pH}$ scale. $\mathrm{A} \mathrm{pH}$ of $0 \mathrm{in}$ dicates maximum acidity, 14 represents maximum alkalinity, and 7 is neutral. Each full point on the scale represents a tenfold change in acidity. Normal, slightly acidic rainwater has a pH somewhere between 5.0 and 5.6. But during the $1980 \mathrm{~s}$, the average $\mathrm{pH}$ of rainfall over central Ontario was 4.2 , or about ten times more acidic than normal rainwater.
Acid rain gets its acidity from two air pollutants, sulphur dioxide $\left(\mathrm{SO}_{2}\right)$ and nitrogen oxides $\left(\mathrm{NO}_{x}\right)$, which react with water in the air to produce sulphuric and nitric acids. In Ontario, sulphur dioxide comes mainly from the burning of sulphur-containing coal to produce electricity and from the smelting of sulphurcontaining ores. Nitrogen oxides are produced during combustion. Various means of transportation, taken together, add up to the largest source of nitrogen oxides in the province, accounting for about 60 per cent of emissions. Motor vehicles produce more than two thirds of those emissions.

The acids reach the earth's surface in two ways. One is through wet deposition, in which the pollutants are washed out of the air by precipitation - not only the familiar acid rain but acid snow, fog, and hail as well. The other is dry deposition, in which acid gases or particles in the air reach the earth directly. Acid deposition, the preferred scientific term for acid rain, encompasses both of these possibilities.

Because acid pollutants can travel hundreds of kilometres before being deposited, Ontario is exposed not only to its own acid emissions but also to those from adjacent industrial areas of the United States. These U.S. emissions are carried by weather systems moving in a northeasterly direction and account for about 50 per cent of the sulphuric acid deposited in the province.

In Ontario, acid deposits formed from sulphur dioxide have had a much greater impact on the environment so far than those formed from nitrogen oxides. One reason is that there are far more sulphur dioxide emissions - nearly 1,000,000 tonnes per year as compared to less than 500,000 tonnes a year for nitrogen oxides. Another is that the nitrate from nitric acid is used rapidly as a nutrient by plants during the growing sea- 


\section{acid rain continued}

son. It is usually only in the spring, after the ground has been frozen and plants have been dormant for several months, that nitrate shows up to any significant extent in surface runoff. Consequently, the battle against acid rain has been fought largely on the sulphur dioxide front.

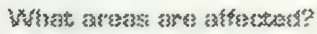

Some parts of Ontario receive more acid rain than others, but some areas also have natural characteristics that help to protect them against acidification. The greatest amount of acid rain in the province, for example, falls in the southwest, yet the area has no acidic lakes or rivers. The reason lies in geology.

Most of southem Ontario has limestone bedrock underlying it. In these limestone regions, soils and water have a strong capacity to neutralize the acid deposition falling on them - much like antacids that neutralize stomach acidity. These are the areas of high neutralizing capacity shown in Figure 6.1.

Soils and water in areas of underlying granite bedrock, however, have very little neutralizing capacity. These are the areas shown as low in Figure 6.1., and they include the Canadian Shield as well as the Muskoka, Haliburton, Parry Sound, and Nipissing cottage country of south-central Ontario. Under unpolluted conditions, the $\mathrm{pH}$ levels of lakes in these areas would lie somewhere between 6 and a little more than 7; however, today many are between 5 and 6 . Smaller lakes have been found to be particularly susceptible to acidification.

Some of these sensitive areas, such as the cottage country of south-central Ontario, are exposed primarily to acid pollutants originating in the United States. Others, such as the Sudbury area, receive most of their acid pollutants from local sources.

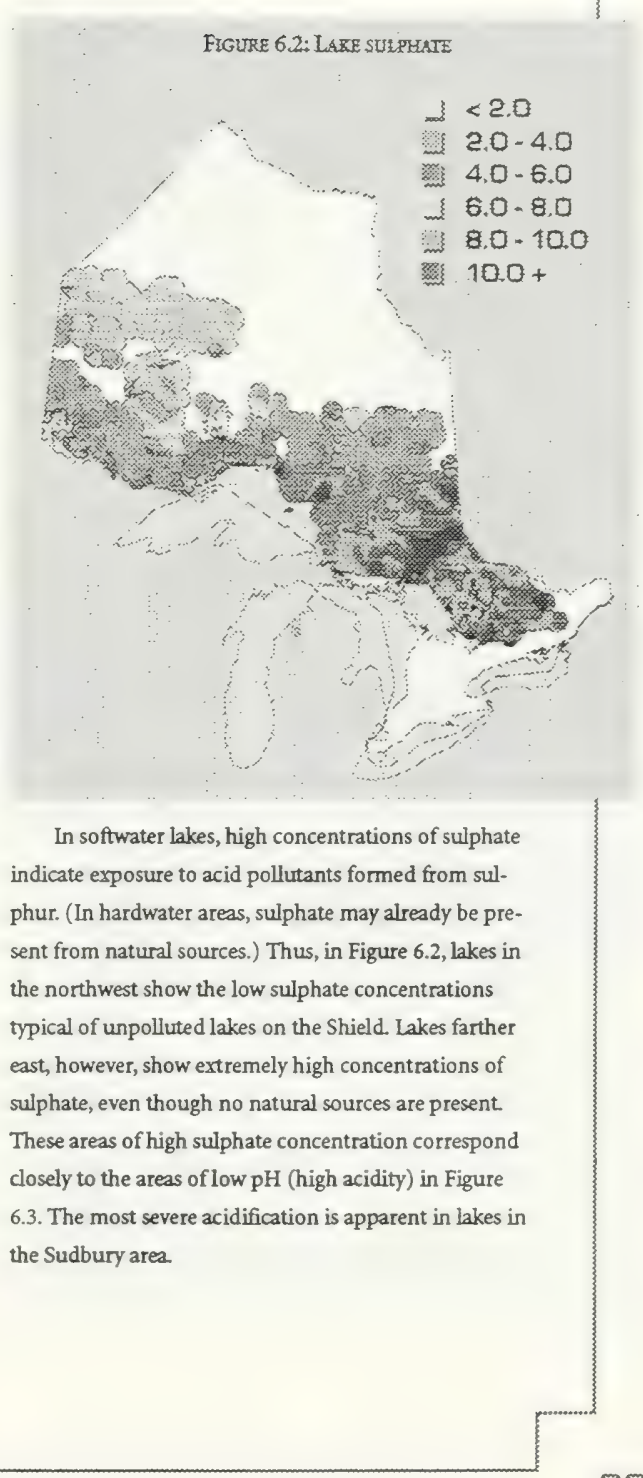




\section{acid rain corbinued}

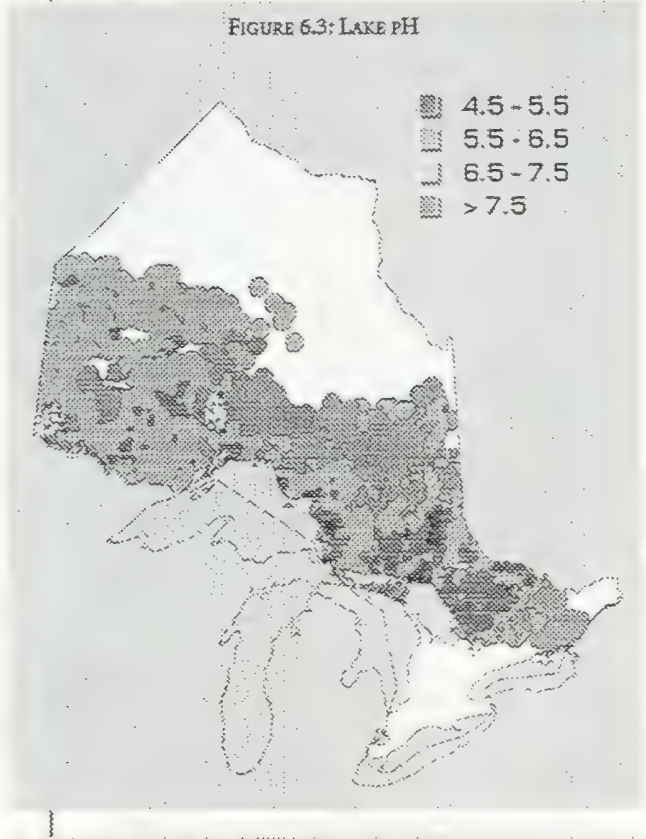

FIGIRE 6.4: P ZANTSTON DUERSITY AND LAXE ACIDITY fnumber of phytoplankton genera and zooplankton species in lakes with pol less thin 6.5)

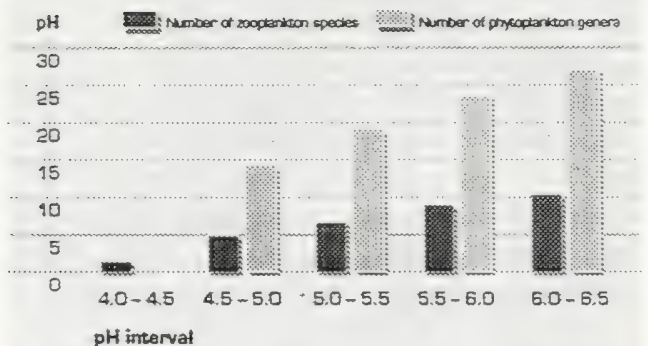

pH interval

\section{Efiects of acid deposition}

\section{LAKES}

Unpolluted Ontario lakes support a wide variety of life which depends on microscopic plankton for food. Plankton can be broadly divided into phytoplankton (microscopic plants) and zooplankton (microscopic animals).

As the $\mathrm{pH}$ of a lake decreases, indicating a rise in acidity, the number of different kinds of plankton drops dramatically (Figure 6.4). This result is not unexpected, as they developed in systems with near-neutral acidity and some of them may lack the means to adapt to an acidified environment. The total quantity of plankton in the lake may remain the same, however, as populations of the surviving types expand to fill the gap left by those that have died out.

The effect on fish is much the same. As lakes acidify, fewer and fewer species can tolerate the conditions (Figure 6.5) and populations of sensitive species begin to dwindle. Lake trout are among the first to be affected. Yellow perch, on the other hand, have a much greater tolerance for acidity. Exactly how the fish are affected is unclear, but it is believed that the acidity may interfere with reproduction.

If conditions become severe enough, lakes become much more limited in their ability to support life, and are commonly described as 'dead'. The fish populations disappear completely, and only microscopic life and vegetation survive. 
Figure 6.6 shows where many of the known extinctions of lake trout populations have occurred. Extinctions can be caused by overfishing, various forms of pollution and other factors besides acid rain. But there is clearly a close association between the extinctions shown in Figure 6.6 and high levels of lake acidity in the Sudbury area.

Biological damage to a lake appears to occur at $\mathrm{pH}$ levels below six. On the basis of data collected in the 1980s, it has been estimated that 19,000 of Ontario's 250,000 lakes have $\mathrm{pH}$ levels less than six because of acid deposition. The majority of the affected lakes are fairly small, but some larger lakes have been affected as well, particularly in the Sudbury area.

\section{FORESTS}

During the last 25 years, forests in Europe and North America have shown signs of environmental stress, such as yellowing and gradual loss of leaves, loss of twigs, and even death of the trees themselves. Ontario forests have shown these symptoms in birch, ash, oak and maple trees. Air pollution is a major stress to the forest ecosystem and it is suspected of contributing to these effects.

It is known that acidic deposition can have a major effect on forests. Given the number of possible causes, it is difficult to make a direct link between the environmental stress observed in Ontario's forests described above and acidic deposition. However, these effects are most obvious in central Ontario where acid deposition is higher and where the soils of the Canadian Shield are relatively more acid-sensitive than elsewhere in the province.

\section{FIGURE 6.5:}

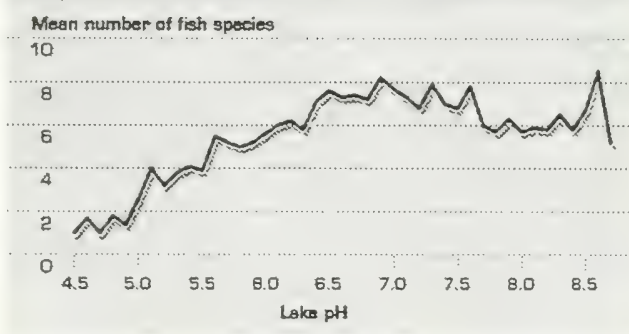

FIGURE 6.6: EXTIACT AND LOST LAKE TROUT POPULATIONS

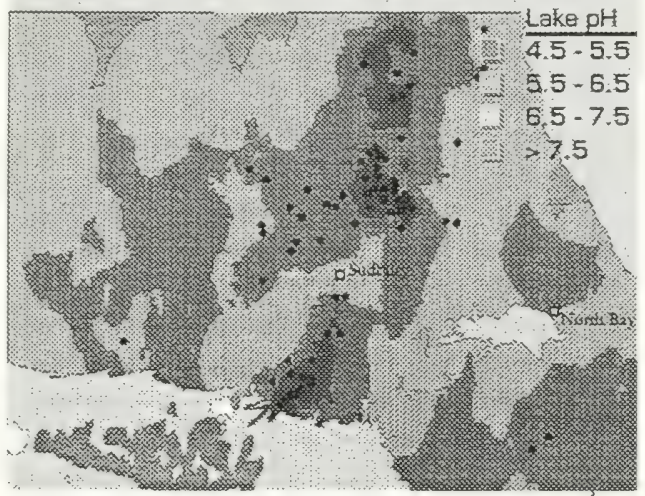




\section{3eid rain continued}

FGGURE $6.7 \%$

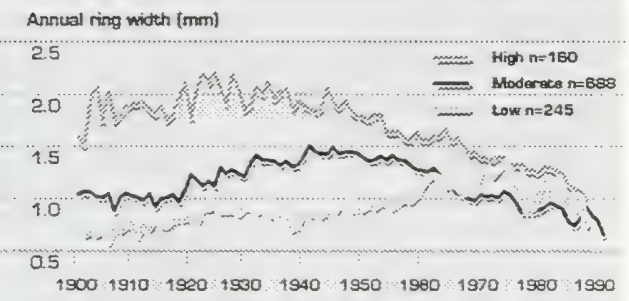

High $=>35 \mathrm{~kg} / \mathrm{ho} / \mathrm{m}$ met SO4 $4>50 \mathrm{ppb}$ deyfiglt GS DS

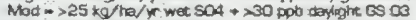

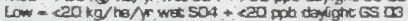

Mean of at urees > 1 com ob

Studies in Ontario forests showing signs of environmental stress revealed that extreme climate stress, defoliation by tent caterpillar, and infection by root diseases were the main causes of the decline. At some of these sites, where the soil was very acid-sensitive, high aluminum concentrations were detected in the soil and roots of affected trees. Studies show that aluminum might block the plants' intake of nutrients.

This is consistent with what we know about the effects of acid rain on forests. The impact of acid rain is not always obvious, as the trees appear to die of natural causes. But, acid deposition might affect a plant's ability to absorb nutrients. As the soil acidifies, natural decomposition slows down, reducing nutrient recycling. Potentially toxic metals such as aluminum may change form, inhibiting root growth and interfering with a plant's absorption of nutrients. The trees become weaker and subsequently more susceptible to environmental stress and insects and diseases.
Although the effects on forests in those acid-sensitive areas was mainly due to natural causes, the evidence suggested that acidic deposition, contributed to the decline.

Figure 6.7 illustrates the trend in sugar maple growth rates across the province. In areas where acid deposition is greatest, the growth rate has declined about 27 per cent relative to the rate of tree growth in the early part of the century. Although it cannot be concluded with certainty that this growth reduction is caused by acidic deposition, research has shown that air pollution is a stress on the forest ecosystem.

In 1986, Ontario began a seven-year survey of the health of hardwood forests, tracking tree decline across the province. Overall, tree condition was considered to be good to very good, although significant decline was observed in the Espanola, Parry Sound, and Minden areas. Tree decline has persisted in these same three areas. Based on results from this province-wide survey, tree decline in the hardwood forest ecosystem of Ontario is not considered a significant problem, although isolated, persistent, pockets of decline exist.

\section{HUMAN AND ANIMAL HEALTH}

The direct effects on human health of sulphur dioxide and nitrogen oxides in the air were noted in chapter 2 , but the effects of acidified lakes and soils on human and animal health are less clear. One possibility is that birds and animals that feed on fish, crustaceans and other endangered forms of aquatic life will find it more difficult to survive because their food supply has decreased. 


\section{and rain conthued}

Another is that some birds and animals, as well as humans, will be exposed to higher levels of toxic metal. lic compounds that may cause cancers, mutations, or reproductive failure. High acidity increases the rate at which toxic metals are leached from soils and rocks into the water and also encourages the formation of toxic compounds of these metals. These substances may then accumulate in the food chain, where they would be particularly harmful to fish-eating predators, including humans.

Studies at a number of acid lakes in the province have shown that fish-eating waterfowl, such as the Common Loon, produce fewer young as the supply of fish decreases. On the other hand, some insect-eating waterfowl, like Common Goldeneyes, which compete for the same food supply, actually prefer fishless lakes.

\section{EROSION OF BUTLDINGS}

Acidic air pollution eats away at many kinds of building materials. Limestone and marble are particularly vulnerable to damage by sulphur dioxide and sulphuric acid because of chemical reactions that cause these materials to expand and crack. Acid pollutants are at least partially responsible for an increase in the decay of historic buildings in Ontario.
CHAPTER 7

\section{ACID RAIN: ARE WE MAKING PROGRESS?}

\section{Cantrobung acid rain}

Efforts have been under way since 1970 to control emissions of acid gases, both to reduce local pollution from sulphur dioxide and nitrogen oxides and to minimize acid deposition.

During the mid-1980s, Ontario set two important control targets. One was to reduce the rate of sulphate deposition in sensitive areas to less than $20 \mathrm{~kg}$ per hectare a year. The other - needed to achieve the first was to cut sulphur dioxide emissions to one half of the 1980 level, by the end of 1994 ( 885,000 tonnes of sulphur dioxide a year). Targets were set for Ontario's largest emitters: Ontario Hydro's thermoelectric power plants, the large smelters belonging to Inco and Falconbridge in the Sudbury area, and Algoma Steel's sintering plant in Wawa. Inco expects to reduce its sulphur dioxide emissions to 265,000 tonnes annually by 1994 . In the late 1960 s, before controls were implemented, Inco emitted nearly $2,000,000$ tonnes of sulphur dioxide a year.

Because acidic air pollutants are transported into Canada from the United States, American control measures are also critical to our success in reducing acid deposition. Amendments to the U.S. Clean Air Act, adopted in 1990, have set sulphur dioxide emission limits for 


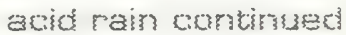

\section{FIGURE 7.1: WET SULPEATE DEPOSTION 1981-83}

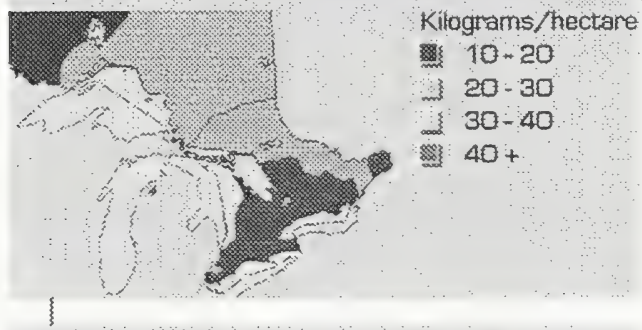

FHGURE 7. E: WET SUIPHATE DEPOSTTON 1984-86

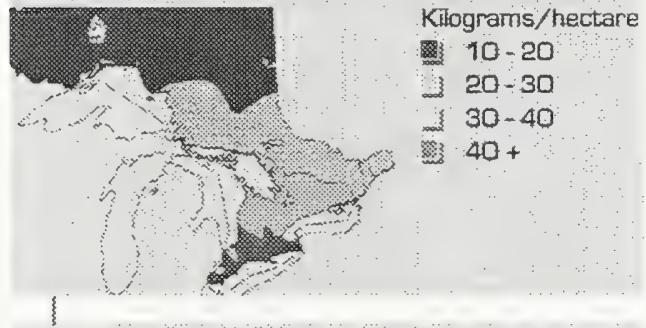

FICURE 7.1. WET STIPHANE DEPOSTION 1987-89

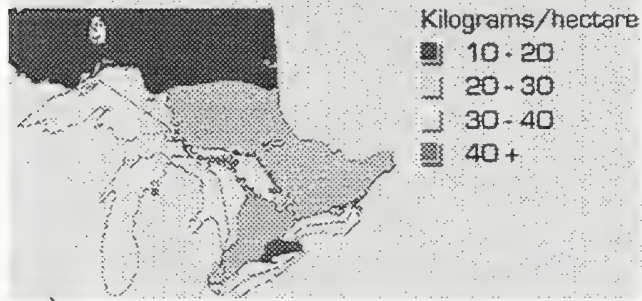

specific electric power generating stations. These limits should reduce annual emissions in the United States by 4.5 million tonnes by 1995 and by an additional 4.5 million tonnes by the year 2000 .

Because nitrogen oxides have been the lesser contributor to acid deposition, efforts to control them have not been as vigorous. Over the past two decades the most important NOx controls have been the use of catalytic converters in motor vehicle exhaust systems and the trend towards more fuel-efficient cars. Ontario's current position is that emissions of nitrogen oxides should be held to 1987 levels, al though that target could change as more scientific information on the effects of nitrogen oxides becomes available.

\section{3)}

As shown previously in chapter 2 (figure 2.1), annual emissions of sulphur dioxide in Ontario have fallen by more than 70 per cent since 1970. In 1992, they totalled about 900,000 tonnes. The province is therefore well on track towards meeting its emission target for 1994. Tighter emission controls and improved production technology in metal smelters account for the major portion of these reductions. Conversion to low-sulphur fuels has also brought about large reductions in emissions from thermal power generating stations.

Emissions of nitrogen oxides have also decreased, though less dramatically. As shown in chapter 2 (figure 2.4), emissions remained fairly constant between 1983 


\section{acid rain sartinused}

and 1989, then declined by more than 10 per cent between 1989 and 1991. These reductions were primarily the result of lower emissions from vehicle exhaust and electricity production. As the number of motor vehicles on the road continues to rise, the level of nitrogen oxide emissions may change.

The decline in emissions of sulphur dioxide has been accompanied by a definite improvement in the amount of acidic material deposited. This can be seen in Figure 7.1, which summarizes data from a network of monitoring stations that has been tracking acid deposition since 1979. Very high levels of sulphate deposition are evident in the early 1980 s, especially in southern and southwestem Ontario. By the late 1980s, the very high deposition areas had virtually disappeared and the areas of lower deposition had increased markedly. It remains to be seen, however, if affected systems will recover when the rate of sulphate deposition is within the control target of $20 \mathrm{~kg}$ per hectare a year or if lower levels of sulphate deposition are required to protect sensitive lakes. Ultimately, the response of the environment will tell.

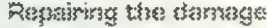

Can acidified lakes and their biological communities be returned to their normal, healthy state? There is good evidence that they can. Figure 7.2 shows trends in $\mathrm{pH}$ and acid-neutralizing capacity for a set of 38 lakes in the Sudbury area Acid-neutralizing capacity is a measure of the amount of acid a lake can still neutralize. If a lake can no longer neutralize acid, its neutralizing capacity is negative and it is an acid lake. As the graph shows, both the $\mathrm{pH}$ and the neutralizing capacity of these lakes have increased. Clearly, lakes in the Sudbury area are recovering from their severe acidification.
FIGURE 7.2: $P$ H AND ACID-NEUTRALZZING CAPACTTY OF 38 LAKES IN THE SUDBURY AREA

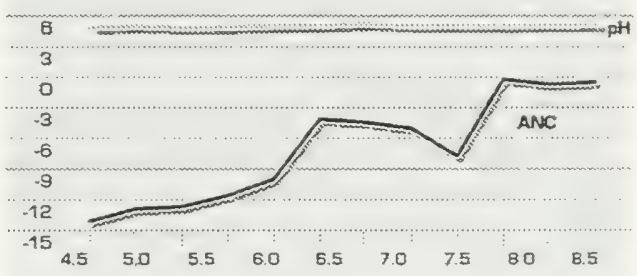

FEGURE 7.3: PH AND ACID-NEUTRAJJZING CAPACTYY OF TWO LAKES IN THE MUSKOKA-HLLIBIRTON AREA

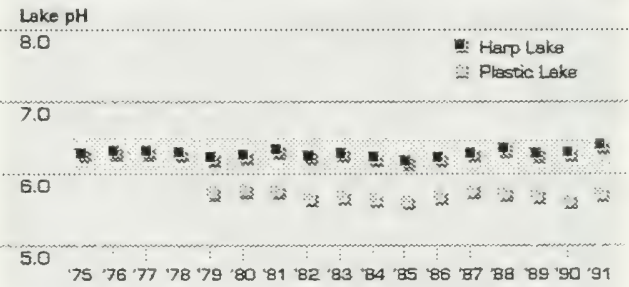




\section{acid rain cormbimues}

A survey of 54 lakes in the Algoma region has also reported some rapid recoveries. Two lakes that had $\mathrm{pH}$ levels below 5.5 and were fishless in 1979 have recovered to the point where it has been possible to re-establish their fish populations.

Farther south, in the Muskoka-Haliburton area, the trends are more ambiguous. Figure 7.3 shows data from two intensively studied lakes in that area. While it seems safe to say that the lakes are not getting worse, it is not clear that they are recovering significantly from their acidification. However, most of the acid deposition in this area originates in the United States and the full impact of American reductions in sulphur dioxide emissions has yet to be felt.
Overall, the prospects for controlling acid emissions and recovering from their effects are very good. But this does not mean that the book on acid rain can now be closed. It still remains to be seen if most of the affected lakes and their ecosystems return to normal or whether further controls are required. Still, evidence suggests that a potentially large ecological disaster has been arrested. 


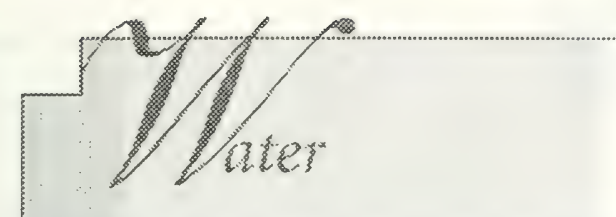

Ontario has a generous share of the world's water resources. It has more than 250,000 freshwater lakes, uncourted rivers and streams and a $5,300-\mathrm{km}$ shoreline on four of the five Great Lakes. The Great Lakes alone, counting both the Canadian and American portions contain 20 per cent of the world's surface freshwater supply.

Water is also extremely usefud as a means of transportation, an industrial raw material, a source of energy, a sewage disposal system and a medium of recreation. Unfortunately these uses often diminish its capacity to support life and, in some cases, may even make it dangerous to the life forms that depend on it.

Water quality varies from place to place and to same extent depends on local geological conditions. But as a result of human activities, water is exposed to pollutants that can harm aquatic plants and animals and make it unfit for recreation, drinking, irrigation, or other ases. Surface waters are exposed to pollution from point sources such as municipal and industral waste discharges, from non-point sources such as urban and agricultural land use, and from airborne pollutants that may have originated several hundreds or thousands of kilometres away. Groundwater, though less susceptible to contamination, may also pick up contaminants from. landfills, storage tanks, farm fields and other surface sources. These pollutants may stwl be carried by the groundwater when it eventually retums to the surface to replenish rivers and streams.

Pollutants, however, are not the only problem. Waterways may also be modified physically through the building of dams and artificial ponds, dredging, modification of channels and stream diversions. All these activities can have a impact on habitat and water quality and can disrupt an aquatic ecosystems.
This section looks at the issues affecting the main water groupings in Ontario - inland waters, the Great Lakes and groundwater - and concludes with an assessment of water quality as it affects human health.

\section{CHAPTER 8 INLAND SURFACE WATERS}

Ontario's inland waters flow through some of the world's most pristine wilderness and some of its most intensively industrialized urban areas. The quality of these waters varies enormously from one part of the province to another.

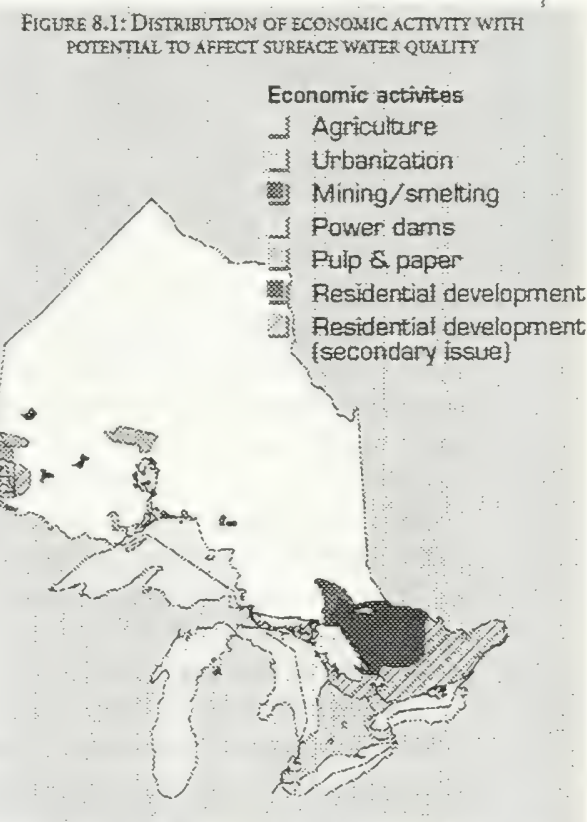

Arote: map based on data collected as part of Proprincial Water Quality Monitoring Network $\{1990-93$ ) and Inland Lakes (1986-90): 


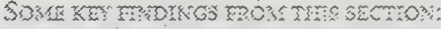

- Water quality in inland waters across the north is generally good except for sensitive areas exposed to acid tain and the focal effects of pulp and paper milts, mining, and fotestry. However, problems of nutrient enrichment, turbicitty and. bacterial contamination are widespread in inland rivers and takes across southern Ontario, fargely as a result of urtain and agricultural land use.

- Consumption restriotions for farger sizes of some sport fish ate fairly common across central and northetn Ontarto. - Alost of these are partiat rather than total restrictions, although women of ehild bearing age and chlidren under 15 should not eat fish in any of the restricted categories. Mercury contamination, from both natural and human saurces, is the mast common reason for consumption advisoties.

- Problems of algae growth in Lakes Erie and Ontario have diminished considerably duting the past two decades but have not been eliminated. In the western basin of Lake Erie, ladings of phaspharas the nutrient largely responsible for the problem) have fallen from about 20,000 tonnes per year in the 1960 s to between 5,000 and 6,000 tonnes per year in the late 1980 s:
- Water quality is generally good in the open waters of the Great lakes, bat locafized problems exist throughout the basin.

- Concentrations of PCBs and other toxic substances in the Great lakes, as measured in the tisstes of fish, have dropped substantially since 1975 , although the rate of decrease has tevelled off in recent years. Excessive concentrations are still meastured in some locafíties.

* It is estimated that there are mote than 500,000 water wells in Ontario. On average, the ministry receives about one complaint about ground water quality or quantity per year for every 250 wells.

- A surwey of well water from 1300 ontario farms showed that 37 per cent contained cancentrations of contaminants in excess of the provincial drinking wafer objectîtes.

- Drrnking water from muricipal water supplies is very safe. Between 1985 and 1992 , mote than 165,000 aralyses were carried out on drinking water samples from more than 100 Imunicipalities. Only 66 instances of exceeding the drinking water objectives were reported.
The human impact on surface waters comes from a number of sources, including urbanization and residential development, farming, recreational activities, dams, mining and smelting, pulp and paper operations and forestry. Figure 8.1 shows how these are distributed across the province.

In southem Ontario, agriculture is a key cause of poor water quality in the area's rivers and lakes. Valuable wild dife habitat can be destroyed through drainage of wetlands, the straightening or destruction of river banks and streamflow alterations. The use of tile drainage in fields lowers the water table, whlle the clearing of forest cover from stream and river banks increases exposure to sunlight and raises water temperatures. In addition, streams flowing through intensively farmed areas often pick up large quantities of soil particles, fertilizers, pesticides, cattle manure and other wastes, leading to problems of turbidity, nutrient enrichment, toxic and bacterial contamination and oxygen depletion.

Urbanization, is another significant cause of poor water quality in the heavily populated areas of the south. Cities and towns produce enormous quantities of industrial wastes and municipal sewage that are often high in nutrients, oxygen-depleting material, solids and bacteria. The paved streets and compact soils of urban areas also decrease the absorption of stormwater, lowering the water table and increasing surface runoff. As well as altering levels and flow rate of rivers and streams, runoff 
washes substantial quantities of dirt, oil, garbage, road salts and other urban debris into adjacent water bodies. In addition, wetland drainage and the straightening or destruction of river banks destroy important aquatic habitats.

Because farms and cities are spread throughout most of southern Ontario, water quality problems from agriculture and urbanization are widespread. In the north, on the other hand, problems tend to be more localized and connected with point sources of pollution such as mines, smelters, and pulp and paper mills, although the effects of recreational activities and airborne pollutants such as mercury and acid gases are spread over a wider area. Hydro dams also may have local impacts on some northern rivers, causing fluctuations in water levels that can destroy habitat for fish and other aquatic life. In addition, urban centres in the north, especially the larger ones such as Sudbury, Thunder Bay and Sault Ste. Marie, can have much the same kind of impact on local watersheds as their counterparts in the south.

The quality of Ontario's inland waters is monitored at some 700 sampling stations. Samples collected at these sites are a useful source of information about many aspects of water quality and the stresses affecting it, particularly in southern Ontario.

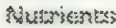

Phosphorus and nitrogen are important nutrients. Too rich a supply of these substances, though, can overstimulate the growth of phytoplankton (algae) and other aquatic plants, to the detriment of fish and other water life. Large blooms of algae are the most visible evidence that rivers and lakes are receiving an overabundance of nutrients. From a human point of view, algal blooms are

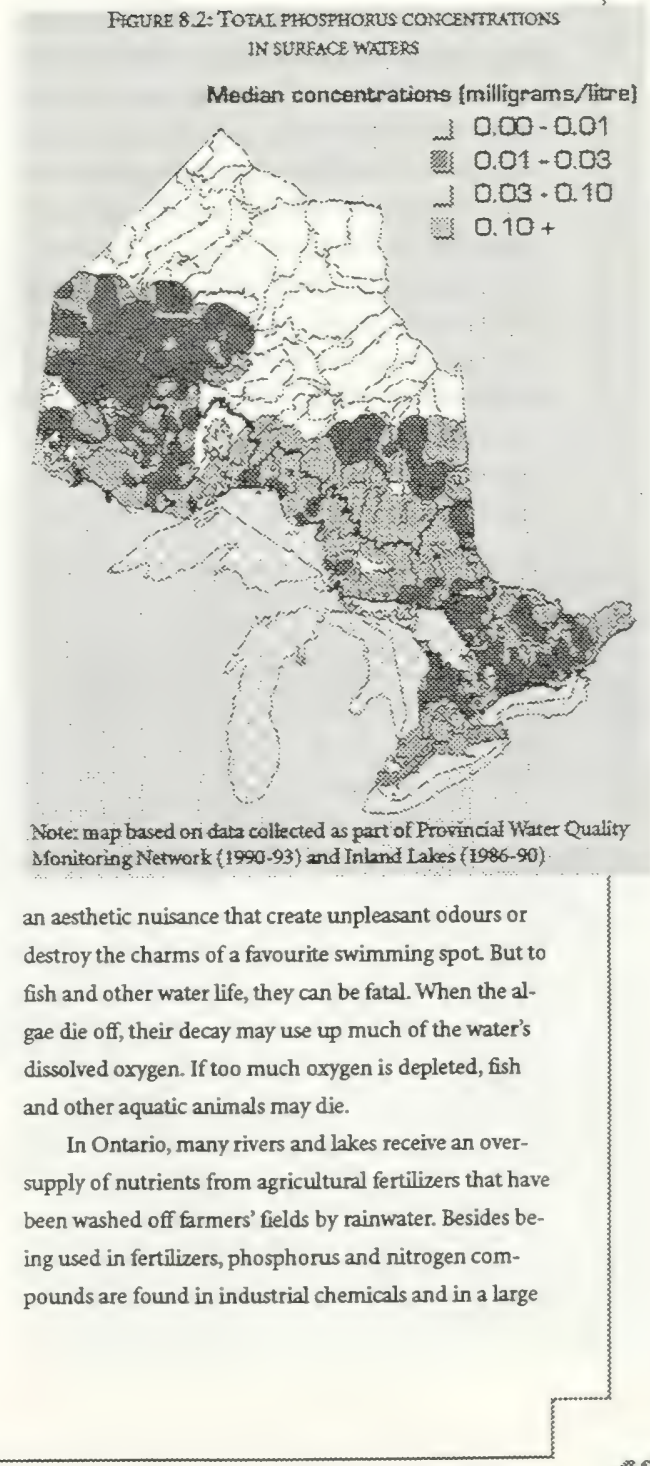

FFUURE 8 .2: TOTAT PHOSPHOMUS CONCENTRATTONS IN SUREACE WATERS

ns/htel

$0.01-0.03$

$0.03 \cdot 0.10$

$0.10+$

Note: map based on data coltacted as part of Prozincial Water Quality Sfonitoring Network (1990-93) and Inland Lakes (1986-90)

an aesthetic nuisance that create unpleasant odours or destroy the charms of a favourite swimming spot. But to fish and other water life, they can be fatal. When the algae die off, their decay may use up much of the water's dissolved oxygen. If too much oxygen is depleted, fish other aquatic animals may die.

In Ontario, many rivers and lakes receive an oversupply of nutrients from agricultural fertilizers that have been washed off farmers' fields by rainwater. Besides be ing used in fertilizers, phosphorus and nitrogen compounds are found in industrial chemicals and in a large 


\section{water combinuec}

assortment of everyday products, including detergents, household cleaners, motor lubricants and food. Consequently, phosphorus and nitrogen show up in substantial amounts in effluent from municipal sewage systems, rainwater runoff from city lawns and streets, and discharges from pulp and paper mills, food processing plants, chemical factories and other industrial sources.

Figures 8.2 and 8.3 show median concentrations of phosphorus and nitrates (a form of nitrogen) in surface waters in various parts of Ontario. (The median or midrange value is the value halfway between the highest and lowest readings obtained.) These maps are based on measurements taken between 1986 and 1993. According to ministry guidelines, excessive plant growth in rivers

\section{FHGURE 8.3: NIRATE CONCENTRATYONS IN SURFACE WATIRS}

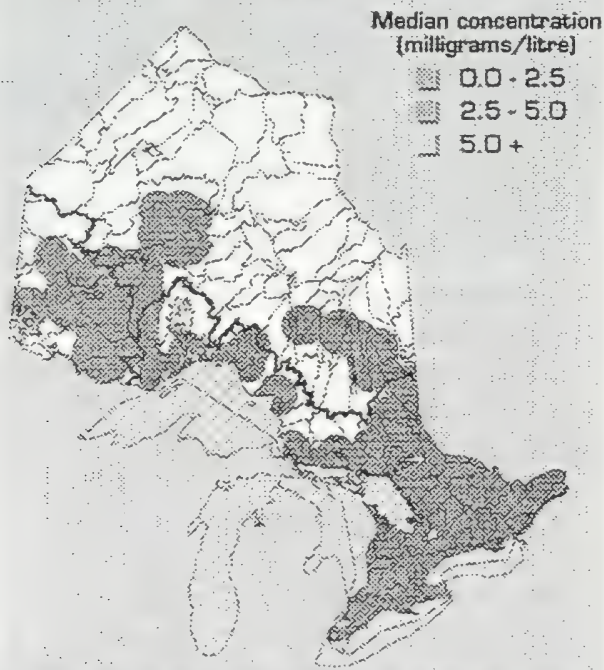

Note: map based on data collected as part of Provinctal Warer Quality Monitoring Network (1990-93) and Intand lakes (1986-90) and streams is unlikely to occur if the total phosphorus concentration is below 0.03 milligrams per litre. In lakes, the guideline value for nuisance growths of algae is slightly lower. A similar guideline is not yet available for nitrate, but natural concentrations in surface waters are rarely greater than 0.5 milligrams per litre.

As the maps in Figures 8.2 and 8.3 show, both phosphorus and nitrate concentrations are exceptionally high in the farming counties of the southwest. Many of the water bodies in this area are now degraded by excessive algae growth. The Fanshawe and Gordon Pittock reservoirs on the Thames River provide good illustrations of the impacts. Both of these popular recreational areas have been closed to the public at times and have had fish die because of nutrient enrichment and algae growth.

Phosphorus levels are also high in other farming areas - particularly around the eastern end of Lake Ontario and in the southeast between the Ottawa and St. Lawrence rivers. In addition, phosphorus concentrations above the guideline value are found in scattered locations in northern Ontario, where they may be a result of industrial discharges, municipal sewage, or local geological conditions.

Also, oxygen in the water can be used up by the decay of organic matter in waste water or the oxidation of chemicals such as ammonia. These substances are known as biochemical or chemical oxygen-demanding materials (BOD and COD, for short). Municipal sewage treatment plants and industries that produce large amounts of organic or chemical waste - pulp and paper manufacturing, food processing, iron and steel production and petroleum refuning, for example - are common sources of oxygen-depleting materials. 


\section{ลasteria}

A century ago, bacteria in drinking water caused large numbers of deaths from diseases such as typhoid and cholera. Thanks to improved sewage disposal practices and routine treatment of drinking water, municipal water supplies are now safe. Bacterial contamination remains a common water quality problem and causes the closure of many swimming areas every year.

Rural watercourses are commonly polluted by wastes from cattle that are watered in streams, by the dumping of milkhouse wastes, by leakage from septic tanks and by manure spread on fields. In urban areas, sewage treatment plants and sewer overflows during heavy rains are common sources, as are some industrial fa. cilities such as food processing plants and pulp and paper mills. The most common indicator of bacterial contamination in water is the presence of elevated densities of faecal coliforms or E coli bacteria.

Water with an average faecal coliform density of more than 100 counts per $100 \mathrm{~mL}$ in a series of water samples is considered unsafe for swimming or other recreational uses that involve bodily contact with the water. As Figure 8.4 shows, levels in excess of this guideline are reached in many parts of southern Ontario, especially in and downstream of farming areas. In some urban areas, temporary increases in bacterial levels often follow heavy rainstorms, because the sewage system cannot handle the extra flow and raw sewage is discharged
FIGURE 8.4: FAECAI COLIFORM DENSITES WN SURFACE WATERS

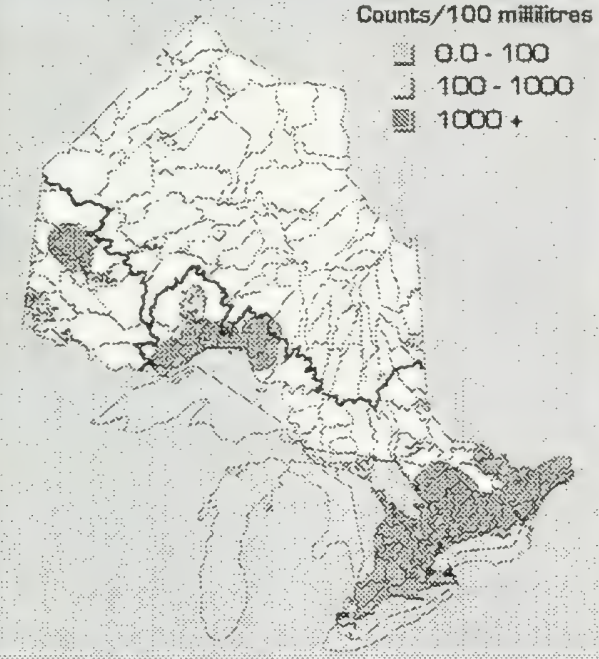

Note: map based on data collected as part of Provincial Water Quality Monitoring Network (1990-93) and Intand Lakes $(1986-90)$ directly to the receiving waters to avoid backups and overtows in the system.

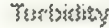

Turbidity is a measure of the scattering of light in water. Essentially, it is a measure of water clarity (or, more precisely, the lack of it), and it is a good indication of the amount of suspended solids that water contains. Many of these solids, such as micro-organisms, minerals and fine particles of clay, are of natural origin, but a number of human activities add large quantities of suspended solids to nearby water bodies. The effluent from pulp and paper mills, for example, contains large amounts of wood fibre. But apart from industrial effluent, much of the extra loading of suspended solids comes from urban and agricultural runoff, from forestry activities such as clearcutting, and from damage to river banks by construction and cattle. 
Too high a concentration of suspended solids may make water unsuitable for recreational and other uses and can have devastating effects on the aquatic environment, smothering bottom-dwelling organisms, ruining spawning grounds, reducing the amount of sunlight reaching plants and phytoplankton and even plugging the gills of fish. Suspended particles also provide a bonding surface for toxic metals and chemicals.

In agricultural areas, turbidity problems have been common for years. To a considerable extent, they are the result of the clearing of forests and drainage of wetlands by the first few generations of agricultural settlers in the nineteenth century. Still, new problems continue to arise.

in the early 1980 s, for example, the clear blue waters of Little lake at Barrow Bay on the Bruce Peninsula were turned brown and murky by sediments released from the clearing of agricultural drainage ditches. This work also resulted in the loss of a brook trout stream, while cattle access to the ditches and runoff from fields continued to contribute bacteria, chemicals and additional sediments to water flowing into the lake. Some remedial action has been undertaken since then, but a number of water quality problems remain.
Figure 8.5 shows that the highest levels of turbidity are found in the highly urbanized watersheds around Lake Ontario and in the farming country of the southwest. Turbidity levels on the Shield are much lower, although forestry, mining, and pulp and paper manufacturing can have local effects.

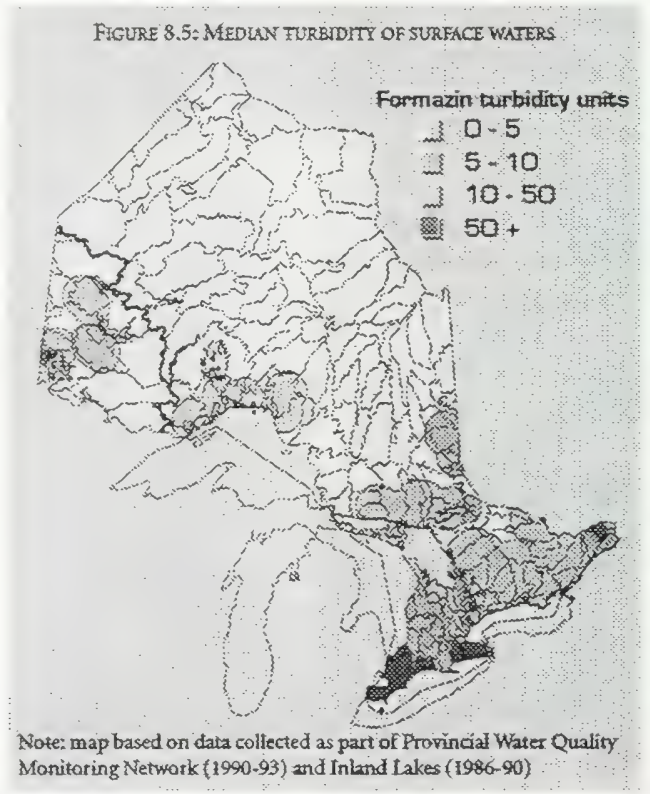

Note: map based on data collected as part of Pronincial Water Quality Monitoring Network (1990-93) and Inland Lakes (1986-90)

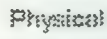

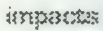

Many of Ontario's rivers have been dammed to control flooding or to provide water for power generation. Hundreds of streams were also dammed in the nineteenth century to provide water for grist mills and many of these dams still survive. Dams and the ponds behind them have a number of disruptive effects on aquatic ecosystems. Among other things, they may destroy habitat, isolate fish from their spawning grounds, deplete oxygen, alter water temperatures and increase evaporation from the watershed. They also contribute to the release of toxic metals from newly flooded areas, particularly mercury, which can accumulate to high levels in fish from reservoirs. 
Water level fluctuations caused by the operation of a hydroelectric dam on northern Ontario's Nipigon River, for example, have contributed to the decline of the river's brook trout population, mainly because of damage to the fish's spawring grounds. In other parts of the province, flow alterations have been caused by a variety of factors, including stormwater systems, field drainage, the elimination of wetlands and the increased imperviousness of the ground in many watersheds (as a result of paving, for example, or the compacting of soils by heavy machinery).

Other common physical stresses on waterways include dredging, deforestation, boat wakes, and shoreline alterations such as the straightening of river banks.

These can be very destructive of aquatic habitat and can greatly increase turbidity. Flow alterations and habitat destruction are major causes of water quality impairment in many of the province's aquatic systems.

\section{و}

Toxic substances interfere with important biochemical processes in living organisms. There are many different types of toxic substances, but of particular environmental concern are those (such as mercury, lead and other heavy metals) that cannot be broken down into less harmful substances, or those (organochlorine compounds such as PCBs and dioxins) that do so very slowly. Many of these substances also accumulate readily in living tissue. These are known as persistent bioaccumulative substances and organisms can eventually build up harmful concentrations of them in their systems, even when levels in the surrounding environment are barely detectable.

While the individual effects of each substance vary, long term exposure to these substances has been linked to cancer, reproductive failure, birth defects, genetic mutations, organ damage and/or damage to the nervous system in both humans and wildlife. The most common persistent toxic substance found in inland lakes is mercury.

Several persistent toxic substances exist in nature, but a number of them are also widely used in manufacturing and found in an extensive variety of ordinary, everyday products. As a result, many of these substances enter rivers and lakes from municipal sewage systems, industrial discharges, rainwater runoff and the air. In farming areas, pesticides and herbicides are the most common source of these contaminants. In northern Ontario, pulp and paper mills, mines and smelters are the most conspicuous sources.

Because persistent toxics can be passed up the food chain from prey to predator, concentrations can become extremely high in fish. Thus, for humans and other top predators such as mammals and waterfowl, the most important pathway of exposure to these substances is not water but fish. Because of the potential health risk from eating contaminated fish, sport fish in Ontario's lakes and rivers have been regularly sampled and tested for toxic substances for a number of years. Consumption advisories are issued for those lakes and rivers where contaminated fish have been found.

Consumption advisories depend not only on location but also on the species and size of the fish. The larger and older the fish, the higher the toxic concentrations are likely to be Figure 8.6 shows where consumption advisories have been issued for $45-55 \mathrm{~cm}$ walleye, a warm-water species that is well distributed throughout the province. Figure 8.7 shows where advisories have been issued for $35-45 \mathrm{~cm}$ lake trout, a representative cold-water species. 


\section{water continued}

FIGURE 8.6: INTAND LAKE FSH CONSUMPTHON ADNISONUES TOR 45-55 CM WALLEXE

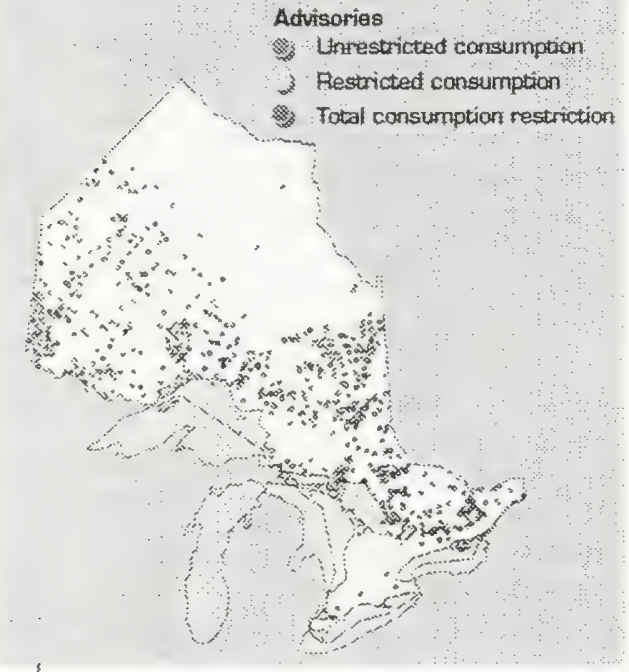

For both species, total consumption restrictions are relatively few, but partial restrictions are widespread. Mercury is by far the most common contaminant for which these restrictions have been issued. Because the industrial use of mercury has declined considerably since the 1970 s, a consumption advisory does not necessarily indicate that there is a current human source of mercury contamination in the area. The mercury in the fish may also have come from natural sources, residues of past episodes of contamination, disturbance of the watershed (e.g., flooding), or airborne deposits from other areas. According to ministry studies, most of the mercury entering remote Shield lakes comes from the air and about half of this amount comes from human sources.
One of the worst cases of mercury pollution in Ontario occurred during the 1960 s and early 1970 s when discharges from a chlor-alkali plant at Dryden severely contaminated the English-Wabigoon river system. With mercury levels in fish running as high as $12.0 \mathrm{mg} / \mathrm{kg}$, sport and commercial fishing on the river had to be closed.

Mercury levels in the English-Wabigoon system declined considerably during the 1970 s and early 1980 s as a result of discharge controls and the eventual closing of the plant. Levels have remained relatively stable since 1983 , but some mercury still remains in the system. Four lakes in the area have been monitored regularly since 1970, and mercury levels in walleye from one of them (Clay Lake) still average more than $2.0 \mathrm{mg} / \mathrm{kg}$. Mercury levels in uncontaminated fish are generally less than $0.5 \mathrm{mg} / \mathrm{kg}$. Elevated mercury levels have also been found in Lake Abitibi, the Mattagami River, the Ottawa River and lakes in the Huntsville area.

High levels of chlorinated organic compounds are relatively uncommon in sport fish from Ontario's inland. waters. Significant levels of PCBs, for example, have been detected in sport fish at only two inland locations in Lake Clear near Renfrew and in the Otonabee River and Rice Lake near Peterborough. The PCBs in Lake Clear have been traced to the use of contaminated materials for oiling nearby roads in the mid-1970s. Cleanup of the lake has now been completed and monitoring is under way to determine if more work is needed.

$\mathrm{PCB}$ in the Otonabee River and Rice Lake have been found only in bottom-feeding fish such as carp and levels have been below the federal guideline of $2.0 \mathrm{ppm}$ for the sale of commercial fish. The source has been traced to contaminated wastes that were discharged into Peterborough's sewer system over a number of years by 
two local industries. The industries have co-operated in cleanup efforts, but the sewer system still appears to be saturated with PCBs, which are discharged into the lake and river after heavy rains. A committee is now looking into further ways of dealing with the problem.

\section{Eัr}

To improve inland water quality, both point and area sources of impairment must be tackled Controls on point sources have been evolving since the mid1960 s when the Ontario Water Resources Commission began setting objectives for the discharge of a number of industrial water pollutants. These and other initiatives have already significantly reduced loadings of some pollutants in a number of areas. Figure 8.8 , for example, shows how phosphorus concentrations in the Credit River declined in the 1970 s as a result of legislation reducing the phosphate content of laundry detergents and again in the 1980 s as a result of the introduction of phosphorus treatment at an upstream sewage plant.

Regulations being developed under Ontario's Municipal Industrial Strategy for Abatement (MISA) are expected to bring further reductions in pollution discharges from both industrial sources and municipal sewage treatment plants. Regulations for the pulp and paper industry, released in November 1993, for example, will reduce the discharge limit for chlorinated compounds by 68 per cent by the end of 1999 .

Reductions of point-source pollution will benefit a number of water systems, particularly in the north where most water quality problems are related to pointsource impacts. In the south, however, agricultural activities have a much greater and more widespread effect on water quality than either municipal or industrial sources.
FGGURE 8.7: INLAND LAKE FFSH CONSUMPTON ADVISORTES FOR 35-45 CAM LAKE TROUT

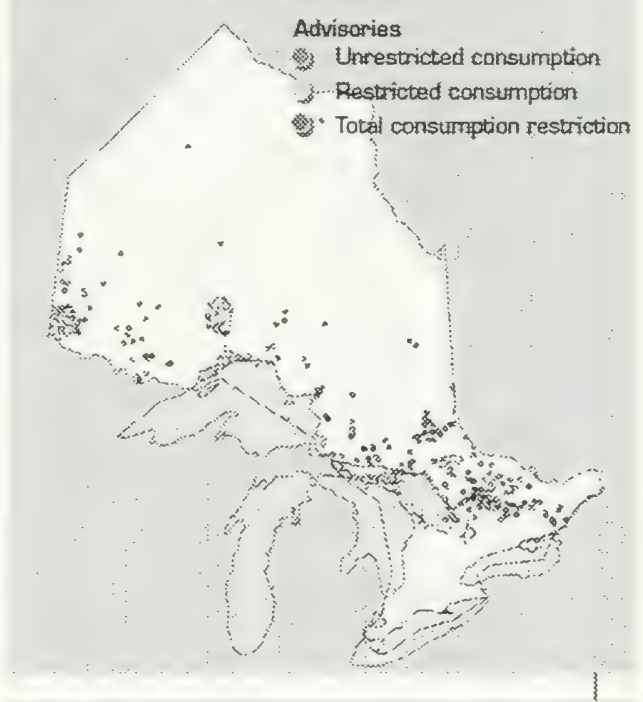

FKGURE 8.8: PHOSPEORUS CONCENTRATIONS IN THE WEST RRANCH OF THE CKEDTT RIVER DOWNSTREAM OF A SEWAGE TREATMENT PLANT

Phosphorus Concentegtion Imiligrams/titre]

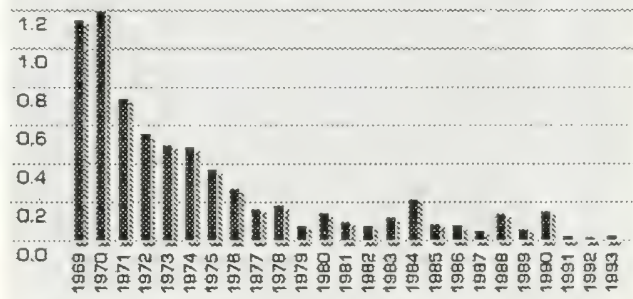


FIGURE 8. 9. CHANGES IN PHOSPHORUS CONCENTKATZON IN INLAND LARES $1973-76$ TO $1990-93$

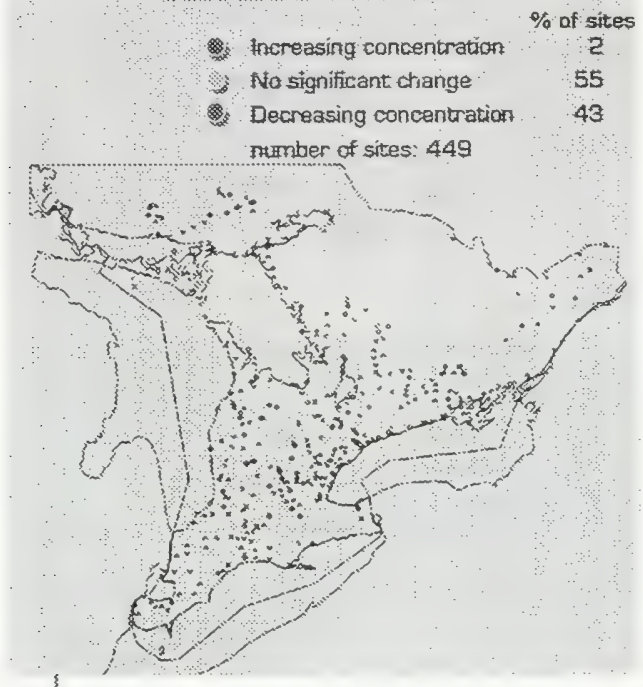

Reducing the impact of agriculture is a difficult task that will require some significant changes in farming practices. For example, changes to tillage practices, such as leaving stubble on the fields in the fall instead of ploughing it under, can reduce soil erosion, which is a major cause of water turbidity. Discouraging cattle form watering in streams can reduce turbidity and bacterial contamination. Using fertilizers more judiciously can reduce nutrient loadings. Leaving, or replanting, strips of forest along river baniks can provide a protective buffer between fields and waterways.

Many Ontario farmers are taking steps to make their farm operations more environmentally sensitive. In 1992, twenty-seven farm associations joined forces to form the Ontario Farm Environmental Coalition
(OFEC). In partnership with the federal and Ontario governments, OFEC has launched the Ontario Farm Environmental Agenda Initiative. The Initiative provides workshops to assist farmers in assessing the environmental risk on their property and in developing appropriate environmental farm plans.

In urban areas, the ministry is involved in preparing Pollution Control Plans (PCPs) for a number of municipalities. These are intended to reduce pollution resulting from the overloading or bypass of sewage treatment systems during storms.

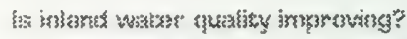

In some areas, surface water quality has improved as a result of pollution prevention programs or changes in economic activity. In others, though, it is deteriorating because of urban expansion, rural residential development, or other such stresses.

Detailed analyses of longer-term trends in water quality are unavailable. However, it is possible to make fairly simple statistical comparisons between monitoring data for 1973-76 and corresponding data from the same sites for 1990-93 to see if changes have occurred. This method does not measure the degree of change, but simply indicates whether levels of a particular pollutant at a particular place are higher, lower, or about the same as they were 20 years ago.

The accompanying maps (Figures 8.9 to 8.12 ) show the pattern of change for phosphorus, nitrate, faecal coliforms and turbidity.

Phosphorus levels have shown the greatest improvement over the past 20 years, having declined at 43 per cent of the sites and risen at only two per cent of them. This improvement reflects the very considerable efforts that have been made during this time to reduce 
FIGUYE 8. OO. CHANGES IN NTRRATE CONCENTRATION WN

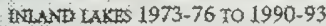

$\%$ of sites

4. Increasing concentration 45

- No sigrificant change

Decreasing concentration 4 number of sites: 337

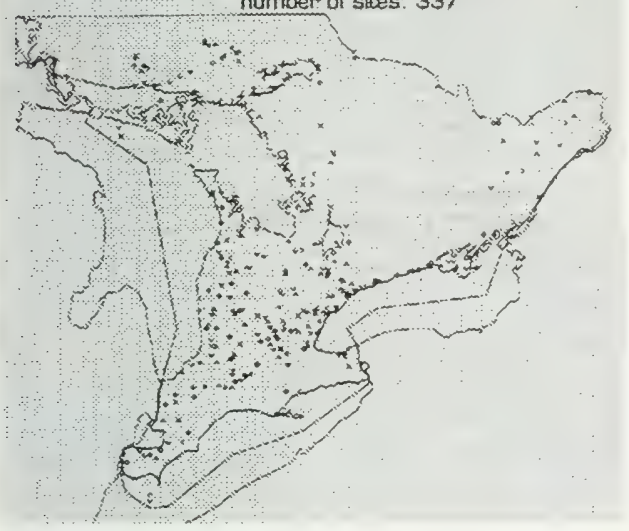

phosphorus loadings in waste water, particularly through reductions in the phosphate content of detergents and improvements to sewage treatment plants.

In contrast, levels of nitrates, faecal coliforms and turbidity have either increased or remained unchanged in most areas since the 1970s. Nitrate levels in particular have been on the rise, increasing at 45 per cent of the sites and decreasing at only four per cent (Figure 8.10). Most of the increases have been registered at sites in the southwest and can be attributed mainly to fertilizers and other agricultural sources.

In most areas, faecal coliform and turbidity levels have changed little since the 1970s, although where changes have occurred they have been more often for
FIGURE 8.11: CHAANGES NN FAECAX COIZFORM COUNTS IN NIAND LAKES 1973-76 ₹O 1990-93

$\%$ of sites

4. Increasing concentration 18

3 No sigrificant ctrange . 75

- Decreasting concentration 6

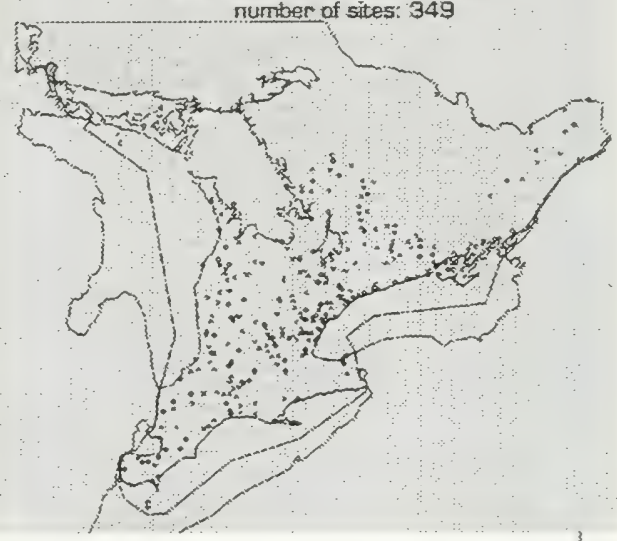

the worse than for the better. Several increases in faecal coliform densities have occurred in the greater Toronto area, mainly as a result of urban development (Figure 8.11). Increases in the Muskoka, Haliburton, and Kawartha Lakes regions probably result from more intensive cottage development and recreational activity.

Increases in turbidity are most noticeable in the Grand River watershed and in cottage country (Figure 8.12). Once again, residential development is the most likely cause.

In general, then, these measures of surface water quality, except for phosphorus, have improved little since the 1970s and in some areas there is evidence of continuing deterioration. Surface waters throughout 
FHGURE 8.12: CHAHGES RA TUREIDITY CONCENTRATION IN INAND LARES 1973-76 TO 1990-93

$$
\text { \% of sites }
$$

sack fing concentration. 23

(3) No significant change 75

Decreasing concentration 2 number of sites: 337

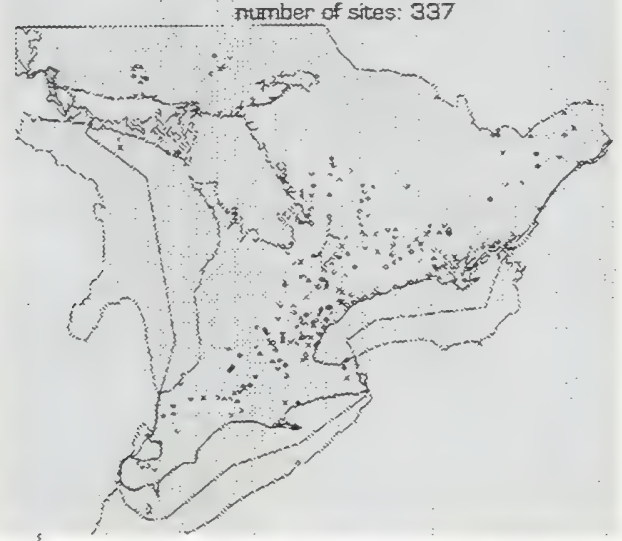

southern Ontario are generally less than satisfactory in terms of their suitability for recreation, aesthetic qualities and ability to support all the fish and plant populations that they once did. The poorest water quality is found in the southwest, in the Golden Horseshoe around the western end of Lake Ontario, and along the Rideau and lower Ottawa rivers.

On the other hand, water quality impairment in northern Ontario is generally much less widespread. Except for localized impacts from resource industries and urbanization and for those areas affected by acid rain and recreational activity, water quality in many northern lakes and rivers remains close to its natural state.

Most of the initiatives for improving surface water quality are fairly recent in origin and although some of them have begun to produce results, for the most part little improvement has been seen yet. It may take some time before significant results are achieved.

\section{CHAPTER 9 The GReat Lakes}

The Great Lakes are one of the world's most important freshwater resources but, set within the economic heartland of North America, they also are subject to intensive pressure from human activities. More than 35 million people live in the Great Lakes basin and more than nine million of those live in Ontario. About 17 per cent of the United States' manufacturing capacity is located here, along with about 45 per cent of Canada's. Some 2.5 trillion litres per day of water are withdrawn for industrial, domestic and agricultural uses as well as for power generation and sanitation.

In addition, the lakes serve as a highway for ships from around the world and as a playground for recreational purposes. They also provide habitat for aquatic life and support a large commercial and sport fishery. In 1990 the commercial fishery alone landed 24.5 million kilograms of fish, with a dockside value of $\$ 42$ million.

In such an environment, the lakes are exposed to pollution from many sources, including discharges from industries and municipal sewage systems, spills from ships and runoff from adjacent fields and city streets. In addition, groundwater and rivers llowing into the lakes bring contaminants from the larger drainage basin, while air currents deposit pollutants from even farther afield.

Because it takes up to 100 years for the waters to enter and leave the Great Lakes system, pollutants tend to remain within the system for a long period of time. In 


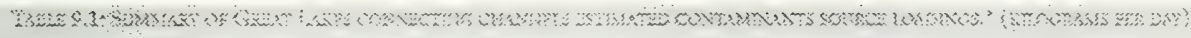

\begin{tabular}{|c|c|c|c|c|c|c|}
\hline Contammant & $\begin{array}{l}\text { Lake Superior } \\
\text { discharge to } \\
\text { St. Marys River }\end{array}$ & $\begin{array}{l}\text { St. Mamy } \\
\text { River } \\
\text { Sources }\end{array}$ & $\begin{array}{l}\text { Lake Huron } \\
\text { discharge to } \\
\text { St. Clair River }\end{array}$ & $\begin{array}{l}\text { St, Clair } \\
\text { Aliver } \\
\text { Sources }\end{array}$ & $\begin{array}{l}\text { St. Clair Aiver } \\
\text { discharge to Lake } \\
\text { St. Clair }\end{array}$ & $\begin{array}{l}\text { Lake } \\
\text { St. Clair } \\
\text { Sources }\end{array}$ \\
\hline Chloride & 251,856 & 34,924 & 320,000 & 400,481 & $4,200,000$ & 490,927 \\
\hline Phosphorus & 1,749 & 120 & 720 & 222 & 5,500 & 3,544 \\
\hline Zine & 266 & 41 & 130 & 79 & 1,100 & 388 \\
\hline Lead & $\because$ & 12 & 7,500 & 21 & 160000 & 179 \\
\hline Cadmium & - & 0.0021 & - & 0.321 & - & 4.6 \\
\hline Mercury & 0.1901 & 0.0067 & 0.09 & 0.0421 & 6.6 & 0.3997 \\
\hline PCBs (total) & 0.06776 & 0.0090 & 0.0 (nd) & 0.09900 & 0.2750 & 0.0393 \\
\hline Hexachlorobenzene & 0.004 .752 & 0.000016 & 0.01 & 0.0295 & 0.7865 & 0.00562 \\
\hline Mirex & $0.0(n d)$ & - & $0.0(n d)$ & - & - & - \\
\hline
\end{tabular}

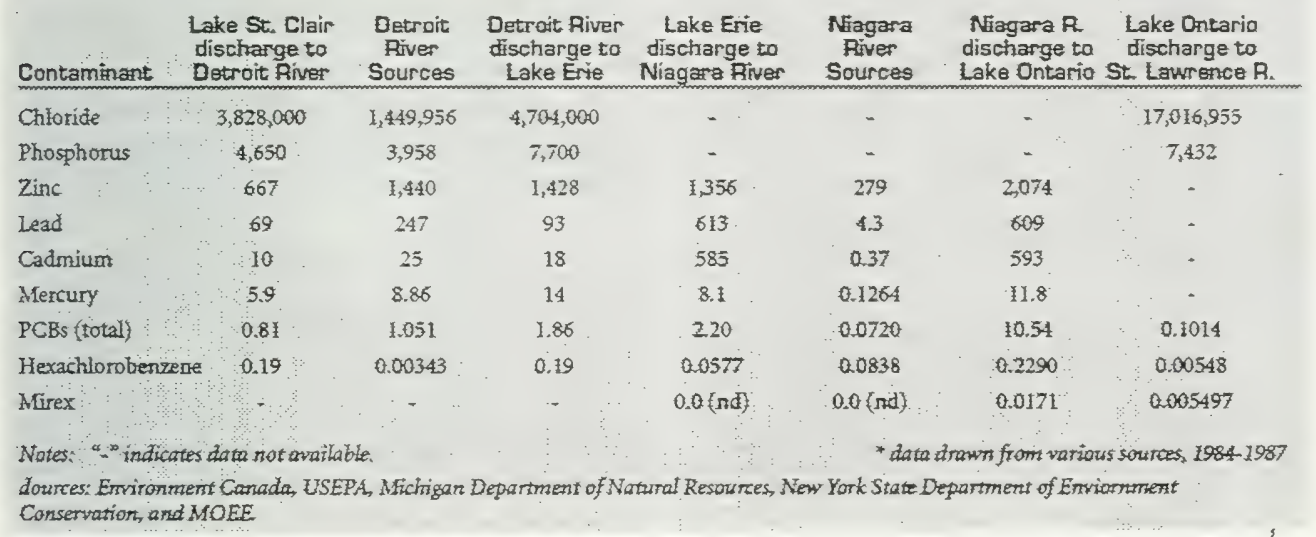

addition, as Table 9.1 shows, loadings of contaminants tend to accumulate as they move through the lakes and their connecting waters. Consequently, the lower lakes and the St. Lawrence River are exposed not only to local sources of pollution but also to accumulated pollutants from upstream.

Lake Superior, with half the water in the Great Lakes system, is the largest of the lakes and the second largest freshwater body in the world. It also has the best water quality, thanks to low population density, little agricultural activity and a heavily forested drainage basin. Thunder Bay and Duluth are the only large urban industrial centres on the lake, although pulp and paper mills have caused local pollution hot spots in some smaller communities. For the lake as a whole, air currents are the largest single source of many contaminants. 
Lake Michigan, situated entirely within the United States, lies outside the scope of this report. However, more than eight million people, or about one-fifth of the population of the entire Great Lakes basin, are settled along its shores. A number of inshore localities are heavily contaminated. Many of them are found within the densely urbanized and industrialized strip that runs from Gary to Chicago in the south, up to Milwaukee, halfury up the westem shore. Although the northern part of the lake is less developed, some areas, especially Green Bay, are affected by wastes from the large number of pulp and paper mills in the area.

Water quality in the open waters of Lake Huron and Georgian Bay is good and remains close to what it was in the nineteenth century. There are no large concentrations of industry or population on the Canadian side, although pollutants from municipal and industrial sources in Sault Ste. Marie enter the lake via the St. Mary's River. Similarly, the Spanish River is a source of pollutants from upstream mining activities and pulp and paper operations. The lands bordering the southern part of Georgian Bay and the lake are mostly an area of small towns and farms with rapidly expanding recreational uses. Consequently, most of the pollution entering the lake comes from municipal sewage or agricultural runoff, with some localized pollution coming from past or present industrial activities and marina shoreline developments.

The industrial and urban impact on the Great Lakes system intensifies considerably, however, at the mouth of the St. Clair River. The St. Clair itself is home to a large segment of Canada's petrochemical industry, while farther downstream the Detroit River is flanked by two cities, Detroit and Windsor, and their many manufacturing industries.
The pollutant load from these sources is substantial and most of it flows into Lake Erie, the warmest, shallowest and most biologically productive of all the lakes. The lake is also exposed to pollution from several large industrial centres on the American shore and from intensive agricultural activity on the Canadian side. In addition, Lake Erie supports a considerable amount of commercial fishing and recreational activity and this increases the stress on the lake as a whole and on its many small harbours in particular. Of all the Great Lakes, Erie is arguably the one that has been most affected by human activities.

Lake Ontario is the smallest of the Great Lakes but the second deepest (next to Superior). With the combination of Toronto and Hamilton - the largest urban and industrial ares in Canada - at its western end and intensive farming in most other areas along its shores, it is exposed to a wide variety of urban, industrial, and agricultural pollutants. However, the most important single source of contamination for Lake Ontario is the Niagara River, which has been heavily contaminated by toxic chemicals leaking from old hazardous waste sites on the American side.

The final link in the system is the St. Lawrence River, its exit to the sea. The Ontario portion of the river receives not only the accumulated load of pollutants from Lake Ontario but also municipal and industrial contaminants from towns along both shores and runoff from farms and other sources in the adjoining watershed. The river is heavily used, as well, by shipping and small boats. The most serious pollution sources affecting the Ontario stretch of the river, however, are chemical plants in Cornwall and hazardous waste sites on the New York side of the river. 
FIGURE 9.1A: TOTAI PHOSPHORUS LOADINGS IN THE GREAT LAKES

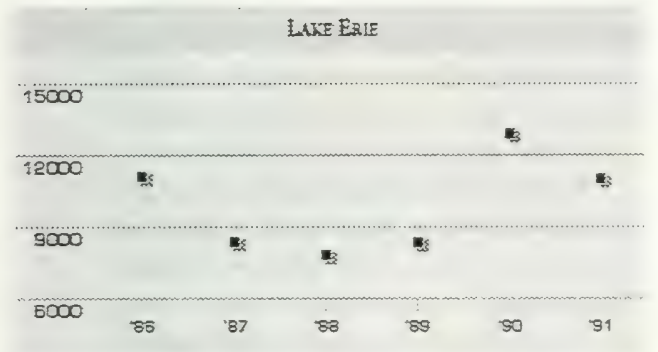

ST. 五WHERCE RTER

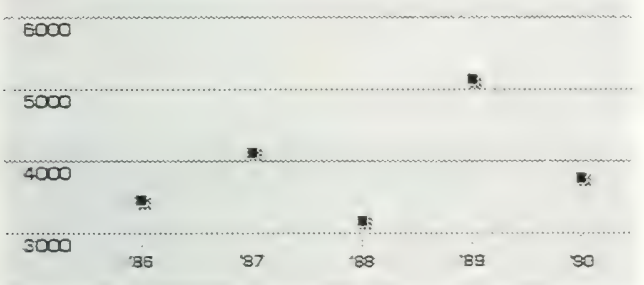

\section{LKEE HURON}

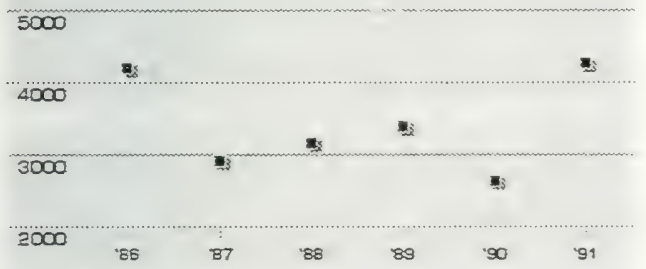

\section{LAKE ONTARTO}

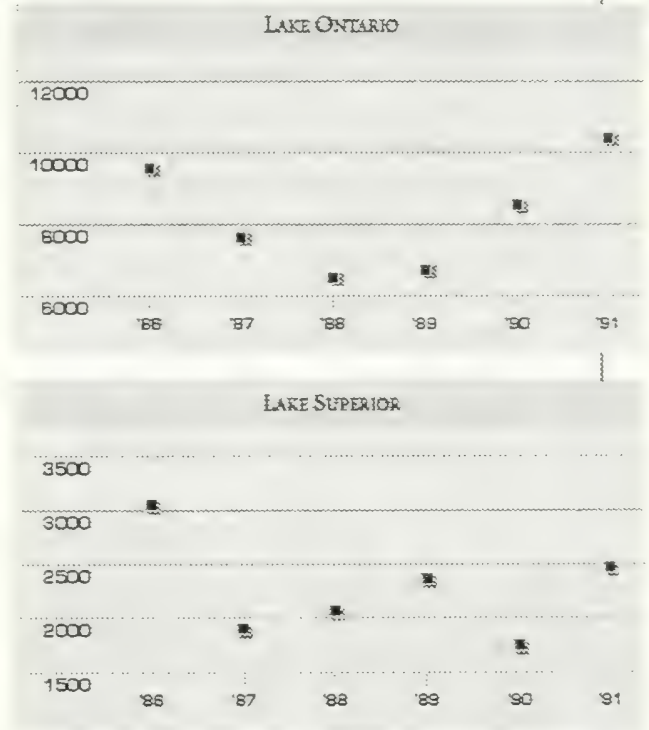

The Great Lakes are affected by a great range of pollutants. They include not only conventional water pollutants - oxygen-depleting materials, suspended solids, nutrients, bacteria, oil and grease and common chemical pollutants like ammonia - but also persistent toxic contaminants such as heary metals and a number of persistent organic compounds. Of these, the two that have caused the greatest and most widespread concern are nutrients and persistent toxic contaminants. 


\section{water contirued}

\section{Nuztrients}

Nutrient enrichment, or eutrophication, was first recognized as a major problem in the Great Lakes when large blooms of algae began to appear in the lower lakes in the 1960s. This sudden explosion of plant life was unwelcome for many reasons. The algae clogged sand filter beds at water treatment plants, added unpleasant tastes and odours to drinking water and fouled swimming beaches. As the algae decomposed, they also used up much of the dissolved oxygen in the water and made it difficult for many aquatic animals to survive.

Lake Erie was so badly affected that it was commonly described as 'dead', meaning that a number of species could no longer survive in some parts of the lake.
By the late 1960 s, the problem was traced to very high amounts of phosphorus entering the lakes from municipal sewage systems, industrial discharges and farmers' fields. Sewage treatment plants were the most important source and about 50 per cent of the phosphorus they discharged came from laundry detergents.

In 1972, Canada and the United States signed the Great Lakes Water Quality Agreement. One of its main aims was to reduce the amount of phosphorus going into the lakes by half and legislation limiting the phosphorus content of laundry detergents was introduced in both countries. Since then, facilities for removing phosphorus from waste water have also been added to many sewage treatment plants.

\section{FIGURE 9.1B: TOTAL PHOSPHORUS CONCENTRATIONS IN THE GREAT LAKES}

\section{LAKE ERIE}

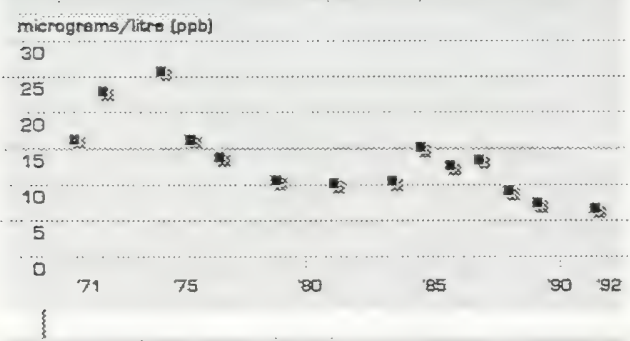

\section{LAKE HURON}

micrograms/Itro (ppb)

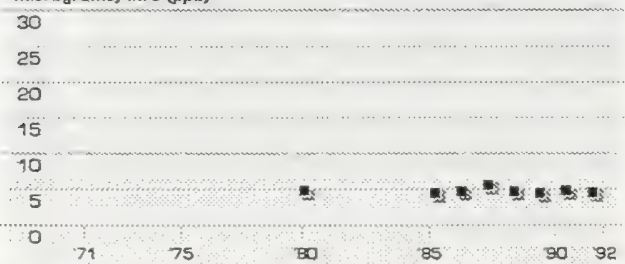

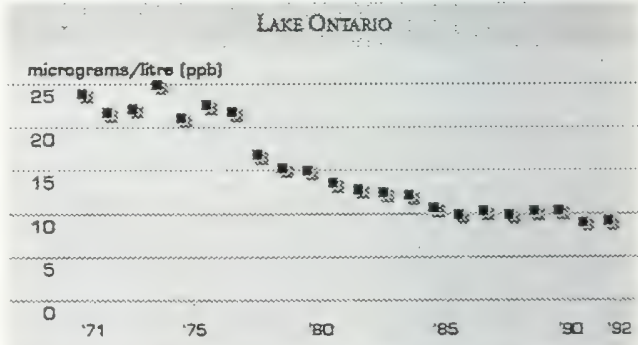

LAKE SUPERToK

micrograms/Itive [ppb]

30

25

20

15

10

5

7175 as

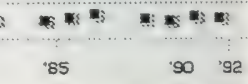


As a result of these controls, phosphorus loadings and concentrations in lakes Erie and Ontario - the lakes most affected - have declined significantly (Figure 9.1). Loadings are an estimate of the total amount of a substance discharged into water from all sources over a specified period of time and concentrations are the actual amounts of the substance measured in water at a certain place and certain time. In the western basin of Lake Erie, for example, total phosphorus loadings have decreased from about 20,000 tonnes per year in the 1960 s to between 5,000 and 6,000 tonnes per year during the late $1980 \mathrm{~s}$.

As phosphorus levels have declined, concentrations of nitrates in lake water - largely from agricultural fertil- izers - have continued to increase. Nitrates also have the potential to stimulate algal growth and concentrations of these chemicals have been increasing since the early years of this century. During the 1980 s, concentrations of nitrates in Lake Superior decreased slightly, but further increases were reported in the other lakes (Figure 9.2). So far, however, no adverse impacts from nitrates have been reported in the Great Lakes, but the increasing concentrations do raise concerns about the possibility of future nutrient enrichment problems.

With the decline in phosphorus loadings, problems of algal growth are now much less widespread. At the Union water intake near Kingsville in Lake Erie's westem basin, for example, algal densities are presently 20

\section{FIGURE 9.2: NITRATE-PLUS-NITRITE CONCENTRATIONS IN THE GREAT LAKES}
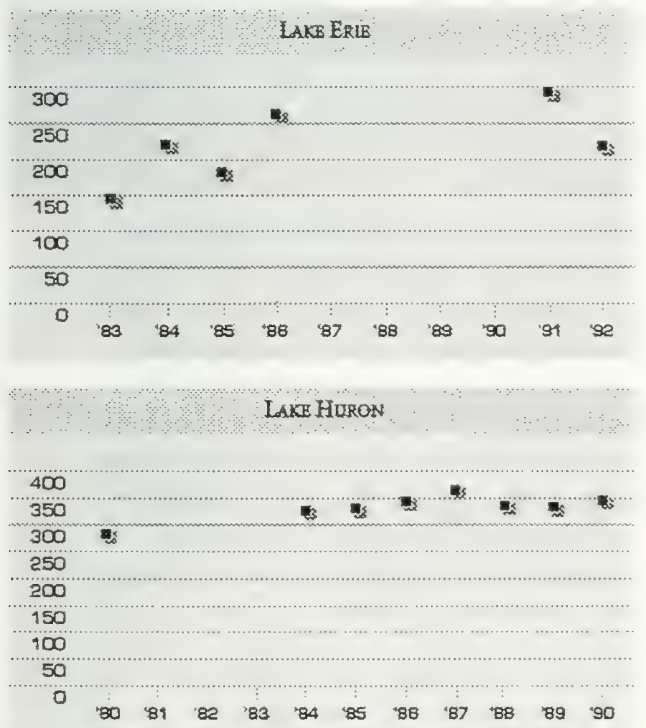

\section{LAKE OATARLO}

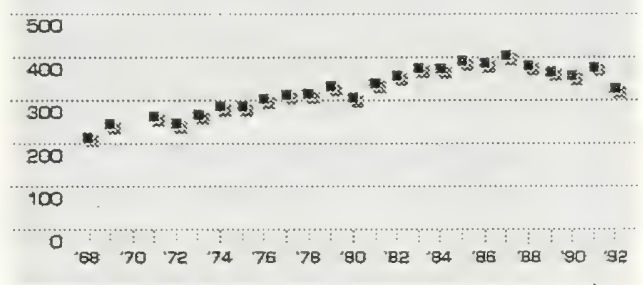

LAKE SUPERIOR

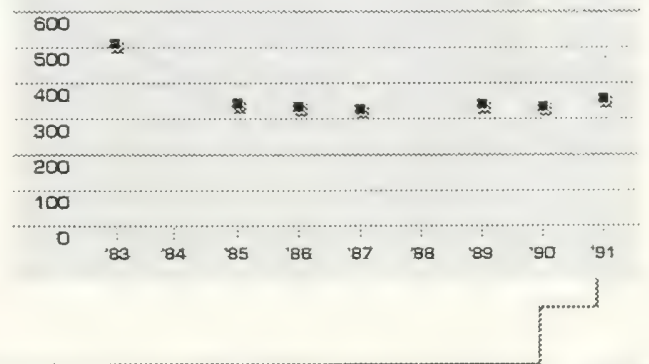




\section{water continued}

FIGURE 9.3A: LAKE ERIE PHOSPHORUS LOADS

\section{DETROTT RTVER LOADS}

\section{$\times 10^{3}$ Metric tons/year}

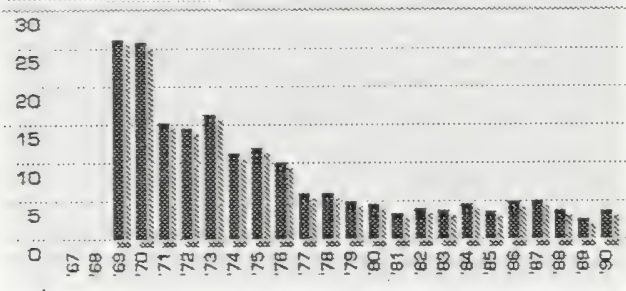

TOTAE WESERRN BASIN LOXOS

\section{$\times 10^{3}$ Metric tons/year}

30

25

20

15

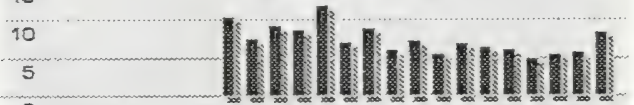

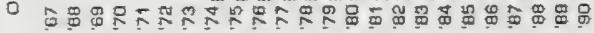

per cent of what they were two decades ago (Figure 9.3). However, in other locations, such as the Blenheim, Elgin and Dunnville water intakes, algal growth has not always diminished in step with decreases in phosphorus levels. This seems to be true in areas where phosphorus loadings have been moderate or have come from agricultural sources rather than municipal discharges. In the Bay of Quinte on Lake Ontario, for example, the amount of algae appears to be influenced more by interactions in the food web than by phosphorus loadings alone.

Ironically, the recent arrival of the zebra mussel, a non-native species that is now causing a number of problems in the Great Lakes, has also greatly decreased

\section{FIGURE 9.3B: LAKE ERIE PHYTOPLANKTON DENSITY}

HnoN

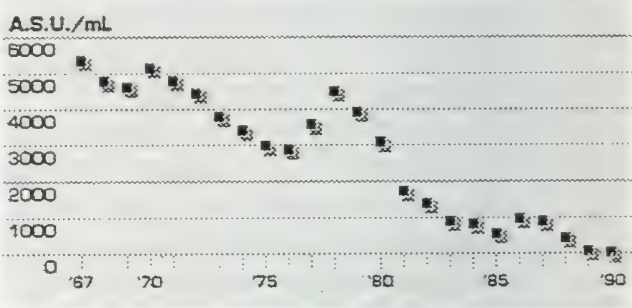

BLENBELA

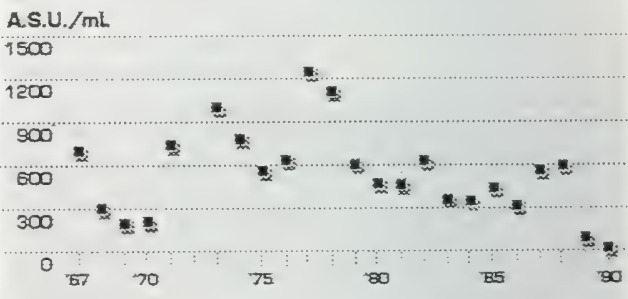

the amount of algae in some parts of Lake Erie (Figure 9.3). The fingernail-sized mussels feed by filtering water through their gills and removing phytoplankton. Large colonies of zebra mussels greatly improve the clarity of the water, but they also diminish the food supply for other aquatic organisms, create conditions that overstimulate the growth of bottom plants, clog water intake pipes and foul beaches and shorelines. It is estimated that keeping the mussels in check and repairing the damage they cause already costs $\$ 500$ million a year for the Great Lakes basin as a whole. 
FIGURE 9.3B: LAKE ERIE PHYTOPLANKTON DENSITY CONT'D

\section{EtarN}

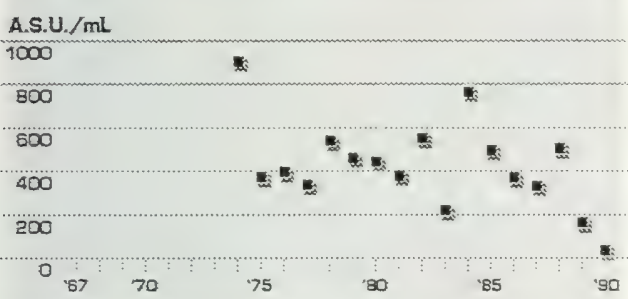

\section{DUNAMILLE}

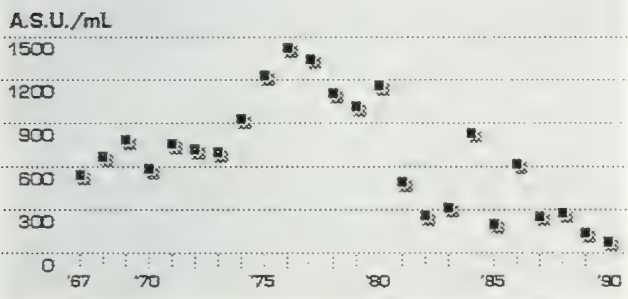

Since their arrival from Europe - probably in the ballast water of a freighter sometime in 1986 - the mussels have spread to all of the Great Lakes, although they have become most widely established in Lake Erie (Figure 9.4). Although they are now altering exological balances within the system, their long-term effects on the food web and other ecological relationships remain to be seen.

\section{parsiszeme toxic substances}

The International Joint Commission (IJC), the binational body that reviews progress under the CanadaU.S. Great Lakes Water Quality Agreement, has identified more than 360 chemical contaminants in the Great Lakes. Of these, 11 have been classified as critical pollutants because of their persistence, their tendency to accumulate and magnify in the food chain and their wide distribution throughout the region. In April 1992, Ontario released a similar list containing 21 substances that were primary candidates for bans, phase-outs, or reductions. The dominant items on both lists are organochlorine pesticides, heavy metals, polychlorinated dioxins and furans and polynuclear aromatic hydrocarbons (PAHs).

The heavily populated and industrialized lower lakes area has been most widely affected, with contaminants coming from municipal sewage, industrial discharges and surface runoff from fields and roads. For both Lake Ontario and Lake Erie, however, the most significant sources of persistent toxic contaminants are the Niagara and Detroit rivers respectively. In the upper lakes, toxic pollution problems tend to be more localized and associated with large industrial or municipal discharges.

With their large surface areas, the lakes also receive a substantial amount of pollution from the air. Airborne deposits are a particularly significant source in the upper lakes, where local sources of contaminants are fewer. An IJC study has estimated that atmospheric deposits account for as much as 90 per cent of the PCBs and 97 per cent of the lead entering Lake Superior. 


\section{water combinued}

\section{FIGURE 9.3C: ZEBRA MUSSEL EFFECTS ON PHYTOPLANKTON AT FOUR WATER INIAKE STATIONS ON LAKE ERIE}

\section{UNION}

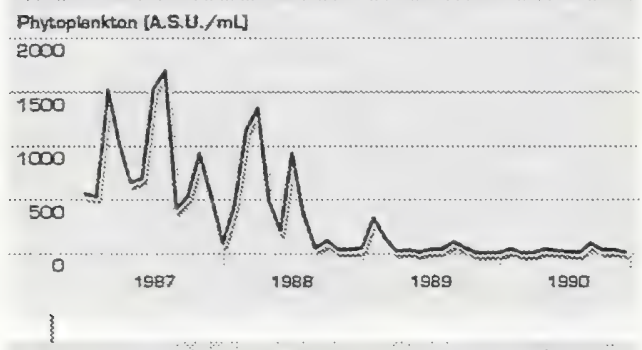

BXENHER

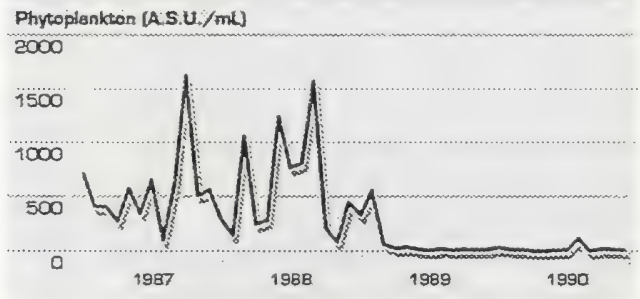

As part of a joint Canada-U.S. program to monitor atmospheric deposition to the lakes, MOEE has been measuring atmospheric concentrations of PCBs and three organochlorine pesticides ( $\mathrm{HCB}$, alpha- $\mathrm{HCH}$, and gamma-HCH) at half a dozen sites in the Great Lakes Basin. Atmospheric levels of these chemicals are very low, with little difference between northern rural and southern urban sites, but the total amount deposited in each of the lakes ranges from as low as 15 kilograms a year to as high as 550 kilograms a year. The quantity depends on the surface area of the lake, the atmospheric concentration of the chemical and the amount of precipitation.

\section{ELGIN}

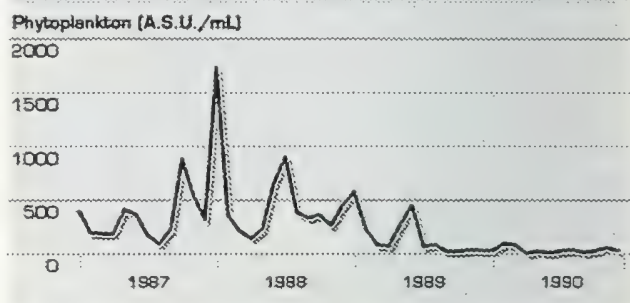

DUNWVIITE

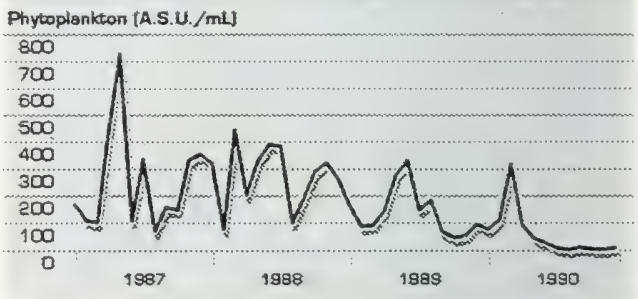

Since the substances in the study have either been banned or restricted for several years, their continuing presence is a powerful illustration of how difficult it is to eliminate persistent contaminants from the environment. After being deposited in the lakes, these chemicals may re-evaporate and return to the atmosphere to be deposited again somewhere else. In this way, they can be transported very long distances. Because evaporation is less likely as temperature decreases, it is believed that most of these chemicals will eventually work their way towards the poles. 


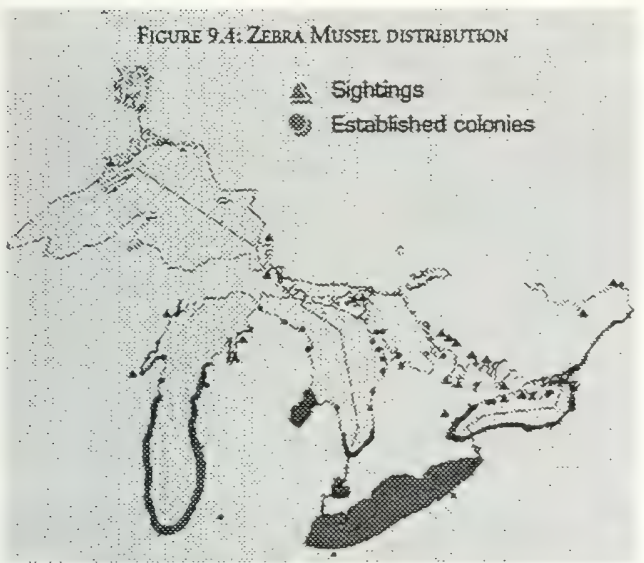

In the open waters of the lakes, concentrations of toxic chemicals are in the low parts per trillion range well within the objectives of the Canada-U.S Great Lakes Water Quality Agreement (GLWQA), which have been set to protect aquatic animals, the most sensitive users of the lakes. The highest levels of contaminants are found in nearshore areas, such as harbours, connecting channels and bays. Overall, lakes Ontario and Michigan are the most chemically contaminated of the Great Lakes; Lake Superior is the least.

Studies of sediments show that levels of persistent toxic substances peaked during the 1960 s and 1970s. In 1970, mercury concentrations in fish in Lake St. Clair became so high that commercial fishing had to be halted and people fishing for sport had to be warned not to eat their catches. At about the same time, chlorinated organic substances were implicated as a major or contributing factor in a number of other environmental problems around the lake, notably population declines and higher death rates among bald eagles and some species of waterfowl.
FIGURE 9.5A: AVERAGE CONCENTRATIONS OF PCBS, IN YOUNG-OF-THE-YEAR SPOTTAIL SHINERS, 1975-1991

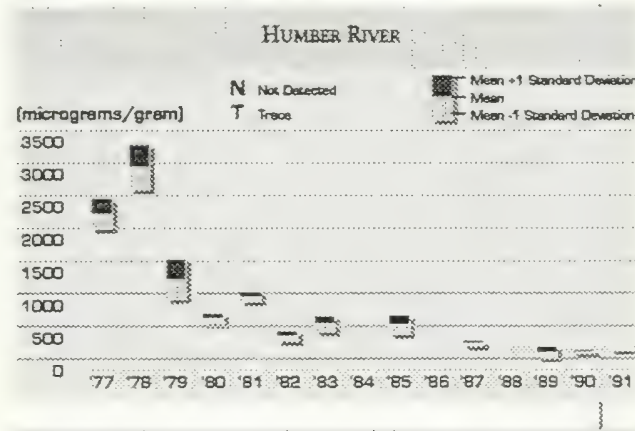

KAM RJVER

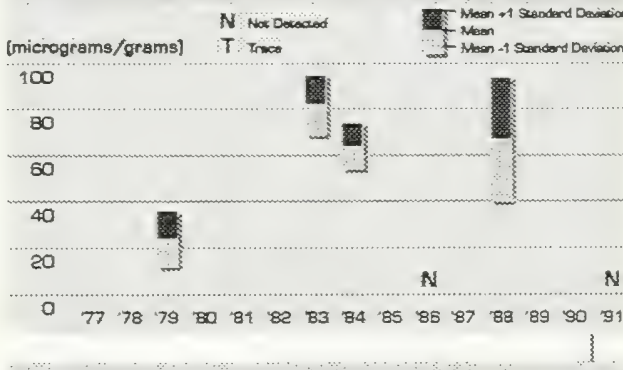

\section{LEAMINGTON}

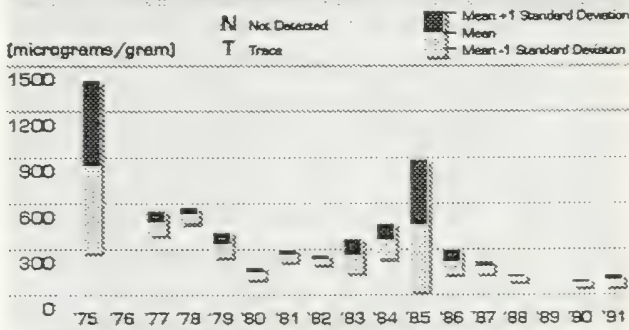




\section{water coratriued}

FigURE 9.5A: AVERAGE CONCENTRATIONS OF PCBS, IN YOUNG-OF-THE-YEAR SPOTIAIL SHINERS, 1975-1991 CONT'D

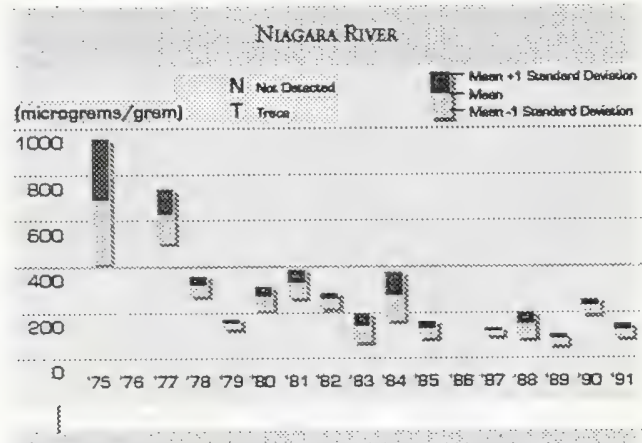

PIKE Creek

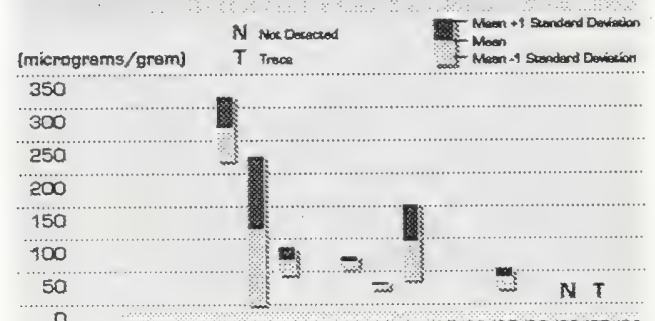

75767778 79 80 81:82:83 84 85 86 B7 BB 89 90 91

Since then, loadings of persistent toxics have declined significantly, mainly because of efforts by government and industry to reduce or eliminate the manufacture and use of mencury, PCBs, organochlorine pesticides and some other toxic substances, and to reduce or eliminate discharges of toxic byproducts such as dioxins and furans.

The reduction in loadings has been matched by a corresponding decline in concentrations of toxic substances in fish tissues during the 1970 s and 1980s. Because of their tendency to accumulate many of these substances, fish are a particularly useful indicator of the presence of toxic contaminants. Not only are the higher concentrations in fish tissue easier to detect than the lower levels in the surrounding water, but the presence of a contaminant in fish also indicates that the substance is biologically available and making its way through the food web.

Ontario has monitored the concentrations of more than 25 toxic substances in young-of-the-year minnows (spottail shiners) since 1975. Specimens have been collected and tested from more than $\mathbf{1 5 0}$ sites on the Great Lakes and their connecting rivers. As the graphs in Figure 9.5 show, levels of PCBs have for the most part dropped substantially since 1975, although the rate of decrease has levelled off in recent years. Levels of mercury and of DDT, chlordane and other organochlorine pesticides have shown a similar decline.

In spite of a general improvement in levels of persistent toxic contaminants in the lakes, excessive levels of some contaminants are still found in a number of areas. In the most recent sampling of spottail shiners (199091), for example, PCB levels exceeded the IJC's aquatic life guideline of 100 parts per billion (which is intended to protect fish-eating wildlife) in 14 of the 38 locations surveyed. The highest concentrations in Ontario waters were found in fish from Etobicoke Creek on the west side of Toronto (Figure 9.6). Mirex (an organochlorine pesticide) was also above the guideline at five locations (two in the lower Niagara River, two in Lake Ontario and one in the St. Lawrence River).

Mercury levels above the consumption guidelines continue to be found in sport fish in parts of Georgian Bay, Lake Erie and the St. Lawrence River. Instances of exceeding the guidelines for dioxins and furans in sport fish have also been reported from Peninsula Harbour 


\section{water cortinused}

FigURE 9.5B: AVERAGE CONCENTRATIONS OF DDT IN YOUNG-OF-THE-YEAR SPOTLAIL SHINERS, 1975-1991
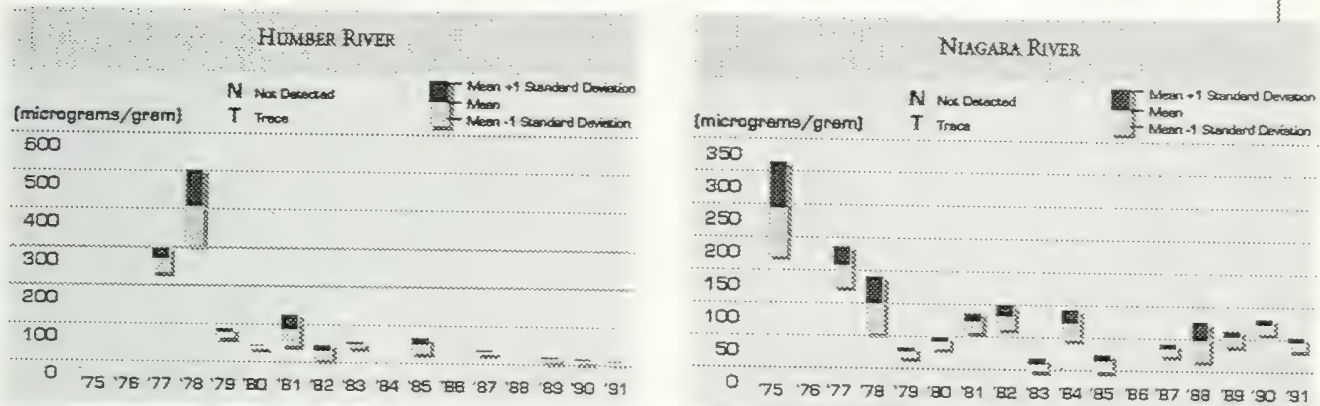

\section{KAM RNER}

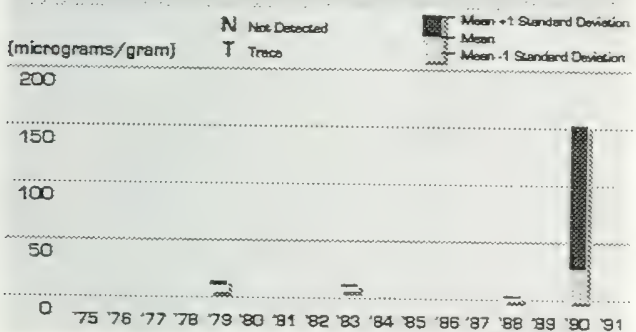

\section{PTEE CREEK}

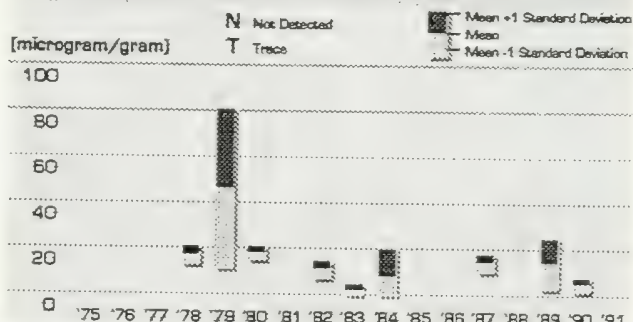

\section{LEAMABETON}

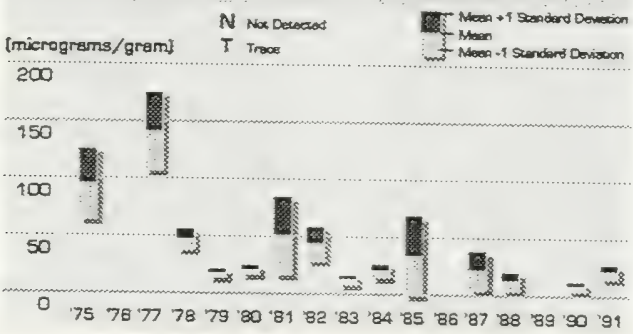




\section{water continued}

FIGURE 9.5C: AVERAGE CONCENTRATIONS OF CHLORDANE IN YOUNG-OF-THE-YEAR SPOTTAIL SHINERS, 1975-1991
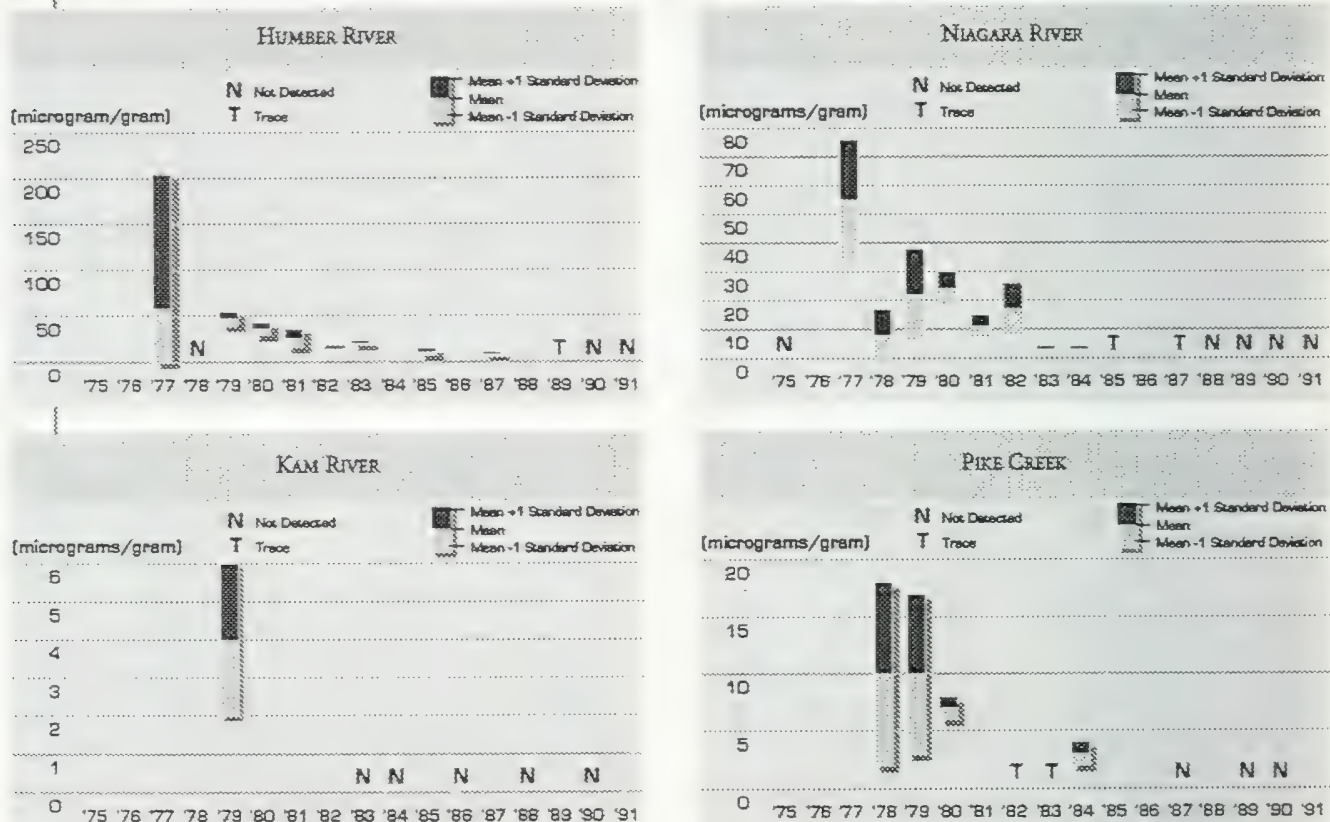

,

\section{LEAMINGTON}

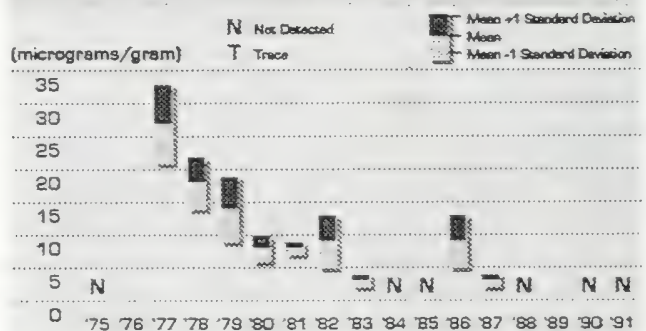


and Jackfish Bay in Lake Superior, from the southern part of Lake Huron and from Lake Ontario, especially the western end, where organic contaminant loadings are higher than anywhere else in the Canadian Great Lakes.

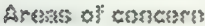

Concentrations of pollutants are usually heaviest in inshore areas, where they enter the lakes, but decrease rapidly offshore as the pollutants are diluted or settle to the bottom. Consequently, water quality in the open waters of the lakes is generally good. The serious problems tend to be found inshore, in the harbours and bays exposed to high levels of human activity and along the connecting waterways that join the lakes to each other.

In 1985, the International Joint Commission identified 43 areas of concern where pollution was serious enough to impair the water for human use or to cause serious ecosystem damage. Of the 43 areas, 12 are on the Ontario side of the lakes and five are located along waterways shared with the United States. These are not the only areas in the Great Lakes where environmental problems exist, but they are the ones in which the most serious and extensive problems have been identified so fat.

Typical problems, as shown in Table 9.2, include water that is unsatisfactory for recreational, agricultural, industrial, or domestic use, and sediments that are so contaminated that dredging and the disposal of dredged materials must be restricted. In addition, there is a wide variety of effects on wildlife and natural communities. Some of these effects have shown up in dramatic fashion as tumours in fish or as deformities in fish-eating birds and mammals. Others have appeared more subtly as shifts in the proportions or populations of various bot-
Figure 9.6: Total Concentrations of PCBS IN YOUNG-OF-THE-YEAR SPOTLAIL SHINERS, 1990-1991

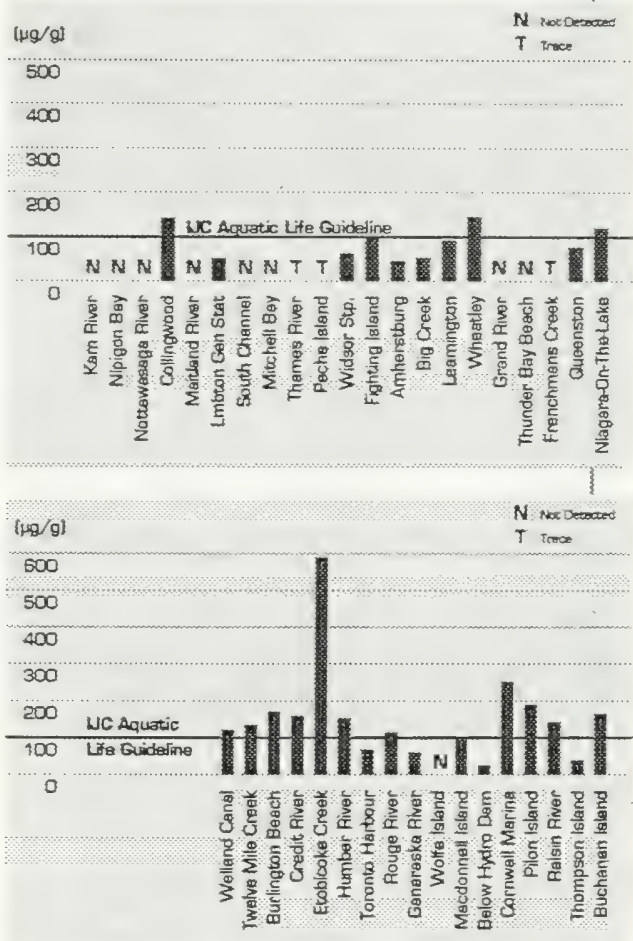

tom-dwelling (benthic) organisms. Loss of habitat due to shoreline development is also a common concern.

Most of these problems are related to continuing long-term sources of conventional and toxic pollutants. In a few areas, however, the problems are mainly the result of historical causes, as in the case of Collingwood where debris from former logging and shipbuilding activities had contaminated the harbour bottom. 


\section{water contimued}

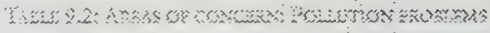

\begin{tabular}{|c|c|c|c|c|c|c|c|}
\hline $\begin{array}{l}\text { Area of } \\
\text { Concern }\end{array}$ & $\begin{array}{l}\text { Effects on } \\
\text { fistt. widdlife }\end{array}$ & $\begin{array}{l}\text { Contarrinated } \\
\text { sedirtents }\end{array}$ & $\begin{array}{l}\text { Eutrophication } \\
\text { excess algae }\end{array}$ & $\begin{array}{c}\text { Fish } \\
\text { consumption }\end{array}$ & $\begin{array}{l}\text { Habitat } \\
\text { Loss }\end{array}$ & $\begin{array}{l}\text { Drinking } \\
\mathrm{H}_{2} \mathrm{O} \text { quality }\end{array}$ & $\begin{array}{l}\text { Closed } \\
\text { beaches }\end{array}$ \\
\hline
\end{tabular}

iake Superior

Penirsuta Harbour

Jackfish Bay

Nipigon Bay

Thunder Bay

lake Huton

Coltingwrood Harbour

Severn Sound

Spanish Riter Harboar

Lake Exie

Whea tey Harbour

Lake Ontario

Hamititon Harbour

Metro foronto

Porf Hope

Bay of Quinte

Connecting channets

St. Afary's River

5. Clair River

Detroit River

Niagara Fiver

St. Lawrence River
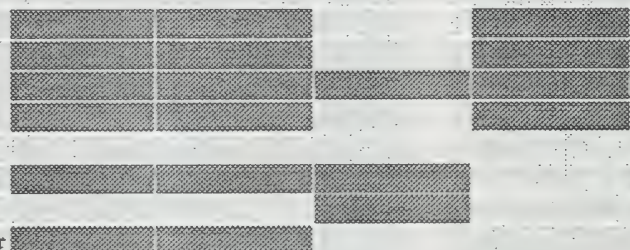

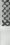
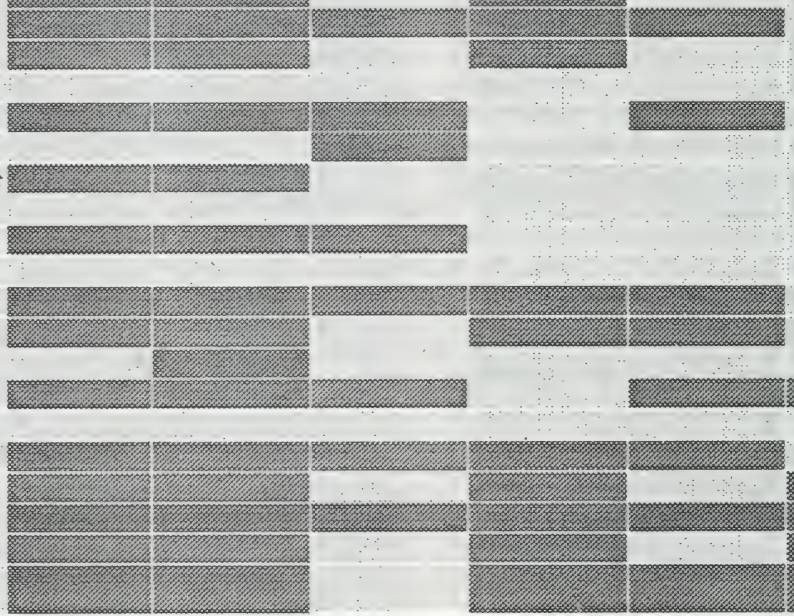

\section{ษndoing trise damage}

Since 1970 there has been a good deal of progress in reducing human stresses on the lakes. In addition to the reductions in phosphorus loadings and phase-outs or restrictions on the use of persistent toxic contaminants such as PCBs, organochlorine pesticides and mercury, substantial reductions have been made in discharges of many common pollutants. The pulp and paper industry, for example, reduced discharges of biochemical oxygen demanding materials from Ontario mills by more than 60 per cent between 1971 and 1990 (Figure 9.7). Similarly, since 1975, Ontario steel mills have reduced discharges of ammonia by 65 per cent per tonne of produc- tion and cyanide by 90 per cent, although they have not made the same progress in reducing discharges of oil and grease (Figure 9.8).

In the past, efforts at reducing pollutant loadings to the lakes have focused mainly on municipal and industrial point sources, and they continue to do so now. That is because they are usually easier sources to identify and control. Even with the gains that have been made so far, there is still room for improvement in controlling municipal and industrial discharges. Not all municipal sewage systems provide adequate treatment for chemicals like phosphorus and many of them cannot prevent the discharge of raw sewage during storms. And while 
many companies in the industrial sector have made enormous progress in pollution reduction, others have been less effective or consistent in their efforts.

A major effort to further reduce pollution from these sources is now being made through the province's Muricipal Industrial Strategy for Abatement (MISA). Initiated in 1985, MISA has been developing 'Clean Water' effluent quality regulations and guidelines and a monitoring program for municipal sewage treatment plants and major industries that discharge wastes directly into Ontario waterways. About 170 industries and nearly 400 municipal sewage treatment plants are involved in the MISA program and most of them discharge directly into the Great Lakes or waters flowing into them.

Although final Clean Water regulations are still under development for some industries, the program already appears to have had some effect on reducing pollution discharges. In 1985, two-thirds of the industrial dischargers failed to comply with their pollution limits at least once during the year. By 1991 , nearly half of the companies had no compliance failures. Overall, companies meet their monthly discharge limits for individual pollutants about 90 per cent of the time. Total discharges of pollutants from these companies have fallen from more than 1,600 tonnes per day in 1985 to about 1,400 tonnes per day in 1991.

Municipal sewage treatment plants also are improving their operating procedures and the quality of their eflluent. The performance of these plants is critical because they handle sanitary sewage from approximately $4,000,000$ households in the province as well as liquid wastes from more than 12,000 industrial establishments.

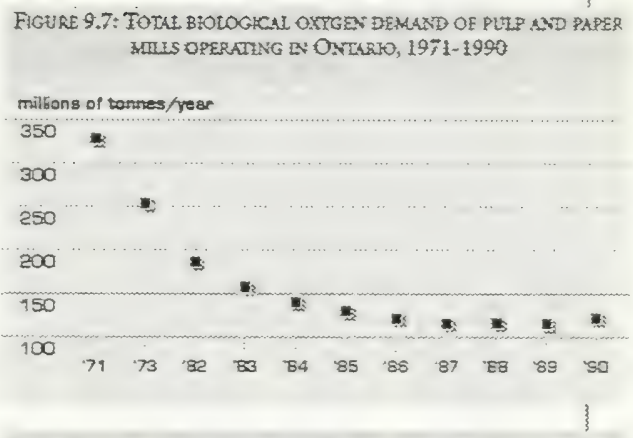

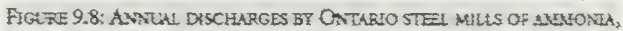
CANTDE, AND OLL AND GEEASE PER TONWE OF PRODECTON; 1975-1990

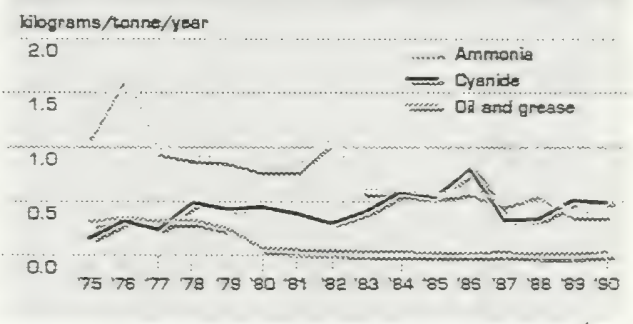

FACURE 9.9. PERCEATAGE OF SEVAGE TKEATMENT P:AATS EXCEEOTNC EFFUENT GUTDEIRES, 1986-1990

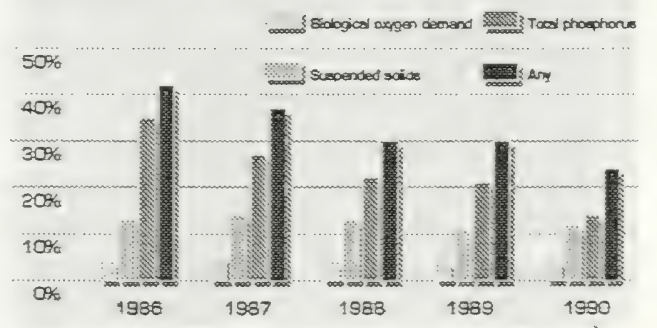




\section{water combinued}

In 1986,42 per cent of the plants involved in the program exceeded their effluent guidelines. By 1990, the proportion had dropped to 24 per cent. The greatest improvement has come in meeting guidelines for total phosphorus (TP). Instances of exceeding the guidelines in this category dropped from 35 per cent in 1986 to 14 per cent in 1990 (Figure 9.9).

Another line of attack in cleaning up the lakes is directed at the areas of concern. Remedial Action Plan teams (RAPs) have been set up in each of these to develop and implement plans for restoring water quality and habitat. The plans are being developed by federal and provincial agencies in close consultation with the local municipalities, industries, residents and others who have an interest in the area. In the case of sites on waterways shared with the U.S., the process also involves co-ordination and liaison with governments on the American side.

The effort required to clean up a particular area of concern depends on the complexity of the problems affecting it and the objectives the community wants to achieve. Complete remediation of an area could involve not only reducing polluting discharges from major point sources such as local industries and sewage treatment facilities but also reducing pollution from nonpoint sources such as farms and urban areas in the surrounding watershed. In addition, contaminated sediments might have to be removed to prevent the resuspension or recycling of pollutants, and measures taken to restore fish and wildlife habitat. Before any of this can be done though, a detailed assessment of environmental conditions and possible solutions has to be carried out.

Hamilton Harbour is an example of what can be accomplished. For most of the present century it has been one of the most heavily stressed and degraded water bodies on the Canadian side of the Great Lakes.
With the second largest cargo tonnage of any Canadian port on the lakes, the largest concentration of heavy industry in the country, and a population of more than 600,000 people, the harbour receives very large discharges of industrial and municipal wastes, large volumes of urban runoff and spillage from the loading and unloading of ships. Development along the shoreline has also been destructive, eliminating about 75 per cent of the bay's original wetlands and destroying the nursery for what, at the tum of the century, had been the largest fishery on Lake Ontario.

Remediation efforts have been underway since 1970 and have been part of the RAP process since 1986. These have focused largely on point sources. Hamilton's two large steel companies, for example, have installed treatment facilities for removing contaminants such as chromium, ammonia, cyanide, oil, phenols, and solids, while the Regional Municipality of Hamilton-Wentworth has installed holding tanks to prevent the discharge of raw sewage during storms from its sewer system.

As a result of these and other efforts, provincial water quality objectives are now being met in most areas of the harbour. Populations of gulls, herons and cormorants, seriously threatened by reproduction problems in the 1970s, have rebounded dramatically. In 1993, for the first time since the 1940 s, swimming was permitted (at two locations) in the harbour.

Yet, in spite of these improvements, there is still a distance to go before the harbour is fully restored to health. Eutrophication remains a problem and nuisance growths of algae are still abundant. Contamination of sediments, mostly from past industrial discharges, is a major problem. The fish population is stable but still carries large accumulations of toxic substances and is dominated by species, such as carp, that can tolerate low 


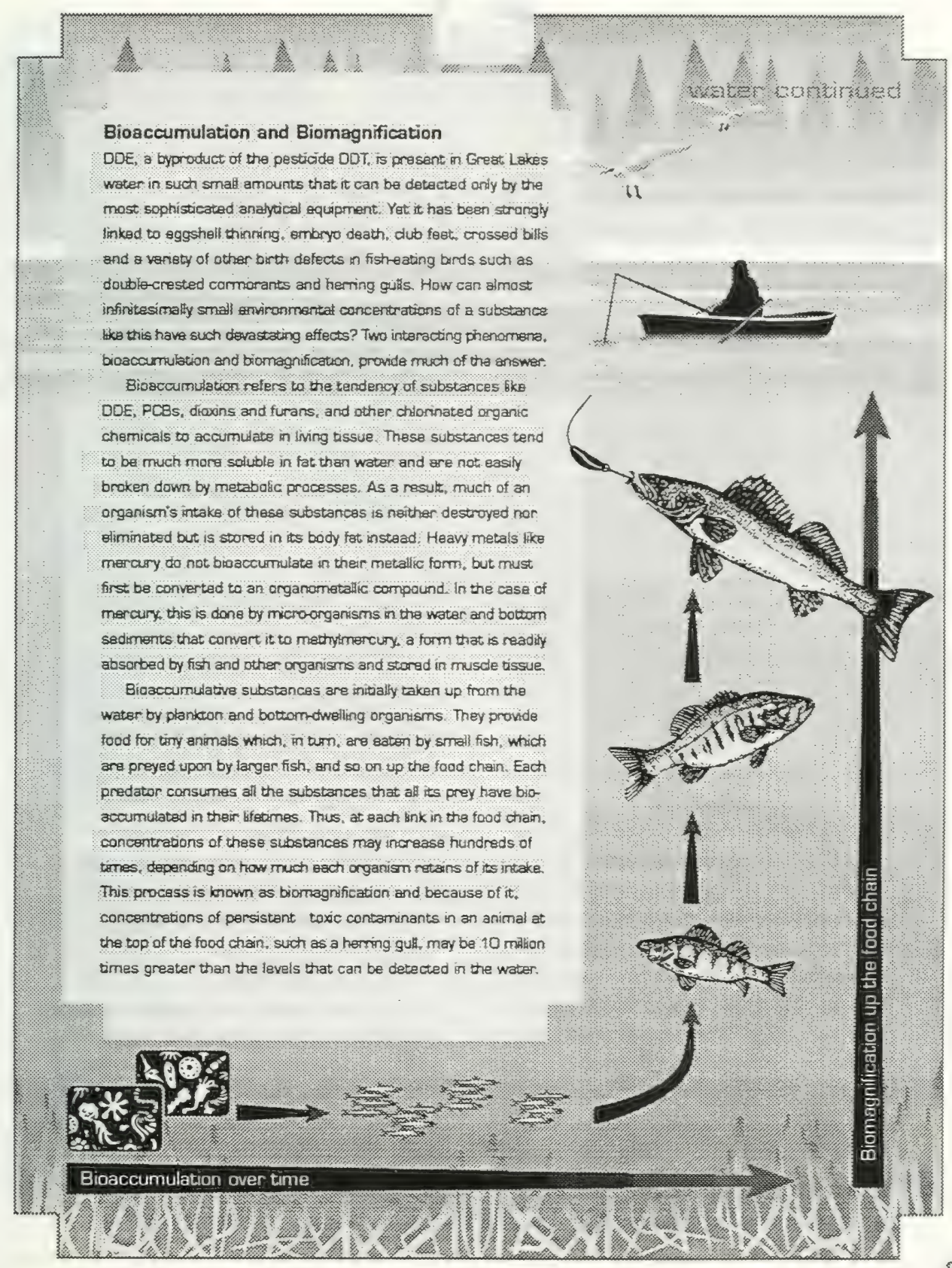




\section{Water contrimued}

oxygen and turbid water conditions. Zebra mussels are also well established in the harbour. Dealing with these problems will require further reductions of pollution loadings, especially from municipal sewage systems, removal and/or stabilization of contaminated sediments and restoration of fish and waterfowl habitat.

Improving Hamilton Harbour to its present condition has already cost close to half a billion dollars. About 80 per cent of this has been spent by industry, and most of the rest by local municipalities. It is estimated that remaining improvements will cost a similar amount, most of which will be required for further improvements to the sewage systems that discharge into the harbour.

Important progress has also been made in a number of other RAP areas, such as Collingwood and Severn Sound. By the end of 1993, Hamilton, Collingwood, Severn Sound and the Bay of Quinte had submitted detailed remediation plans to the provincial and federal governments and the remaining sites are expected to follow suit before the end of 1996. In many areas, however, it will take several years before all of the recommended actions can be completed and the aquatic environment restored to a reasonably healthy state.

In looking at the condition of the Great Lakes system as a whole, it is important to recognize how much progress has been made. The lakes are in substantially better condition than they were 25 years ago and further improvements can be expected. But it is also important to recognize that the gains that have been made so far are only partial solutions to some very large and complex problems. The challenges that remain - particularly the problem of persistent toxic contaminants - are very daunting. Restoring and protecting water quality in the Great Lakes will remain an environmental priority well into the next century.

\section{CHAPTER 10 GROUNDWATER}

When Ontario's freshwater resources are considered, its abundant rivers and lakes come first to mind. But, in fact, much more of the province's water is to be found beneath the surface, as groundwater.

About 2.8 million Ontarians - more than a quarter of the province's population - get their water from the ground. Many of them live in the country and draw their water from private wells, but more than half live in towns and cities, including larger centres such as Kitchener, Waterloo, Guelph and Woodstock, where water comes from municipal wells . Altogether, it is estimated that there are more than 500,000 wells in Ontario, and between 14,000 and 22,000 new ones are being added every year.

Apart from being used for drinking and household purposes, this water is used for irrigation, livestock watering, fish hatcheries, swimming pools and a variety of commercial and industrial purposes.

In addition, groundwater is an important source for replenishing surface vaters. On average, about 20 per cent of annual streamflow comes from groundwater. In some areas, this may be as high as 60 per cent and in summer and early fall, when surface flow diminishes, some streams may be fed entirely by groundwater.

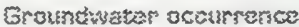

Groundwater is found in geological formations that were created thousands, even millions of years ago. It is replenished mainly by precipitation and snowmelt that percolate down through the soil. It occurs in two layers. The upper layer, the unsaturated zone, contains liquid water as well as water vapour and air. The lower layer is the saturated zone, or the groundwater zone, and here 


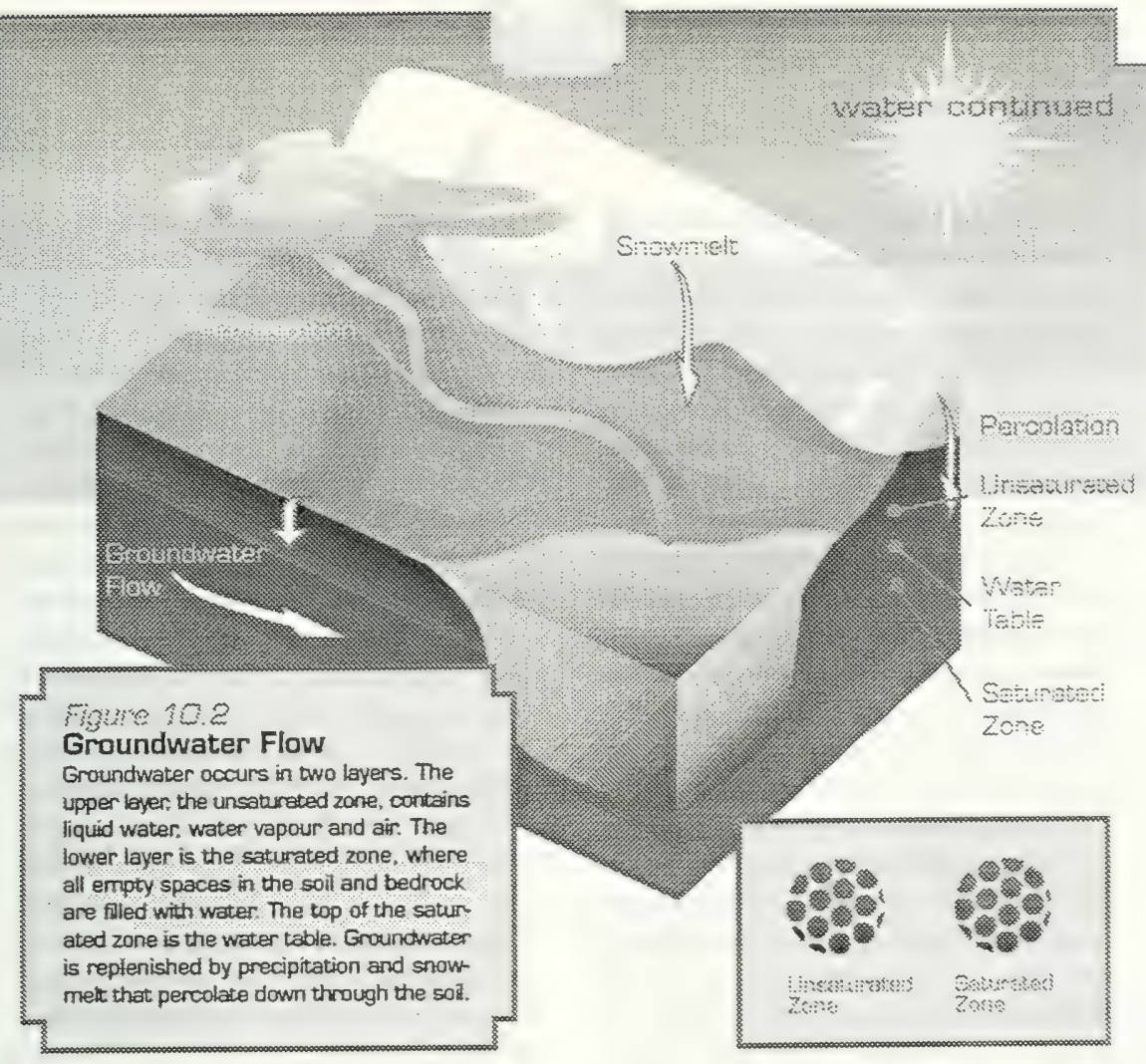

all empty spaces in the soil and bedrock are filled with

Geological formations that can store and transmit a water. The top of the groundwater zone is the water table and may lie anywhere from a metre to more than 50 metres below the ground, depending on the geology of the area, the season and local precipitation conditions. Groundwater eventually returns to a stream, lake, or ocean, but it flows slowly and it may take hundreds to thousands of years before some of this water returns to the surface and enters the next phase of the water cycle large amount of water are known as aquifers. These may be small formations limited to an area of a few hectares or they may be quite extensive, covering several hundreds or thousands of square kilometres. Coarse gravel and sand make a particularly good aquifer that can yield a plentiful supply of pure water. Silts give up their water more slowly and clay acts as a barrier to the movement of water.

(Figure 10.1) 


\section{water continued}

The natural quality of groundwater is very much influenced by geology. Frequently, minerals in the aquifer or in surrounding formations may affect the colour, flavour, smell, or hardness of the water, though without necessarily affecting its suitability for drinking. In some cases, though, the water may be of naturally poor quality and unfit for human consumption. Excessive levels of metals such as arsenic, cadmium, nickel, lead, copper, zinc, and uranium sometimes occur in groundwater in parts of northern Ontario. In parts of southwestern Ontario, groundwater can be contaminated by hydrocarbons from oil and gas deposits, while in the south and southeast salt and saltwater deposits occur naturally.

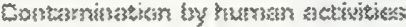

Compared to surface water, groundwater is less susceptible to contamination. Nevertheless, it can become contaminated by human sources. Once this has happened, the aquifer may remain contaminated for centuries. With present technology, cleanup is difficult and sometimes impossible Frequently the best that can be done once groundwater has been polluted is to prevent the contamination from spreading.

In farming areas, there is potential for groundwater contamination from fertilizers, pesticides, manure, petroleum products and milkhouse wastes, which can result in high levels of nitrate, bacteria and toxic chemicals in the water supply.

Septic sewage systems are another potential source of nitrate and bacterial contamination. There are approximately one million private septic systems in Ontario and many of these are now 20 to 30 years old and reaching an age when they will be more likely to malfunction.
Groundwater in some communities has been damaged by leakage from underground fuel storage tanks at gas stations and other sites. In most of these cases, the contaminated aquifers have been small and fewer than a dozen homes have been affected, but cleanup costs have still ranged from rens of thousands to hundreds of thousands of dollars.

In the mining country of the north, hundreds of deep boreholes are drilled every year in search of minerals. These are left open when they are finished and provide a route by which contaminants can penetrate deep underground. In the southwest, old, improperly abandoned oil wells provide pathways by which briny, petroleum-contaminated water can enter freshwater aquifers.

Road salt is a problem in many parts of the province. Approximately 1.4 million tonnes of it are spread on Ontario's roads and highways every year Some of this eventually seeps into the groundwater and raises its chloride content to unacceptable levels. The Ministry of Environment and Energy investigates about 200 cases of road salt contamination a year.

Both municipal and industrial landfills are a possible source of groundwater pollution, but those currently in use are subject to strict controls and the risk from them is slight. Spills and leaks from industrial storage tanks and production facilities, however, are still occasionally the cause of major incidents of groundwater contamination.

One such case came to light in 1989, when it was discovered that the groundwater supply for the town of Elmira had been contaminated with $\mathrm{N}$-nitroso dimethylamine (NDMA) that had leaked from a local chemical plant. 


\section{water continued}

Other incidents of contamination by toxic chemicals have occurred at Smithville, where the groundwater has been contaminated with PCBs, and, more recently, in Manotick, where 74 wells serving 200 to 300 homes and businesses were found to contain perchloroethylene, a dry cleaning solvent that had leaked from a storage tank at a dry cleaner's shop.

Dealing with such incidents is expensive. The pollution source must be identified and the contaminants tracked, contained and, if possible, cleared up. In addition, bottled water and filtration units must be supplied until the original water supply can be cleaned up or an altemative supply established. An interim water supply for Manotick is expected to cost in the vicinity of $\$ 5$ million. To date, $\$ 15$ million has been spent in Smithville and costs in Elmira could go as high as $\$ 50$ million.

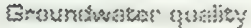

Groundwater is not monitored systematically throughout the province. Consequently, much of the information that we have about groundwater quality comes from complaints that MOEE has been asked to investigate. The ministry deals with about 2,000 of these cases every year. The problems vary from region to region, but the most important involve contamination by agricultural chemicals and wastes, road salt, toxic chemicals, and industrial wastes (Figure 10.2).

The number of complaints is relatively small about one for every 250 wells in the province - but, unfortunately, complaints only serve as an indicator of problems that have already been recognized or suspected. Obviously, there are other cases in which water quality has been impaired but has gone undetected
Some valuable information about the effect of agricultural practices on groundwater quality comes from a recent survey of well water from 1,300 Ontario farms. Carried out between October 1991 and March 1992, the survey sampled each of the wells for common agricultural contaminants: nitrate nitrogen, total and faecal coliform bacteria, and pesticide and herbicide residues. Tests for petroleum contaminants were also carried out at 160 of the sites.

The results showed that 37 per cent of the wells contained one or more of these contaminants at concentrations above the provincial drinking water objectives. Thirty-one per cent exceeded the maximum acceptable level for coliform bacteria and 20 per cent had faecal coliform bacteria. More than 13 per cent exceeded the maximum acceptable concentration for nitrate. Eight per cent of the wells had detectable levels of pesticides and one well exceeded the interim maximum acceptable concentration. No petroleum-based contaminants were detected in any of the 160 wells tested. A follow-up study in the summer of 1992 produced a similar pattern of results but showed a slightly higher percentage of contaminated wells in most categories.

The surveys indicate that unsuitable well location, improper well construction, or poor well maintenance were the causes of well contamination, in the majority of cases. The surveys, however, do not provide evidence of widespread aquifer contamination in rural Ontario. 


\section{water eancingues}

\section{FIGURE 10.2: GROUNDWATER COMPLAINT INVESTIGATIONS BY REGION}
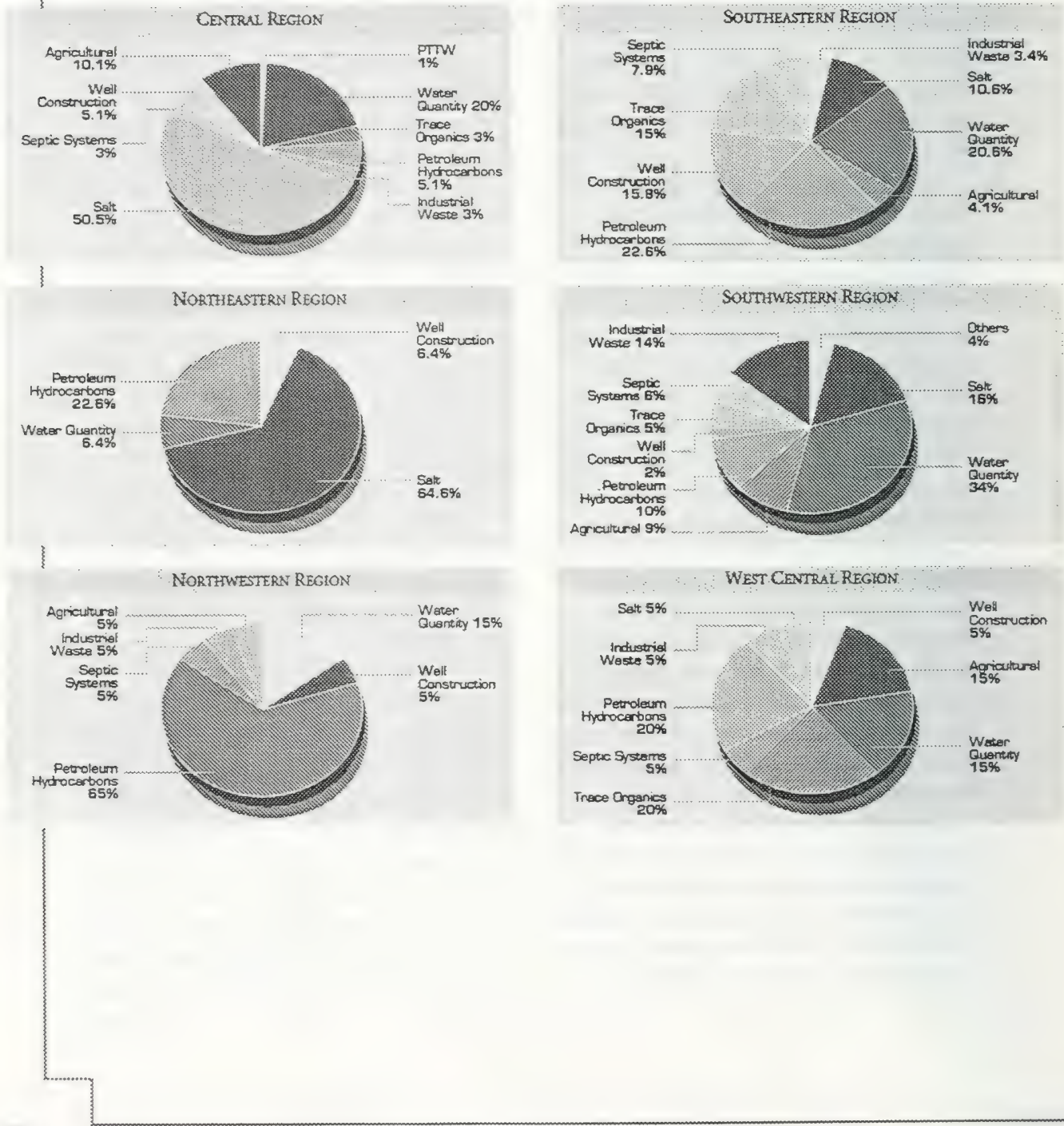
Grounduater: is there staugh 70 co around?

Although Ontario has plenty of groundwater, from the point of view of the user, not all of it is in the right place or of the right quality. Consequently, some aquifers must meet very heavy demands for usage. In some cases, water is drawn off faster than it can be replenished, the water table drops and some wells may go dry. This situation is known as aquifer mining. Water quantity problems are fewest in northeastern Ontario but make up 15 to 20 per cent of the complaints investigated in most other parts of the province. In southwestem Ontario, water quantity problems account for 34 per cent - the largest single category - of the complaints investigated (Figure 10.2).

Apart from natural causes such as decreased precipitation, water quantity problems may arise because of increased demand, improved surface drainage and paving and house construction. Heavy pumping may temporarily dewater the area around the well. Less commonly, the supply may be diminished because of mining of the aquifer by large users or disruption of the groundwater flow by quarrying operations.

To prevent supply interference due to high-volume pumping and aquifer mining, the province requires anyone taking more than 50,000 litres of water a day to obtain a Permit to Take Water (PTTW), except where the water is for private domestic and livestock use. The PTTW program promotes the efficient development and fair sharing of water in Ontario. Before a permit is issued, the applicant has to submit to MOEE all the necessary information and supporting documents. Variables of water availability and water use are considered by the ministry as factors which would place limits on the terms and conditions of the permit. Failure to comply with the terms and conditions can result in the cancellation of the permit.

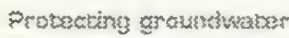

As Ontario's population expands, so will the demand for its groundwater and so too will the risks of contaminating it. Improved ability to manage this increasingly vulnerable resource will be needed to protect it.

Muricipalities have a role in protecting groundwater through their planning procedures. Individual well owners also have a particular role in the management of this fragile resource, through the proper application of construction, maintenance and abandonment procedures.

One of the most pressing needs at the moment is for more information about the state of the resource. To provide this, the ministry is now taking preliminary steps towards establishing a provincial Groundwater Quality Monitoring Network. Further information about water quality will become available as a result of improvements to the ministry's Water Well Information System. This computerized database, which has been in operation since 1972, describes the location and physical characteristics of approximately 400,000 water wells in the province.

With better monitoring and data collection, the ability to observe changes in water quality over time and to detect contamination problems at earlier stages should gradually improve. Better information also will increase the ability to identify those aquifers that are most vulnerable to pollution, so that they can be protected against inappropriate land uses. 


\section{water contratued}

In addition to preventing contamination, further research, particularly into methods of decontamination, will add to the capability to deal with contamination when it does happen.

Ultimately, protection of groundwater depends on the actions and support of an informed public.

\section{CHAPTER 11}

\section{WATER AND THE INDIVIDUAL}

Whether people drink it, swim in it, or eat the fish that live in it, water has the potential to transmit disease and harmful chemicals. In the more populated parts of the province, lakes and rivers are exposed to pollution from many sources - industries, farms, roads and highways, sewage systems and the air. Even in remote areas, surface waters may contain bacteria or parasites from wildlife.

Figure 11.1: Resiets of DrRKanc Water SURVEY, 1985-92

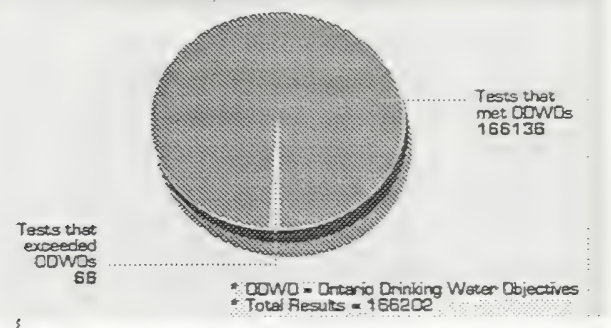

\section{TESTS THAT EXCEEDED ODWOS}

$$
\text { Furoride } 1
$$

Turbidity

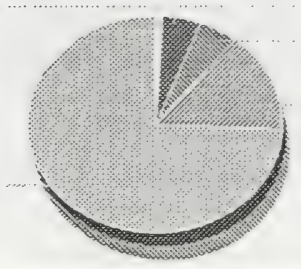

3 Chromium

Trinalo methanes 3 Nitrate
Groundwater is less susceptible to pollution but, as has been already seen, it is by no means invulnerable.

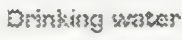

There are almost 500 municipal water supplies in the province. Of these, about 200 use surface water and the rest use groundwater as a supply source. Surface water generally has to be treated before it can be considered safe for drinking. In municipal water supplies, this is commonly done through the use of chlorine to disinfect the water and aluminum sulphate to clarify it. The water may also be treated to improve its taste or appearance and to control other characteristics such as corrosiveness and hardness that might limit its use or interfere with the distribution system.

Municipal tap water is tested regularly for bacteria to ensure that it is microbiologically safe to drink. In addition, the quality of municipal water supplies has been closely monitored by the Drinking Water Surveillance Program (DWSP) since 1985. The DWSP monitors as many as 180 substances and has produced more than two million analysis results since its inception. As of 1992, 109 municipal water systems serving about 80 per cent of the population are involved in the program, which will eventually include all municipal water supplies in the province.

Water quality is judged by comparing the program's monitoring results with the limits set out in the Ontario Drinking Water Objectives (ODWOs). The ODWOs specify acceptable levels for more than 100 substances or characteristics, including bacteria, chemicals, metals, and radioactive materials. Test results are passed on to local authorities, who can take remedial action if any of the levels exceed a health-related limit. 
So far, testing has shown the treated water supplies of the participating municipalities to be very safe, both bacteriologically and chemically. Between 1985 and 1992 , for example, more than 165,000 analyses of health-related criteria were carried out, but only 66 instances of exceeding the drinking water objectives were reported (Figure 11.1). During the same period, close to 350,000 tests were carried out for an additional set of more than 90 potentially harmful chemicals, including pesticides, polyaromatic hydrocarbons, volatile organic compounds and chlorinated organic compounds. The test results showed the presence of 36 of these chemicals in about three per cent of the samples, but all at very low concentrations (Figure 11.2).

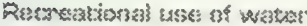

Swimming in bacterially contaminated waters increases the risk of contracting ear and eye infections and gastro-intestinal diseases. According to provincial guidelines, water is unsafe for swimming if the average faecal coliform density is greater than 100 organisms per 100 millilitres $(\mathrm{mL})$ or if the total coliform density exceeds 1,000 per $100 \mathrm{~mL}$.

In the more populated areas of southern Ontario, these levels are often exceeded in many localities and commonly result in the closing of beaches by health authorities (Figure 11.3). In many cases the problem is a consequence of sewage systems being overloaded during heavy rainstorms and conditions generally improve within a few days.
FICHRE 11.2: RESULTS OE ANALXSES OE DRANITNG WATER FOR 57NTHETIC ORGAMIC CONTAMINLNTS AND PESTIDIDES, 1985- 1992
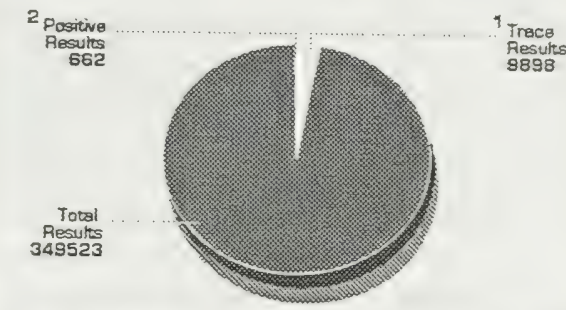

A trece result is a vake so low thet ic cannot be confidently meesurad

2 A positive resuk shows that a substance is present above trace levels and can be confidanty maesured.

\section{FiguRE 11.3: BEACH CLOSURES, 1986-90}

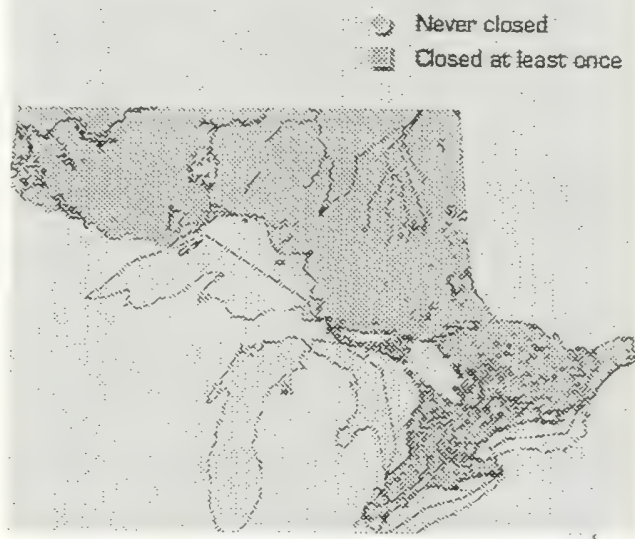



Since the 1970s, new regulations and improved waste maragement practices have been devised to control the growing output of waste and its impact on the environment. These practices are based on a hierarchy of disposal options, with the highest priority going to the reduction, reuse and recycling of waste that minimize disposal requirements.

As a relatively prosperous, mass production, mass consumption society, Ontario is a large producer of waste. During the last 30 to 40 years, its potential for waste generation has been augmented by the profiferation of a wide array of disposable convenience products, from coffee cups and diapers to printer ribbons. Paclaging, which has become increasiagly attractive both as a marketing tool and a labour-saving device, has also added to the waste stream. In addition, consumer demand for a steady flow of new products hastens the obsolescence, and the disposal, of the old.

Wastes in Ontario are divided into two major streams: solid non-hazardous waste and hazardous and liquia dindustrial waste Solid non-hazardous wastes do not require special treatment or handing. Hazardous and liquid industrial wastes, on the other hand, must have special handling to be disposed of safely. The chapters in this section examine each of these major streams.

\section{CHAPTER 12 SOLID NON-HAZARDOUS WASTE}

Solid, non-hazardous waste is what we usually think of as garbage. It includes not only kitchen waste and other household refuse but also wastes from industries such as manufacturing and construction, businesses such as stores and restaurants and institutions such as schools and hospitals. In 1987, all these sources in Ontario disposed of an estimated 8.9 million tonnes of garbage, or about one tonne a year for each person in the province.

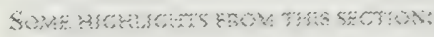

- In 1987, Ontario generated one tonne of waste per head of population. By 1992 this had been reduced by 25 per cent, to three-quarters of a tonne per head.

- Blue Box recyling now serves more than 3.2 million houses and apartments in the province and is regutarly used by 90 per cent of the Ontario residents it serves. In 1992 , bhite boxes diverted 431,000 tonnes of waste from tandfills.

- By the end of 1997, more than 800,000 home composters had been distributed in Ontario. Afore than 100 communities now offer central composting of leaf and yard waste.

- Ontario needs to increase its capacity to haulde hazardous wastes. Because of fimited dipposal capacity, the quantity of PCB wastes in storage has increased dramatically. At the end of 1992 , there were 1,751 PCB storage sites in Ontaria.

- Ontario is atso sending more of its tazardous and liquid indust ral wastes for out-of-prorince disposal. Eetween 1987 and 1992, the proportion of hazardous and liquitd industrial waste being exported grew from about five per cent to 17 per cent

- Overall, the anount of hazardous and liquid industrial waste being recycled has remained steady brof new programs have dramatically increased the amount of household hazardous wastes being diverted from landfills. Between 1986-87 and 1992-93, the diversion rate of hotsehold hazardous wastes increased from less than 50 tonnes per year to more than 1,600 tonnes. 
Disposing of that amount of material without harming the environment or endangering human health adds up to an enormous challenge and meeting it is demanding new and innovative approaches to waste management.

\section{Lu3nd}

Traditionally, most waste materials have been disposed of in landfills; most still are today. This method has the short-term advantages of cheapness and convenience. However, as old landfills reach capacity, new landfill space is becoming harder and more expensive to obtain. Many communities are reluctant to have landfills within their boundaries and the costs of geological, engineering and other studies are increasing as the assessment of environmental impacts becomes more detailed. Landfills also use up increasingly scarce land that could be used for other purposes, such as farming, building, recreation, or as a wildlife habitat. As well, there are the nuisances of odours, dust, unsightliness and scavenging birds and animals.

Landfills produce a certain amount of leachate, or polluted water, that forms as rainwater trickles down through the decomposing garbage and absorbs contaminants from it. If the soil surrounding the landfill is permeable, the leachate may drain into nearby ground and surface waters, making them unfit for drinking or perhaps contaminating the food chains they support.

Landfills also produce methane gas as buried organic matter decomposes in the absence of oxygen. Other gases may be produced as well, including carbon dioxide and small amounts of toxic volatile organic compounds (VOCs) such as benzene and toluene. Apart from the danger of a methane explosion, these gases also contribute to atmospheric pollution and global warming. Landfill sites account for about 35 per cent of all methane emissions in Ontario.
To control these problems, the provincial government began regulating landfill sites in 1971. These regulations require close attention to local geological details in choosing a site so that the chance of groundwater pollution and other potential environmental effects will be minimized. The site must also incorporate features for the control of leachate and gases and steps must be taken when the site is finally closed to ensure that it remains harmless.

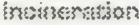

Incineration has been the most common alternative to landfilling. It reduces waste to a fraction of its former volume and also produces heat that can be used to warm buildings or produce electricity. But incineration is also a source of common air pollutants, such as carbon monoxide and carbon dioxide, and acid gases, such as sulphur dioxide, hydrogen chloride and nitrogen oxides. In addition, it may release a variety of toxic substances into the atmosphere, such as heavy metals, dioxins and furans, benzene and other dangerous organic compounds. Modern incinerator technology can reduce these toxic emissions to very low levels, but it cannot eliminate them entirely.

A further difficulty is that incineration still leaves a residue, in the form of ash, that must be landfilled. Incinerator ash can amount to as much as 30 per cent by weight of the original waste and it is usually contaminated with heavy metals and other toxic residues. These come either from toxic materials already in the waste stream or are produced by chemical reactions during combustion. In many cases, incinerator ash must be treated as toxic waste.

Incineration is no longer widely used as a disposal option in the province. Apartment building incinerators were phased out in 1989 and the province banned the 
construction of new municipal solid waste incinerators in September 1992. Incineration is still preferred for the disposal of some biomedical and hazardous wastes, however, because it is the safest and most effective way of dealing with them.

As the use of incineration decreases, landfilling is the local disposal option for most communities.

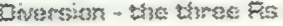

To lessen the need for landfilling or incineration, modem waste management practices are placing more and more emphasis on diverting waste from disposal. A quick look at what typically goes into the waste stream (see Who Throws Out What) shows just how much potential there is for reducing the amount of waste that must finally be disposed of Much of what we discard consists of things that either did not have to be used at all (like some forms of packaging) or that can be used again - for their original purpose, another purpose, or as raw material for making something else.

The principal methods of diverting waste from disposal - familarly known as the three Rs - are reduction, reuse and recycling. As well as saving valuable disposal space, these methods also offer significant savings in the use of energy and natural resources. In some cases they can provide important financial benefits by treating waste as a resource.

Reduction is the first choice because it promotes efficiency in the use of resources, and eliminates the need for any additional handling of materials. It can be accomplished through means such as eliminating unnecessary packaging or redesigning products so that they use fewer raw materials and offer greater durability.

Reuse extends the life of a product or materials beyond a single use. Refillable pop bottles are a familiar example, as are rebuilt toner cartridges for photocopiers and printers. Many people also reuse their shopping bags. While providing savings in raw materials and energy for manufacturing, reuse can involve some additional costs if the product has to be cleaned or refurbished before being used again.

Recycling involves treating waste as a resource from which new products can be made. Many of the most common materials in the municipal waste stream, such as paper, plastic and glass, can be handled in this way. For all its merits, though, recycling is not as efficient as either reduction or reuse. It involves additional collection and handling costs, requires some consumption of energy (though usually not as much as manufacturing the same product from primary materials), and may itself generate some wastes (as in the case of de-inking sludges from the recycling of printed paper). However, it is a practical way of keeping some items, such as newspapers, out of landfills.

Recycling also depends on a demand for products made from recycled materials and on the ability of manufacturers to make them at competitive prices. Recognition of the benefits of recycling has gradually created widespread public acceptance and strong demand for many different types of recycled papers, for example, but until the opening of two new de-inking plants in 1990 , the supply of waste paper in Ontario often exceeded the capacity to process it As a result, paper intended for recycling occasionally ended up in landfills or was exported.

Markets for waste paper, glass and plastic are now maturing and at the moment the demand for these materials exceeds the supply. However, the market for waste glass is potentially fragile, as there is only ore glass recycler in the province. 
FIGURE 12.1: MATERTALS RECTCTFE THROUKCH THE BUUE BOX RROGRAM 1992

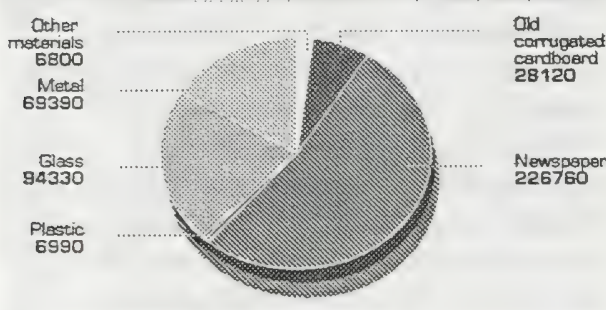

Tannes of waste diverted

3.

FIGURE 12.2: NUMBER OF HOUSEHOLDS WHTH ACCESS TO THE BLUE BOX SYSTEM IN ONTARYO, 1986-1992

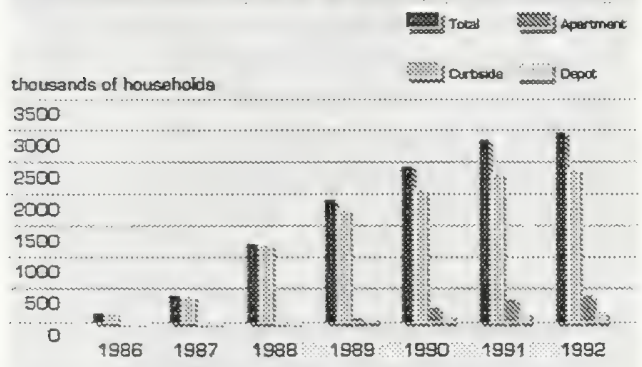

Sourcec Entario MitotMatarial Fecycking lne

Residential recycling is carried out primarily through the Blue Box program, although central recycling depots are also available in some communities. The system provides for the collection of such common waste items as newspaper, magazines, glass conitainers, metal cans, polyethylene terephthalate (PET) soft drink containers and rigid plastic (HDPE or high density polyethylene) bottles (Figure 12.1).

Since its introduction in Kitchener in 1983, the Blue Box program has spread to more than 500 municipalities and now serves more than 3.2 million householders and apartment dwellers (Figure 12.2). The system is used regularly by 90 per cent of the people it serves. Only about three to five per cent of the waste collected is unmarketable and has to be sent for disposal.

Composting is another variety of waste reduction, suitable for organic wastes such as vegetable scraps and garden waste. So far, more than 800,000 home composters have been distributed by municipalities, with financial assistance from the Ministry of Environment and Energy's Municipal Reduction/Reuse Program. A recent study estimates the cost of managing wet waste by home composting at between $\$ 30$ and $\$ 40$ per tonne, which is considerably cheaper than today's landfill fees.

Collection and central composting of leaves and yard waste were offered as well in more than $100 \mathrm{com}$ munities in 1992. Some are also looking into more extensive programs, with curbside pickup and central composting of both kitchen and yard wastes. The city of Guelph plans to have such a program operational by the end of 1994 while the county of Northumberland has a similar program under consideration.

In the industrial sector, recycling has been a common practice in some industries for years. Printers, for example, have traditionally resold their waste paper to mills for pulping and wreckers' yards have turned discarded motor vehicles into scrap metal and parts since the earliest days of the automotive industry. Many other businesses, though, saw little value in such practices.

This attitude changed in the $1980 \mathrm{~s}$, however, in response to growing public awareness of the problems of waste disposal. Many companies, and public institutions as well, came to see waste reduction and recycling as a mark of good corporate citizenship. Many of them also found they could save money by using resources more efficiently and reducing their waste disposal costs or by 


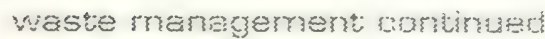

using their waste as a resource. In addition, initiatives such as the establishment of the Ontario Waste Exchange in 1978 have played a critical role by greatly expanding the market for industrial and commercial wastes.

Another initiative that is expected to make an important difference is the National Packaging Protocol (NAPP). Packaging such as bottles, cans, boxboard, plastic wrap and pallets makes up about a fifth of Ontario's waste stream. By the year 2000, NAPP aims to have reduced these wastes to 50 per cent of their 1988 levels. Interim targets of 20 per cent and 35 per cent have been set for 1992 and 1996.

In the early 1990 s, a number of municipalities also took further steps to encourage recycling by closing their landfills to some of the more common types of commercial and construction waste, such as wood, drywall, construction rubble, corrugated cardboard and office paper. Several municipalities also greatly increased tipping fees for companies and institutions using their landfills.

These measures have not always had the desired effect, however. Taking advantage of the removal of American regulations forbidding the importation of waste, a number of companies are now exporting their waste to cheaper and less restrictive landfills in the United States. Approximately 1.3 million tonnes of waste were shipped to American landfills in 1992.

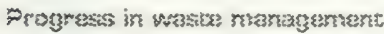

Through its Waste Reduction Action Plan, Ontario is attempting to cut the amount of garbage disposed of per person to 50 per cent of the 1987 level by the year 2000. So far, the per capita disposal rate has been cur by 25 per cent, from one tonne per person in 1987 to 0.75 tonnes in 1992.

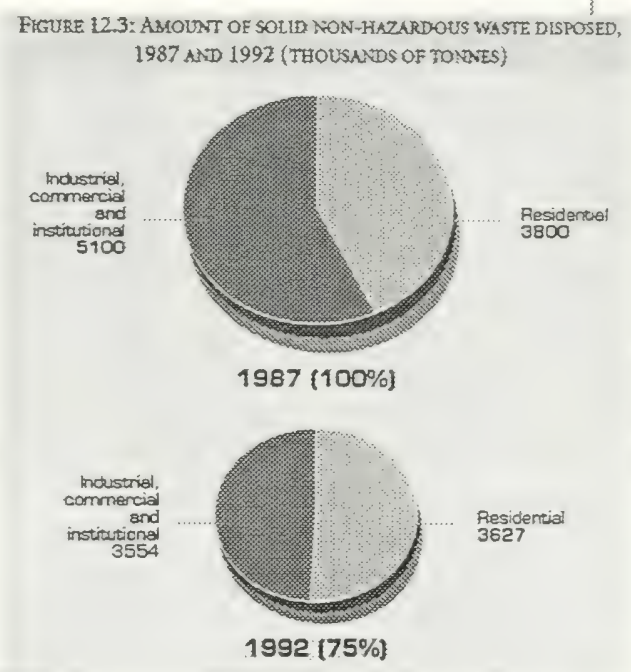

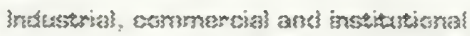

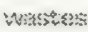

As Figure 12.3 shows, the biggest reduction has been in industrial, commercial and institutional wastes. In the mid-1980s, this category made up nearly 60 per cent of the total volume of solid, non-hazardous wastes. By 1992 it accounted for only 49 per cent of the total A significant part of these reductions has come from a decrease in packaging. In addition, voluntary waste reduction initiatives in the private sector have been very effective and are estimated to have diverted at least 600,000 tonnes of waste in 1992 alone. However, the economic slowdown of the early 1990 s has undoubtedly also made a contribution to waste reduction. 


\section{waste maraçernent contimues}

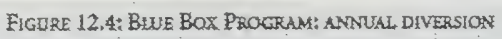

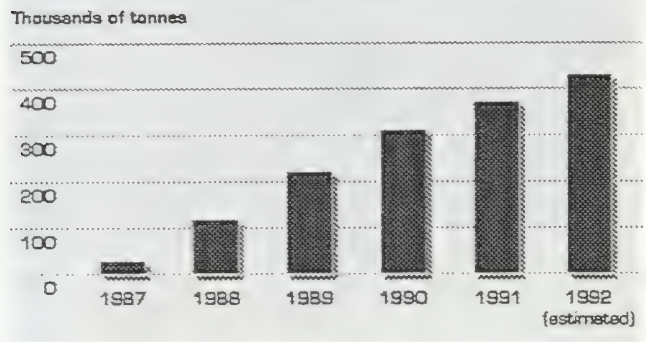

\section{Residential พyastes}

With the expansion of Blue Box services, the amount of residential waste diverted from landfills has increased considerably. Since 1987, the amount collected through the program has risen from 29,000 tonnes to more than 431,000 tonnes, and the program now handles more than 10 per cent of all residential waste (Figure 12.4).

Composting is also beginning to show appreciable results in the diversion of wet or compostable wastes. A 1989 study estimated that about 1.88 million tonnes of wet waste were produced in the province, with households accounting for about two-thirds of the total. In 1992, it was estimated that composting diverted at least 300,000 tonnes of wet waste, or about 16 per cent of the 1989 amount.

\section{รื้ฉs}

Vehicle tires remain one of the most difficult wastes to deal with. They take up too much space and are too durable to be acceptable for landfilling and, although they are recyclable, recycling capacity has been slow to develop. As a result, tires have been stockpiled or exported to the United States for disposal.
Approximately 10 million tires are discarded every year in Ontario. In 1990, after the Hagersville tire fire, there were some four million tires in storage in the province. By 1993, this number had been cut in half, largely because of concerted efforts by govermment and industry to build an infrastructure for tire recycling.

Tires can be retreaded for further use or converted to crumb rubber, which can be used to make a variety of products like matting, patio blocks, running tracks and car parts. Scrap tires also provide high-energy fuel for cement kilns, where they are burned under controlled conditions to minimize air pollution. In 1992, about 40 per cent of scrapped tires were diverted from disposal to reuse, retreading, or recycling. That number is expected to rise to 60 per cent by 1994 .

\section{Eametritsts}

Diversion can greatly reduce the amount of waste going to landfills, but it cannot eliminate all of it. Ontario will therefore continue to need a substantial amount of landfill capacity, but in some areas much of what it now has is being rapidly used up and new landfill space is becoming harder to find.

Approximately 10 per cent of Ontario's 1,365 active landfill sites will have reached the limits of their capacity within the next five years. This is a normal and manageable rate of attrition, but in central and southern Ontario the proportion is closer to 20 per cent. The problem of disposal capacity is most acute in the Greater Toronto Area, where the two major landfills are nearing the end of their useful lives. The recent upsurge in waste exports to the United States, however, has taken some of the pressure off these sites.

Apart from the problem of capacity, there is also some concern about groundwater contamination or gas 


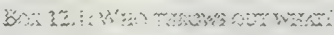

Generators of non-haczardous solid waste fail into two categories - pesidential ard IC

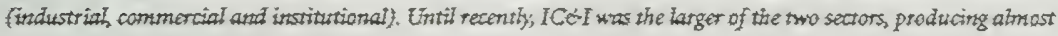
60 per cent of all wastes disposed. As of 1992,1 C 6 I accounsed for onty 49 per cent of the totaL

A recerst study, based on dats. from 1959 provides a breskdown of the types of waste being thrown out. Notably paper fatmost half of it siews-print) and organic wastes are the two biggest iterns in the residential strearm. Corrugated cardboard, wood, paper, organic materials and metal are the msior ICSI wastes. The construction and demolition industry is the largest generator of IC\&I rubbish, accounting for 17 per ceat of alf praste in that sector.

Another study estimates that packsiging prastes, including paper produets, glass, plastic, wood and metals, accounted for 1.6 mittion. tonnes or 20 per cent of Ontrrio's municipal solid wastes in 1990. Ontario has the highest per capitz consumption of peckaging in Canada. Howeves, because of higher reç- cling tates, the province raniks fifti in terms of per capita disposal of packaging.
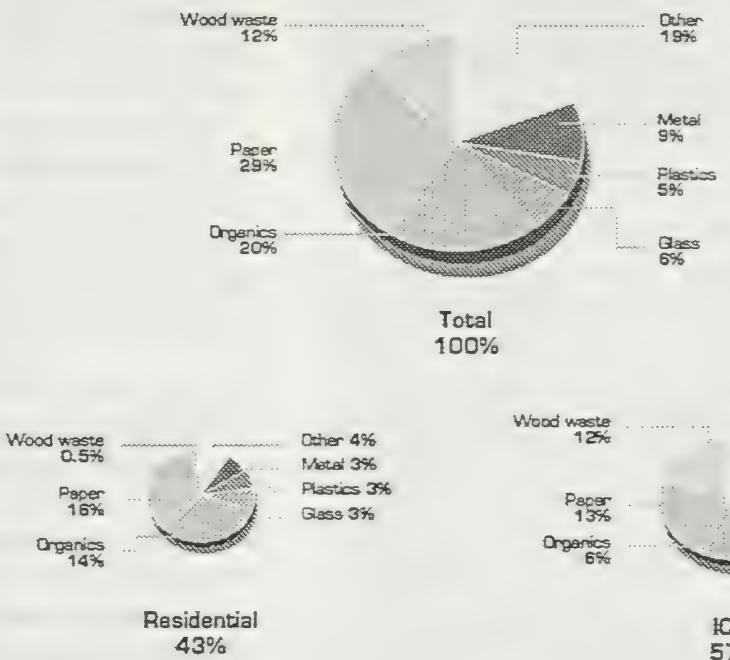

Cother $4 \%$ Matal $3 \%$ Plastics 3\% Glass 3\%

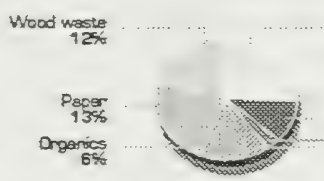
Other
$45 \%$ Metal 6\% Plasios $2 x$ ors 3\%

1C\&! $57 \%$ leakage from landfills, especially from abandoned sites that were not subject to environmental controls when they were in use. There are currently 2,334 closed landfill sites in the province and MOEE has conducted a number of studies to determine whether any of them pose an environmental or health hazard So far, no significant problems have been identified, although the investigation program is continuing.

The most intensive studies have focused on sites located near houses, wells, or streams used for domestic water or recreation. Investigators carried out detailed hydrogeological studies at 21 of these sites, where there appeared to be some potential for the escape of gas or leachate. A gas evacuation system was installed at one site, eight were given a clean bill of health and the remainder were considered safe but recommended for further monitoring as a precautionary measure. Major active sites are subject to regular monitoring, and problems are dealt with as they arise. 
FIGURE 13,1: TYPES OF HAZARDOUS AND LIOUID INDUSZRLLL WYASTE, 1992

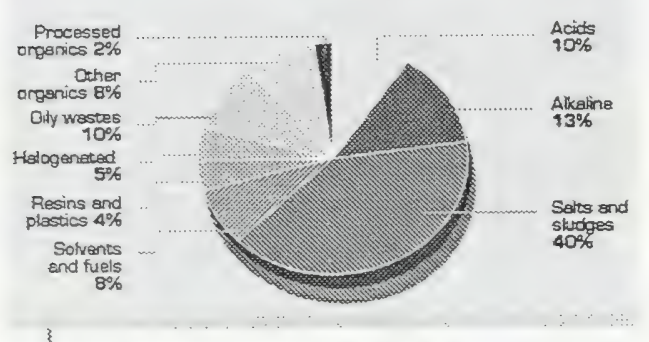

\section{Moxing sxay from theow-awsy}

By the end of the century, Ontario hopes to have a more environmentally acceptable system of waste management in place, one that relies much less on landfilling and disposal and more on the elimination or diversion of waste through the three Rs. Good progress has been made towards this goal, but getting the rest of the way requires a further intensification of waste reduction efforts.

How can this be done? Some small additional gains in waste diversion can be made by extending residential Blue Box and composting programs to more communities. More may come from increasing the amount and variety of material collected through Blue Box programs. In 1992, the average household diverted more than $131 \mathrm{~kg}$ of recyclables, but it is estimated that an improved program could raise that amount to more than $200 \mathrm{~kg}$. More substantial gains can also come from the industrial, commercial and institutional sector through the extension of waste reduction activities to more companies and the improvement of programs already in place.
With these objectives in mind, MOEE plans to require all municipalities with more than 5,000 people to provide Blue Box recycling, yard waste composting and backyard composting programs. In addition, more than 7,000 large industrial, commercial and institutional sites will be required to initiate waste audits, waste reduction workplans and recycling programs. These efforts are expected to divert another two million tonnes of garbage from landfills.

Although these programs will place greater demands on Ontario citizens and companies, they will ultimately pay back important dividends - reducing water and air pollution, improving resource and energy conservation, and lessening the aesthetic impact of waste disposal on the landscape.

\section{CHAPTER 13 HAZARDOUS AND LIQUID INDUSTRIAL. WASTES}

More than two million tonnes of hazardous and liquid industrial wastes are generated in Ontario every year. They include an amazing variety of materials - everything from acids, contaminated sludges and PCBs to motor oil and discarded batteries - and all require special handling and disposal (Figure 13.1).

Wastes are considered hazardous if they are corrosive, toxic, chemically reactive, ignitable or, like biomedical wastes, likely to spread disease. Non-hazardous liquid wastes do not present the kind of obvious threat to health and safety that hazardous substances do, but they may still have the potential to cause environmental problems such as turbidity or depletion of oxygen in watercourses or salinization of soils. 


\section{waste management contming}

Many wastes present a special problem because they are both hazardous and liquid. Liquids are more difficult to contain and are, therefore, more prone to spills and seepage and more difficult to clean up.

Major generators of hazardous and liquid industrial waste are required to register their sites and the types of waste they produce with the ministry. Figure 13.2 shows these waste generators by industry type. Although most of these wastes are produced by large industrial facilities, significant amounts also come from farms, mines, institutions such as hospitals, universities and schools and small businesses such as service stations and dry cleaners. Many common household items, such as solvents, cleaning compounds, paints and batteries, are also hazardous.

Wastes can be managed on-site or off-site. The choice is largely determined by economies of scale, the type of waste and the availability of off-site treatment. On-site management tends to be preferred by larger companies that generate substantial volumes of waste and can operate the necessary disposal procedures costeffectively. Off-site disposal is more suitable for smaller companies or for small volumes of wastes that require expensive handling facilities. Approximately 40 per cent of the hazardous and industrial liquid waste produced in Ontario is disposed of on site.

All disposal facilities, whether on-site or off-site, must be certified by the Ministry of Environment and Energy. However, only transfers of off-site wastes are tracked by the ministry. This is to ensure that these wastes are handled safely, since they must be transported to the disposal facilities on public roads and may require special precautions.
FAGLRE :3.2: GEVERATORS OF HAZARDOUS AND LFQUDD LOUSTRHA WHTE, 1992

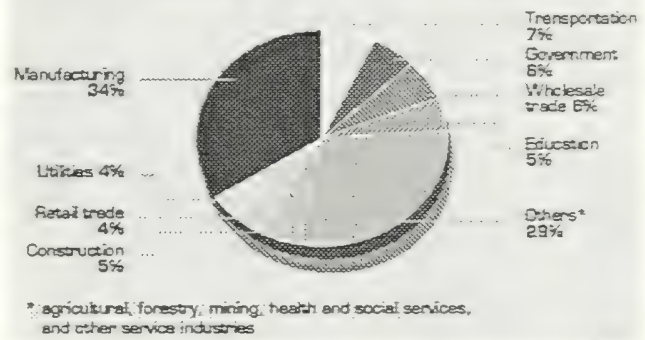

Carriers of these wastes must be certified by the ministry. Manifest forms describing the types and quantities of wastes being shipped must be completed by the generator, the carrier and the receiver of the wastes. A computerized system at the ministry verifies that generator, carrier, and receiver are properly registered or certified for the type of waste being handled and tracks the shipment from source to destination. This system ensures that every load of waste that is generated is properly managed and received at approved facilities.

\section{Cisposal - 38hat are the choices?}

Most non-hazardous liquids can be discharged directly into the sewer if the municipal sewage system has adequate treatment capacity to handle the wastes. If not, or if the generator is not connected to a sewer system, they must be trucked to a water pollution control plant for treatment. About 50 per cent of the wastes treated off-site are non-hazardous liquids that are processed in this way. A substantial proportion of these are leachates - liquids that collect in landfill sites - that must be trucked to the water pollution control plants because of the lack of a direct sewer connection. 
Hazardous wastes, on the other hand, usually require more complex and specialized treatment. Some substances can be made harmless and then disposed of by conventional means. Strong acids and caustic liquids, for example, can be neutralized. Some others can be broken down through chemical or biological processes.

Other materials, however, must be disposed of in one of the following ways:

- Landfilling. Sludges from petroleum refining and other industrial processes are often disposed of in this way. However, care must be taken to prevent contaminated liquids from leaching into the surrounding soil and groundwater. In landfills for hazardous wastes, this is accomplished by the use of natural or synthetic liners to contain the leachate and a leachate collection system to pump it out. Some wastes may also be pretreated or solidified to make them easier to handle or less susceptible to leaching.

- Incineration. High-temperature incineration is the only effective way of destroying some hazardous substances, such as high-level PCBs. Specially designed incinerators can achieve 99.9999 per cent destruction of these wastes, but careful controls are needed to prevent the release of dangerous gases or particles, and any ash that is left over must be buried in a secure landfill.

- Export. Hazardous and liquid industrial wastes are also shipped out of the province for disposal elsewhere, usually in New York or Michigan. In some cases, this is done because adequate disposal facilities for certain wastes (e.g., organic sludges and chlorin-ated organic chemicals like CFCs and some pesticides) are unavailable in Ontario. In other cases, it may be safer and more economical to use a treatment facility closer to the generator, even though it is in another jurisdiction. For the same reasons, wastes from other jurisdictions are also shipped into Ontario for disposal. Both Canada and the United States, however, prohibit the importation of PCBs.

- Storage. Hazardous wastes awaiting destruction or for which there is no satisfactory disposal method must be kept in secure storage. Secure storage, however, involves some risk of fire or spillage and is therefore an unacceptable method for long-term disposal. Thousands of tonnes of PCB wastes are now in storage in Ontario because of uncertainty over the best method of destroying them. Wastes contaminated with low levels of PCBs are now being destroyed using mobile incinerators.

- Recycling and reusing. This is one of the most desirable ways of handling wastes because it reduces the need for disposal, causes less environmental contamination and reduces the demand on natural resources. Waste oils, solvents, antifreeze and metal finishing sludges are commonly recycled materials.

- Dust suppression. Some non-hazardous industrial liquid wastes have also been approved by the ministry for use as dust suppressants. A liquid waste from the pulp and paper industry, for example, is suitable for use on roads, while waste oil from steel mills and thermal-electric power stations is sometimes used on coal storage piles. All of these suppressants must be used in a controlled fashion, however, since improper application can harm vegetation and pollute surface and ground waters.

Figure 13.3 shows the quantity of wastes receiving final disposal by these methods in 1992. Because landfill leachates make up about half of the hazardous and liquid industrial wastes sent for off-site disposal, treatment at water pollution control plants is the largest disposal 
category. For other hazardous wastes, export and landfilling are the most used disposal options and incineration the least. Storage is not shown here because it is not a final disposal option.

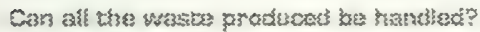

In 1986, when MOEE began tracking hazardous and liquid industrial wastes, some 840,000 tonnes were shipped off site for disposal By 1990 that amount had grown to nearly 1.5 million tonnes (Figure 13.4). In part, this growth reflects an increase in compliance with the regulations as the program became established, but waste generation also tends to follow the fortunes of the economy. Thus, after growing by an average of more than 10 per cent a year from 1987 to 1990 , the output of waste declined moderately in 1991 as the economy went into recession. However, as economic conditions improve, we can expect the output of hazardous and liquid industrial wastes to increase once again.

More waste, however, means a greater demand on disposal facilities. At the moment, Ontario has only one commercial landfill for hazardous and solidified liquid industrial waste. At the present rate of use, this capacity will be exhausted by 1996 or 1997, at which point additional facilities will be required.

Most of the incineration of hazardous and liquid industrial wastes in Ontario is carried out at a liquid waste incinerator near Sarnia. However, this facility cannot handle solids, sludges, or chlorinated organic chemicals, which are making up an increasing portion of the hazardous waste stream. Destruction of these materials requires the use of a rotary kiln incinerator. At the moment, this equipment is not available in Ontario and these wastes must be sent out of province for disposal.

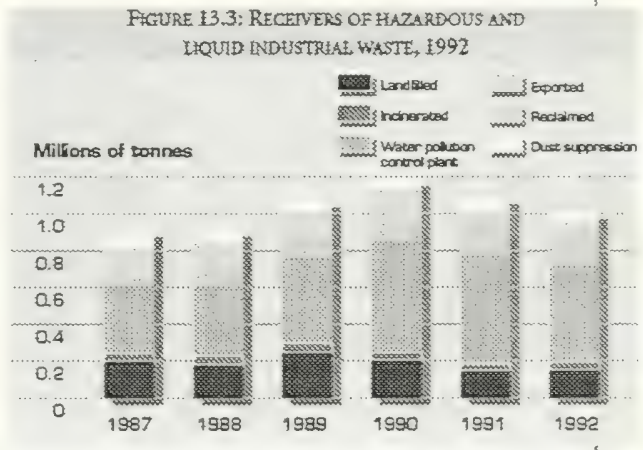

FIGURE 13.4: AMOLNT OF HAZARDOUS AND ERQITD ENDUSTRLAI W.STE SHIPPED FOR OFFSITE DISPOSAL, 1987-1992

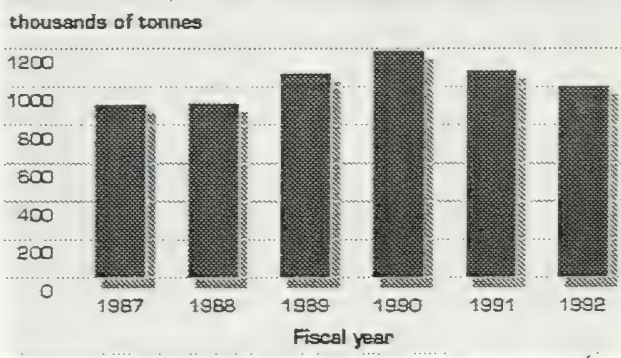

Biomedical wastes are another problem. Currently, about 60 per cent of these wastes are sent either to Quebec or the United States for disposal. The remainder are destroyed locally in small hospital incinerators. However, as these lack modern air pollution control equipment, they are being phased out of operation. The Ministry of Environment and Energy and the Ministry of Health, in cooperation with the Ontario Hospital Association, have developed plans to replace these incinerators with regional biomedical waste disposal facilities. 
FIGURE 13.5: IMPORTS AND EXPORTS OF HAZARDOUS AND IFQUMB INDUSTRIAL, WASTE, $1987-1992$

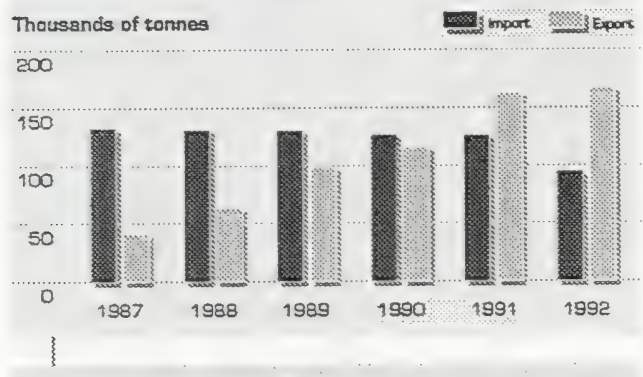

FIGURE 13.6: NUMBER OF PCB WASTE STORAGE STIES, $198 \mathrm{1}-1992$

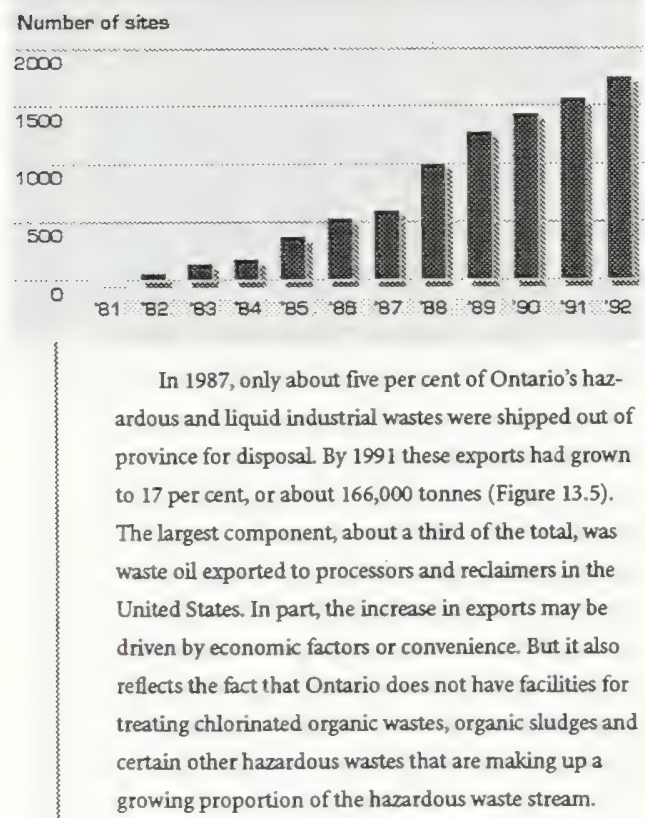

Imports, on the other hand, have declined slightly. In 1992, they totalled approximately 95,000 tonnes, with about half coming from the United States and half from other provinces. About 54 per cent of the import total was waste oil destined for recycling.

Exports and imports are of concern if they increase the amount of transportation and handling of hazardous wastes. However, transborder shipment can also involve the shortest travelling distances and increase the safety of handling. In the longer term, an excessive reliance on exports for disposal could be a problem if authorities in other provinces or states decide to close their borders to incoming wastes.

Although such a ban is unlikely for most of the materials now shipped out of Ontario, the United States has forbidden the importation of PCBs since 1982 Because Ontario does not have adequate destruction facilities for most PCB wastes, Ontario has been left with the unsatisfactory option of placing these in storage until it is possible to dispose of them. Over the past decade the number of storage sites has increased dramatically, from a mere handful in 1981 to 1751 sites at the end of 1992 (Figure 13.6). All these wastes are stored on the properties of their owners, since there are no approved commercial PCB storage sites in the province.

Mobile incinerators have been used to destroy some of these wastes, and more than 15,000,000 litres of contaminated mineral oil have been disposed of in this way. However, Ontario has not yet approved these facilities for the destruction of more concentrated PCB wastes. At the end of 1992, there were still about 113,000 tonnes of these wastes in storage in Ontario, and until more destruction facilities are set up that quantity will continue to increase as old transformers and other equipment and materials containing $\mathrm{PCBs}$ are taken out of service. 
New environmental regulations are expected to further increase the gap between waste management capabilities and requirements. The phasing out of CFCs, for example, will eventually require the treatment of 40000 tonnes of these chemicals. Tighter controls on municipal sewage and industrial effluent and on landfilling will also divert more materials to the hazardous waste stream.

Ontario currently does not have facilities to deal with hazardous wastes that must now be exported or stored, nor to meet future disposal requirements. One option would be to build a single integrated hazardous waste disposal facility which would serve the whole province. A proposal for such a facility, to be built and operated by the Ontario Waste Management Corporation, is now in the environmental assessment process

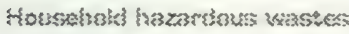

The average household also generates a small but significant amount of hazardous waste - about $2.5 \mathrm{~kg}$ per person, according to one estimate. This includes items such as solvents, cleaners, pesticides, paint, batteries, pool chemicals, propane tanks and many other common household articles. Because many of these items are not recognized as hazardous, they often end up in ordinary household garbage or are poured down the sewer. About $250,000,000$ litres of used lubricating oil, for example, are improperly disposed of every year in Canada.

Many municipalities are now beginning to inform the public about household hazardous wastes and to provide a disposal system for them. Some municipalities have established centres where household hazardous wastes can be dropped off. Others have set up special collection days or pickup services. Since the first of these
FIGURE 13.7: ANOLAT OE HOLSEHOLD HAZAREOLS WUSTE COLIECTED, 1986-87 70 1992-93

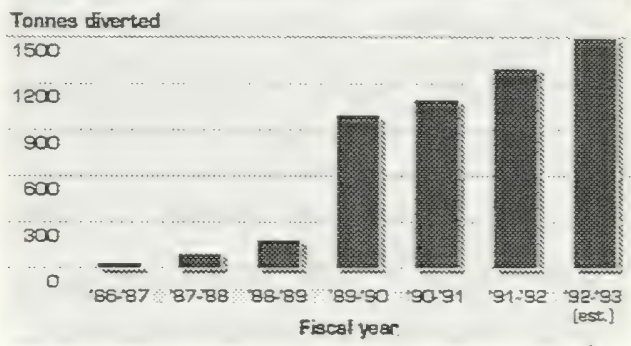

programs was established in the mid-1980s, their use has grown considerably. The dramatic increase in the amount collected in 1989-90 was due to the establish. ment of 10 permanent depots in the Metropolitan Toronto area and several others elsewhere (Figure 13.7).

During the 1992-93 fiscal year, more than 1600 tonnes of household hazardous wastes were collected for proper disposal. However, estimates suggest that Ontario generates more than 20000 tonnes of these wastes every year. A good start has been made, but obviously there is some way to go before most household hazardous wastes are managed properly.

\section{Protilens from these jुast}

Until the late 1970s, the disposal of hazardous and Iquid industrial wastes generally was not adequately controlled. In the United States, toxic substances from abandoned chemical dumps have caused serious water and soil contamination. In 1978, in one of the most notorious of these incidents, more than 1,000 homes near Niagara Falls, New York, had to be evacuated because of contamination from the nearby Love Canal disposal site. 
In Ontario, hazardous wastes have been found in some of the province's 2,400 closed landfills, but monitoring of these sites has not shown any spread of contamination. A potentially more serious problem is the presence of buried coal tar wastes on sites formerly occupied by coal gasification plants. Until the 1950 s, when the use of natural gas became widespread in Ontario, these plants produced gas from coal for both residential and industrial purposes.

Buried coal tar wastes may be harmless if left undisturbed, but in some cases they may contaminate groundwater supplies. If disturbed by construction, they can contaminate surface waters and they may pose a short-term health risk to workers. Long-term exposure may increase the risk of skin and respiratory cancers.

Altogether, the ministry has identified 41 municipal and 44 industrial coal gasification sites. Where a hazard exists, the owners of the site are required to remove the wastes and contaminated soil to an approved disposal facility. The ministry must also be advised before any work can be undertaken that might disturb the site.

\section{Caze Ontario do thetszar?}

\section{REDUCING, RECYCLING, REUSING}

The more hazardous waste that is produced, the more need there is to expand disposal capabilities. That means an increasing demand for secure landfills, specialized incinerators and other treatment facilities. However, setting up these facilities takes time and money and many communities are reluctant to have them nearby. To reduce the need for such facilities and still maintain the capacity to manage these wastes, as much as possible must be done to reduce the amounts sent for disposal.
One way of handling this problem is to reduce the amount of waste that is produced in the first place. This can sometimes be done through changes in production materials and technologies, although the amount of waste produced by industry as a whole is already very small - less than one per cent of total production - and only about 10 per cent of that amount is hazardous.

There may be more scope, though, for recycling and reuse. A study by Environment Canada in 1986 estimated that about half the hazardous wastes produced in Canada had a high potential for recycling. However, offsite recycling accounted for only about 6.5 per cent of Ontario's hazardous and liquid industrial wastes in 1992 and there has been no increase in this proportion over the past decade. Of course, many companies build recycling and reuse into their production processes, but because MOEE does not track wastes that are managed on site there is no way of knowing how much on-site recycling takes place or whether the proportion is increasing or decreasing.

In order to increase opportunities for off-site recycling, the Ontario Waste Exchange was established in 1978. Based on the premise that waste from one company may be usable as a raw material by another, it provides a means for waste generators and potential users to make contact. During the 1991-92 fiscal year, the exchange diverted almost 82,000 tonnes of hazardous and non-hazardous waste from disposal.

Makers of items that eventually end up as hazardous waste are also being urged to assist in the disposal of their products. The Canadian Petroleum Products Institute, for example, recently set up a network of depots for the collection of used oil from consumers. MOEE is now discussing similar arrangements with other industry groups for the disposal of paints, batteries, and pharmaceuticals. 
At the present time, Ontario is able to cope satisfactorily with most of the hazardous and liquid industrial wastes it now produces. But some important capacity problems must still be resolved, particularly:

- the need for a new secure landfill to replace the Sarnia site when it is exhausted;

- the need for additional treatment, destruction and disposal capacity to handle PCBs now in storage and future requirements, such as the destruction of CFCs, that will arise out of new regulatory requirements;

Over the longer term, however, maximizing the reduction, reuse and recycling of hazardous and liquid industrial wastes not only will reduce the demand for disposal capacity but is the most environmentally benign way of dealing with these materials. 



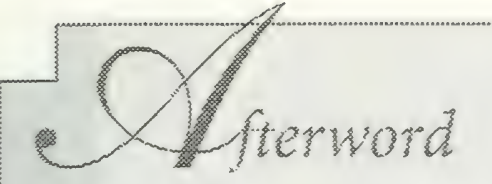

The preparation of this report marks the first time the Ministry of Environment and Energy has brought together information from across the ministry. The data has been presented as clearly and accurately as possible. It is our hope that the information contained in this report informs you about specific environmental condi. tions in Ontario of interest to you and expands your general knowledge and apprecistion of the complexiry of the environment.

From the Ministry's perspective, this project has helped us to appreciate the value, and limitations, of the data that we gather. It has tested our ability to draw a bigget picture from the hundreds of very specific indicators which we monitor, and has helped us identify gaps in our monitoring and reporting programs.

As we turn our thoughts and energy to the development of Ontario's next State of the Environment Report, Fe will evaluate how we can improve on this report. To do this, we need your feedback
We would like your evaluation of this report and your comments and suggestions on what you would like to see in Ontario's next State of the Environment report. You can fill out and return the survey on the next page, or send your own written comments to:

\section{Communications Branch}

\section{Ministry of Environment and Energy}

135 St. Clair Avenue West

Toronto, Ontario

\section{M4V 1P5}




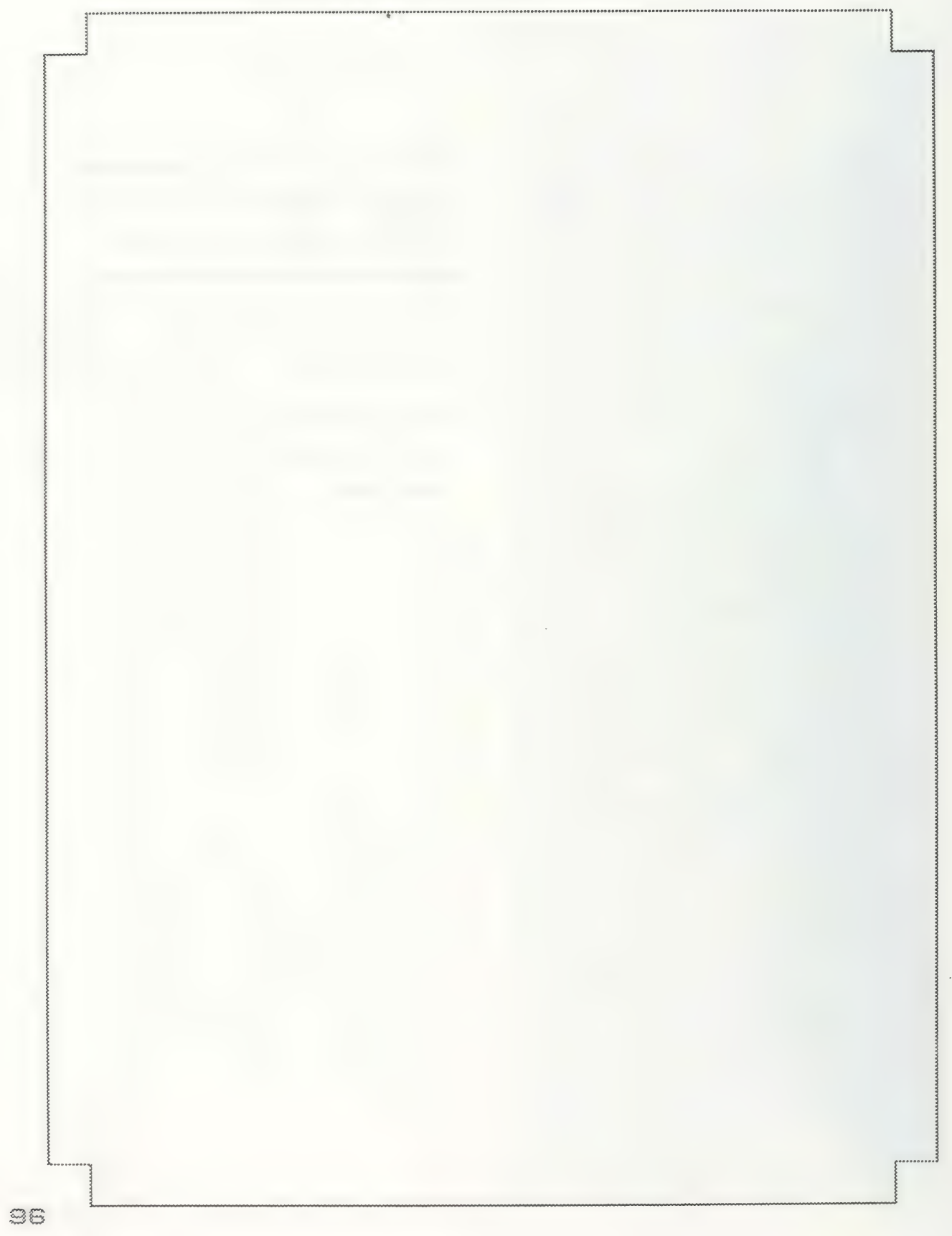




\section{AIR}

Ministry of Environment and Energy. 1992 Air Quality in Ontario. 1993.

Ministry of Environment. Air Quality Monitoring Studies in the Sudbury Area, 1978 to 1988. March 1992

Fraser, D., Yap, D., Kiely, P. and Mignacca, D. Aralysis of Persistent Ozone Episades in Southern Ontario 1980-1991. Tectnology Transfer Conference Toronto Proceedings: pp 222-227. 1991.

Heidom, K.C and Yap, D. A Syroptic Climatology For Surface Ozone Concentrations in Southem Ontario, 1976-1981. Atmospheric Environment: Vol. 20 No 4, pp 695-703. 1984.

Ministry of the Environment, Scientific Criteria Document for Standard Devetopment Na \&84; Polychlorinated Dibenzo-p-dicains (PCDDs) and Polychlorinated Dibenzofurans (PCDFs). 1985.

Regutation Respecting Control of Exposure to Biological or Chemical Agents - made under the Occupational Health ard Safety Act - Ontario Regulation $654 / 86$

\section{ACID RAIN}

BEAK Consultants for MOEE. Ontario Hardwood Dectine Survey 1989 and 1990. 1992.

Dilion, P.L, RA. Reid and E de Grosbois. 1987. The rate of acidification of aquaric ecosystems in Ontario, Canada. Nature, $329: 45-48$.

Kelso, J.M.R, and D.S. Jeffries. Response of headwater lakes to varying atmospheric deposition in north-central Ortario, 1979 to 1983. Journal of Fisheries and Aquatic Sciences vol 45, p. 1905.1988.
Matuszek, J.E., and G.L Beggs. Fish Species in Relation to Lake Area, $p H$, and Other Abiotic Factors in Ontario Lakes. Canadian Journal of Fish and Aquatic Science: vol. 45, pp. 1931-1941. 1988.

Mclaughlin, D.L, MOEE. Etiology of Sugar Maple Decline at Selected Sites in Ontario (1984-1990). 1992.

Neary, B.P., P.J. Dillon, J.R Munro, B.J. Clark, MOEE. The acidification of Ontario lakes: An assessment of their sensitivity and current status with respect to biological damage. 1990.

Neary, B.P. and P.J. Dillon. Effects of sulphur deposition on lake-water chemistry in Ontario, Canada. Nature 333: 340. 1988.

Federal/Provincial Research and Monitoring Coordinating Committee, Environment Canada. The 1990 Canadian long-range transport of air pollutants and acid deposition study. 1990.

\section{WATER QUALITY}

\section{Exarers?}

Canadian Council of Resource and Environment Ministers. Canadian Water Quality Guidelines. 1987.

Govemment of Ontario. Water quantity resources of Ontario. 1984.

Griftiths, R, MOEE. BioMap: concepts, protocols and sampling procedures for the soutitwestem region of Ontario. 1993.

Ministry of Environment and Energy. Our shared resource: Towards a provincial water policy framework for Ontario. Revised Draft May 1993.

Ministry of the Environment. Water management - goals, policies, objectives and implementation procedures of the Ministry of the Environment. Revised 1984. 


\section{further readings continued}

Royal Commission on the Future of Toronto's Waterfront. Pathways: Towards an ecosystem approach. Vol 11. 1991.

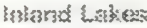

Dillon, P.J., W.A. Scheider, R.A. Reid and D.S. Jeffries, MOEE. The Lakeshore Capacity Study. Part I: A test of the effects of shoreline development on the trophic status of lakes. 1992.

Ministry of Environment and Energy. Cottagers' self-help program enrichment status of lakes in the southeastem region of Ontario 1992 August 1993.

Ministry of Environment and Ministry of Natural Resources. 1993 Guide to eating Ontario sport fish 1993.

Ministry of Environment and Energy and Ministry of Natural Resources. Inland lake trout management in southeastern Ontario. January 1993.

Neary, B.P. and B.J. Clark, MOEE. The chemical water quality of Lake Nipissing 1988-1990. 1992.

Reid, RA. and S.M. David, MOEE. Crayfish distribution and species composition in Muskoka and Haliburton lakes. 1990.

Yan, N.D. and P.M. Welbourn. 1990. The impoverishment of aquatic communities by smelter activities near Sudbury, Canada. In Woodwell, G.M. (ed.). The Earth in Transition: Patterns and processes of biotic impoverishment. Cambridge University Press, pp. 477-494.

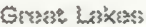

Government of Ontario. Restoring and protecting the Great Lakes: 1991 Progress report. 1993.

Great Lakes Water Quality Board. 1989 report on Great Lakes water quality. Report to the International Joint Commission. October 1989.
Howell, E., MOEE. Great Lakes long-term sensing sites: Preliminary results for the Niagara River corridor stations. February 1993

International Joint Commission. Cleaning up our Great Lakes: A report from the Water Quality Board to the International Joint Commission on Toxic Substances in the Great Lakes Basin Ecosystem. 1991.

International Joint Commission. Review and evaluation of the Great Lakes remedial action plan program. Great Lakes Water Quality Board report to the International Joint Commission. 1991.

Krantzberg, G., MOEE. The influence of the axygen regime in the water column on the toxicity of Hamilton Harbour sediment 1992.

Krantzberg, G. and Boyd, D. The biological significance of contaminants in sediment from Hamilton Harbour, Lake Ontario. Environmental Toxicology and Chemistry. vol. 11,pp. 1525-1538. 1992.

Nicholls, Kenneth H. and Gordon G. Hopkins. Recent changes in Lake Erie phytoplankton: Cumula tive impacts of phosphorus loading reductions and the zebra mussel introduction. Journal of Great Lakes Resources: vol. 19, pp. 637-647. 1993.

1993 Report of the Great Lakes Water Quality Board to the International Joint Commission. International Joint Commission. September 1993.

Richman, L.A., MOEE. Niagara River biomonitoring study, 1989. Summary Report submitted to the Niagara River Toxics Management Plan Secretariat for inclusion in its 50\% Loading Reduction Report March 1992.

Richman, L_A, MOEE. The Niagara River mussel and leech biomonitoring. 1992.

Richman, LA, MOEE. Preliminary technical report: Summary of the 1991 Niagara River mussel biomonitoring survey. 1993. 


\section{further readings contunued}

Smith, I.R, MOEE 1991 Peninsula Harbour sediment study. March 1993.

Smith, I.R. State of the Lake Superior basin reporting series volume II: Draft stage 1 lakewide management plan. Ontario Ministry of Environment and Energy, Ontario Ministry of Natural Resources, and U.S. Fish and Wildlife Service, October 1993.

Smith, J. and Smith, I., MOEE and Environment Canada. Yardsticks for assessing the water quality of Lake Superior. March 1993.

Snodgrass, W.J. and D'Andrea, M. Dry weather discharges to the Metropolitan Toronto waterfront Remedial Action Plan Report, Environment Canada and the Ontario Ministry of Environment and Energy. April 1993.

Suns, K.R, MOEE. Organochlorine Contaminant Trends in Niagara River Spottail Shiners. Report prepared for the Niagara River Toxics Management Plan Secretariat. September 1992.

Suns, K. R, G. G. Hitchin, and D. Toner. Spatial and temporal trends of organochlorine contaminants in spottail shiner from selected sites in the Great Lakes (19751990). Joumal of Great Lakes Resources. 19:703-714. 1993.

Tarandus Associates Limited. 1993. Great Lakes LongTerm Sensing Sites: The Evaluation of Water, Sediment and Benthic Invertebrates from Stations in Lake Ontario and Niagara River Corridor in 1990. Prepared for the Ontario Ministry of Environment and Energy, October 1993 (awaiting publication approval).

Tarandus Associates Limited. 1993. Great Lakes embayments and harbours investigation program, phase I: The Lake Erie harbours synoptic surveys. Prepared for the Ontario Ministry of Environment and Energy, March 1993 (awaiting publication approval).

\section{Remexial Action Plans}

Thunder Bay Remedial Action Plan Stage 1 Report Environmental Conditions and Problem Definition. October 1991.

Nipigon Bay Remedial Action Plan Stage 1 Report Environmental Conditions and Problem Definition. October 1991.

Jackfish Bay Remedial Action Plan Stage 1 Report Environmental Conditions and Problem Definition. October 1991.

Peninsula Harbour Remedial Action Plan Stage 1 Report: Environmental Conditions and Problem Definition. October 1991.

St Marys River Stage 1 RAP - Environmental Conditions and Problem Definitions, May 1992.

Spanish Harbour Stage 1: Environmental Conditions and Problem Definition. November 1993.

Sevem Sound Remedial Action Plan Stage 2 Report April 1993.

Severn Sound Remedial Action Plan Stage 1 - Environmental Conditions and Problem Definition. February 1989.

Collingwood Harbour Remedial Action Plan, Stage 1: Environmental Conditions and Problem Definition. March 1989.

The Collingwood Harbour Stage 2 Document a delisting strategy. August 1992.

St Clair River RAP Stage 1 Update (1st. Draft) - March 1993

Detroit River Remedial Action Plan - Stage 1 - June 1991 Niagara River Stage 1 Report Environmental Conditions and Problem Definitions, October 1993 


\section{further readings continued}

Chemicals of Concern in Niagara River Tributaries 198889, Niagara River Improvement Project, Ontario Ministry of Environment and Energy, July 1993.

Stage I Report Remedial Action Plan for Hamilton Harbour Environmental Conditions and Problem Definition. March 1989.

The Remedial Action Plan (RAP) for Hamilton Harbour Stage 2A. July 1991.

Hamilton Harbour Final Stage 2 Report (to COA RAP Steering Committee). November 1992.

Stage 1:Metropolitan Toronto Environmental Conditions and Problem Definition. May 1989.

Metropolitan Toronto Remedial Action Plan: Strategies for Restoring Our Waters. December 1991.

Port Hope Harbour Remedial Action Plan Stage 1: Environmental Conditions and Problem Definition. January 1990.

Stage 1, Bay of Quinte: Environmental Setting and Problem Definition July 1990.

Bay of Quinte RAP Stage 2 Report September 1993.

St. Lawrence River Area of Concern Remedial Action Plan for the Cornwall-Lake St. Francis Area Stage 1 Report: Environmental Conditions and Problem Definition August 1992.

\section{Groursivazar}

Environment Ontario. 1987. Water wells and ground water supplies in Ontaria ISBN 0-7729-1010-3. Revised 1987.

\section{Brinking หื่ater}

Drinking Water Surveillance Program, Annual Report 1991/92, Ontario Ministry of the Environment. 1994

Ontario Drinking Water Objectives Information Sheet. Summer 1992, Ontario Ministry of Environment and Energy

Parameters Listing System (PALIS). Revised, October 1992. Ontario Ministry of the Environment. Queen's Printer for Ontario, 1992

Pesticides in Ontario Municipal Drinking Water - 1988. September 1990. Ontario Ministry of the Environment. Queen's Printer for Ontario, 1990

Drinking Water Information Sheet Summer 1990. Ministry of the Environment

About Water Treatment Plant Operation Fact Sheet (WFS8). Ministry of the Environment

Ontario's Drinking Water Surveillance Program Information Sheet, Winter 1992. Ministry of the Environment.

\section{Waste Management}

\section{Brinicipas Solid Whast}

Greater Toronto Area 3Rs Analysis, EA Input Document M.M. Dillon Ltd for the Ontario Ministry of Environment and Energy. Draft November 1993. Queen's Printer for Ontario, 1993.

Interim Guidelines for the Production and Use of Aerobic Compost in Ontaria. Ontario Ministry of the Environment. Toronto: Queen's Printer, November 1991. 


\section{Frther readinçs continused}

Market Assessment of $3 R$ 's Activities in Ontario. Resources Integration Systems Ltd. for the Ontario Ministry of the Environment. Queen's Printer for Ontario, 1992.

Meeting the Challenge: Reduction and Recycling Activities in the Greater Toronto Area. Ontario Ministry of the Environment. Toronto: Queen's Printer, 1992

Municipal Waste Management Powers in Ontario. Ontario Ministry of Municipal Affairs. Toronto: Queen's Printer, March 1992.

National Packaging Protocol: Results of the 1990 National Packaging Survey. National Task Force on Packaging, December 1992.

OMMRI - Corporations in Support of Recycling: Overview: Ontario Multi-Material Recycling Incorporated. Toronto: OMMRI, August, 1992.

Ontario Waste Composition Study. Gore and Storrie Ltd. December 1991.

The Physical and Economic Dimensions of Municipal Solid Waste Management in Ontaria. $\mathrm{CH} 2 \mathrm{M}$ Hill Engineering Ltd. and MacLaren Engineers for the Ontario Ministry of the Environment, November 1991. Queen's Printer for Ontario.

Regulatory Measures to Achieve Ontario's Waste Reduction Targets: Initiatives Paper No. 1. Ontario Ministry of the Environment. Toronto: Queen's Printer, October 1991.

A Socio-Economic Assessment of Ontario Waste Management Initiatives. VHB Research and Consulting Inc. for the Ontario Ministry of the Environment. Queen's Printer for Ontario, January 1993.
True Cost of Municipal Waste Management. VHB Research \& Consulting Inc. for the Ontario Ministry of the Environment. Queen's Printer for Ontario, 1993.

The Waste Crisis in the Greater Toronto Area: A Provincial Strategy for Action. Ministry of the Environment and the Office of the Greater Toronto Area. June 1991, Toronto.

Waste Management Planning in Ontario: Initiatives Paper No. 2. Ontario Ministry of the Environment. Toronto: Queen's Printer, March 1992.

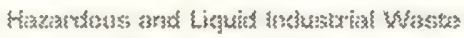
1991 Ontario Waste Exchange Directory. Ontario Research and Technology Foundation (ORTECH). Toronto: ORTECH International, 1991.

Ministry of Environment and Energy Annual Hazardous Waste Public Information Data Set, June 1992.

Practical Guide for Sampling Waste and Industrial Processes. Ontario Waste Management Corporation, Toronto, 1993.

Ontario Waste Management Corporation Waste Reduction Bulletin - Profiles of industrial 3Rs success stories and pollution prevention technologies. (published 3/year).

Pollution Prevention for the Great Lakes: Tips for Small Quantity Hazardous Waste Generators, LURA Group for Environment Canada. Toronto, 1991.

Canada's Present Day and Future Hazardous Waste Management Facilities. Man-West Environmental Group Ltd., Winnipeg, June 1993. 



